University of Nebraska - Lincoln

DigitalCommons@University of Nebraska - Lincoln

7-1-2021

Evidence that toxin resistance in poison birds and frogs is not rooted in sodium channel mutations and may rely on "toxin sponge" proteins

Fayal Abderemane-Ali

Nathan D. Rossen

Megan E. Kobiela

Robert A. Craig II

Catherine E. Garrison

See next page for additional authors

Follow this and additional works at: https://digitalcommons.unl.edu/bioscifacpub

Part of the Biology Commons

This Article is brought to you for free and open access by the Papers in the Biological Sciences at

DigitalCommons@University of Nebraska - Lincoln. It has been accepted for inclusion in Faculty Publications in the Biological Sciences by an authorized administrator of DigitalCommons@University of Nebraska - Lincoln. 


\section{Authors}

Fayal Abderemane-Ali, Nathan D. Rossen, Megan E. Kobiela, Robert A. Craig II, Catherine E. Garrison, Zhou Chen, Claire M. Colleran, Lauren A. O'Connell, J Du Bois, John P. Dumbacher, and Daniel L. Minor Jr 


\title{
Evidence that toxin resistance in poison birds and frogs is not rooted in sodium channel mutations and may rely on "toxin sponge" proteins
}

\author{
Fayal Abderemane-Ali ${ }^{1}$, Nathan D. Rossen ${ }^{1} \mathbb{D}$, Megan E. Kobiela ${ }^{2}$ D , Robert A. Craig $\|^{3} \mathbb{D}$, Catherine E. Garrison ${ }^{3}$, Zhou Chen ${ }^{1} \mathbb{D}$, Claire M. Colleran ${ }^{1}$, \\ Lauren A. O'Connell ${ }^{4}$, J. Du Bois ${ }^{3}$, John P. Dumbacher ${ }^{5,6}$ (D), and Daniel L. Minor Jr. . $^{1,7,8,9,10,11 \mathbb{D}}$
}

Many poisonous organisms carry small-molecule toxins that alter voltage-gated sodium channel ( $\mathrm{Na}_{\mathrm{v}}$ ) function. Among these, batrachotoxin (BTX) from Pitohui poison birds and Phyllobates poison frogs stands out because of its lethality and unusual effects on $\mathrm{Na}_{v}$ function. How these toxin-bearing organisms avoid autointoxication remains poorly understood. In poison frogs, a Nav DIVS6 pore-forming helix N-to-T mutation has been proposed as the BTX resistance mechanism. Here, we show that this variant is absent from Pitohui and poison frog $\mathrm{Na}_{\mathrm{v}}$, incurs a strong cost compromising channel function, and fails to produce BTX-resistant channels in poison frog $\mathrm{Na}_{v}$ s. We also show that captivity-raised poison frogs are resistant to two $\mathrm{Na}_{v}$-directed toxins, BTX and saxitoxin (STX), even though they bear $\mathrm{Na}_{\mathrm{v}} \mathrm{s}$ sensitive to both. Moreover, we demonstrate that the amphibian STX "toxin sponge" protein saxiphilin is able to protect and rescue Navs from block by STX. Taken together, our data contradict the hypothesis that BTX autoresistance is rooted in the DIVS6 $\mathrm{N} \rightarrow \mathrm{T}$ mutation, challenge the idea that ion channel mutations are a primary driver of toxin resistance, and suggest the possibility that toxin sequestration mechanisms may be key for protecting poisonous species from the action of small-molecule toxins.

\section{Introduction}

Many organisms harbor various small-molecule toxins that target ion channels as a means of defense from predation (Savitzky et al., 2012). Among these, batrachotoxin (BTX), a dietacquired (Daly et al., 1994b; Daly et al., 1994a; Dumbacher et al., 2004) steroidal amine found in distantly related vertebrate lineages, including poisonous birds (Pitohui spp. and Ifrita kowaldi; Dumbacher et al., 1992; Dumbacher et al., 2000) and neotropical poison frogs (Phyllobates; Santos et al., 2016), stands out because of its lethality and its unusual ability to facilitate opening and prevent inactivation of voltage-gated sodium channels ( $\mathrm{Na}_{\mathrm{V}}$ s; Catterall, 1977; Khodorov, 1985; Logan et al., 2016; Wang and Wang, 2003). This lipophilic, steroidal neurotoxin is thought to bind in the $\mathrm{Na}_{\mathrm{v}}$ inner pore (Wang and Wang, 2003). How vertebrates that bear BTX or other small-molecule toxins avoid autointoxication remains unresolved (Arbuckle et al., 2017; Almabruk et al., 2018; Hunter, 2018). Toxinresistant mutants of target ion channels in host organisms
(Tarvin et al., 2017; Bricelj et al., 2005; Hanifin and Gilly, 2015; Jost et al., 2008) or their predators (Geffeney et al., 2002; Geffeney et al., 2005; McGlothlin et al., 2016) have been suggested as the primary drivers of toxin resistance (Santos et al., 2016), an idea supported by examples of tetrodotoxin (TTX)resistant (Hanifin and Gilly, 2015; Jost et al., 2008; Geffeney et al., 2002; Geffeney et al., 2005; McGlothlin et al., 2016) and saxitoxin (STX)-resistant (Bricelj et al., 2005) $\mathrm{Na}_{\mathrm{V}} \mathrm{s}$, as well as epibatidine-resistant nicotinic acetylcholine receptors (Tarvin et al., 2017) found in toxin-carrying metazoans. In poison frogs, an $\mathrm{Na}_{\mathrm{V}}$ domain IV segment 6 (DIVS6) pore-forming helix $\mathrm{N} \rightarrow \mathrm{T}$ mutation has been proposed as the BTX resistance mechanism (Tarvin et al., 2016; Wang and Wang, 2017). Although the DIVS6 $\mathrm{N} \rightarrow \mathrm{T}$ change reduces BTX sensitivity when tested in rat $\mathrm{Na}_{\mathrm{V}} 1.4$ (Wang and Wang, 2017), this variant occurs with very low frequency among Phyllobates terribilis (Márquez et al., 2019), and is absent from Phyllobates aurotaenia (Tarvin et al., 2016;

\footnotetext{
${ }^{1}$ Cardiovascular Research Institute, University of California, San Francisco, San Francisco, CA; ${ }^{2}$ School of Biological Sciences, University of Nebraska-Lincoln, Lincoln, NE; ${ }^{3}$ Department of Chemistry, Stanford University, Stanford, CA; ${ }^{4}$ Department of Biology, Stanford University, Stanford, CA; ${ }^{5}$ Institute for Biodiversity Science and Sustainability, California Academy of Sciences, San Francisco, CA; ${ }^{6}$ Department of Biology, San Francisco State University, San Francisco, CA; ${ }^{7}$ Department of Biochemistry and Biophysics, University of California, San Francisco, San Francisco, CA; ${ }^{8}$ Department of Cellular and Molecular Pharmacology, University of California, San Francisco, San Francisco, CA; ${ }^{9}$ California Institute for Quantitative Biomedical Research, University of California, San Francisco, San Francisco, CA; ${ }^{10}$ Kavli Institute for Fundamental Neuroscience, University of California, San Francisco, San Francisco, CA; ${ }^{11}$ Molecular Biophysics and Integrated Bio-imaging Division, Lawrence Berkeley National Laboratory, Berkeley, CA.
}

Correspondence to Daniel L. Minor, Jr.: daniel.minor@ucsf.edu.

(c) 2021 Abderemane-Ali et al. This article is available under a Creative Commons License (Attribution 4.0 International, as described at https://creativecommons.org/ licenses/by/4.0/). 
Márquez et al., 2019), another poison frog having high BTX levels (Albuquerque et al., 1973). Given these issues and the absence of functional studies of poison frog $\mathrm{Na}_{\mathrm{V}} \mathrm{s}$, whether BTX-bearing animals rely on $\mathrm{Na}_{\mathrm{V}}$ mutations or other BTX autoresistance mechanisms remains unclear.

Here, we clone and characterize $\mathrm{Na}_{V}$ s from the BTX-bearing bird Pitohui uropygialis meridionalis (Pum) and two poison frog species that carry alkaloid toxins in the wild (P. terribilis [BTX]; Dendrobates tinctorius histrionicotoxin [HTX] and pumiliotoxin [PTX]). We found that the DIVS6 $\mathrm{N} \rightarrow \mathrm{T}$ variant is absent from Pitohui and poison frog $\mathrm{Na}_{\mathrm{V}} \mathrm{s}$, incurs a strong cost that compromises channel function, and fails to produce BTX-resistant channels when tested in the context of poison frog $\mathrm{Na}_{\mathrm{V}} \mathrm{s}$. Most surprising, poison frogs proved resistant to BTX poisoning and poisoning by another small-molecule toxin, STX, despite expressing $\mathrm{Na}_{\mathrm{V}} \mathrm{s}$ that are sensitive to both toxins. We further show that saxiphilin (Sxph), a high-affinity STX-binding protein found in frog plasma and organs (Yen et al., 2019; Mahar et al., 1991; Doyle et al., 1982; Morabito and Moczydlowski, 1994), can protect and rescue $\mathrm{Na}_{\mathrm{V}}$-expressing cells from STX poisoning by sequestering the toxin. Hence, our data challenge the hypothesis that BTX autoresistance is rooted in $\mathrm{Na}_{\mathrm{V}}$ mutations, underscore the trade-offs between toxin-resistant mutations and fitness cost (Hague et al., 2018), and highlight the potential importance of alternative mechanisms such as toxin sequestration as strategies for protecting toxin-bearing species from autointoxication and environmental small-molecule threats.

\section{Materials and methods}

Identification and cloning of Pitohui $\mathrm{Na}_{v} 1.4, \mathrm{Na}_{v} 1.5$, and $\mathrm{Na}_{v} \mathrm{\beta 2}$ Genomic DNA from Pum (family Oriolidae) blood and tissue was extracted using DNeasy kits (Qiagen) to create whole-genome sequence libraries for the poisonous Pitohui birds. Tissue samples were collected in 1989 near the village of Bonua, Central Province, Papua New Guinea $\left(10^{\circ} 08^{\prime} \mathrm{S}\right.$ by $\left.149^{\circ} 10^{\prime} 30^{\prime \prime} \mathrm{E}\right)$, stored in ethanol in the field, and frozen since being in the laboratory. Two genome sequence libraries were created using Illumina Nextera kits. One library had a target insert size of 500-640 bp and occupied a full run on the MiSeq genetic analyzer using 300-bp paired-end reads. The second library had a target insert size of 640-709 bp and occupied a full lane of a HiSeq 2500 in rapid run mode using $150-\mathrm{bp}$ paired-end reads.

The MiSeq run returned 16,279,946 paired-end reads. The program BBmerge version 4.0 (US Department of Energy Joint Genome Institute; https://jgi.doe.gov/data-and-tools/bbtools/ bb-tools-user-guide/bbmerge-guide/) was used to join the forward and reverse reads into a single long read. 7,050,488 of the read pairs $(\sim 43 \%)$ were joined, and the remaining reads were retained as paired-end reads or single reads for later analyses. The average size of merged reads was 542.6 bases. All reads were then trimmed using Trimmomatic (Bolger et al., 2014) for minimum length, removing adapters, and performing basic quality filtering. All unmerged and unpaired reads were combined into a single FastQ file.

The HiSeq run returned 150,979,291 paired-end reads. We removed adapters, trimmed for minimum length, and performed basic quality filtering using Trimmomatic (Bolger et al., 2014). $130,607,604$ pairs of reads (86.51\%) passed filtering, another 9,199,536 (6.09\%) of forward-only reads passed filter, and 3,342,519 (2.21\%) of reverse-only reads passed filter. These two read sets (the MiSeq and HiSeq Illumina datasets) composed the data for gene assembly.

Corvus brachyrhynchos and Corvus cornix crows (family Corvidae; from Joel McGlothlin, Virginia Tech, Blacksburg, VA) were the closest living relatives of Pitohuis that had a fully annotated genome in the sodium channel gene regions. Crow sequences were used as reference sequences for BLAST searches of Pitohui sequences and for assisting with Pitohui $\mathrm{Na}_{\mathrm{V}}$ assembly. These sequences included the complete nuclear DNA sequence with all exons, introns, and upstream and downstream untranslated regions.

To assemble the SCN4A gene from our Pitohui reads, we used the following pipeline, written as a Bash shell script. First, we used BLATq version 1.0.2 (https://github.com/calacademyresearch/BLATq), which uses BLAT (Kent, 2002; https://users. soe.ucsc.edu/ kent), to search all Illumina data (those merged and unmerged, as well as paired and unpaired reads) for any sequences that aligned with the full genome sequences of one of the Corvus $\mathrm{Na}_{\mathrm{V}} 1.4$ sodium channel genes. We then used the script excerptByIDs version 1.0.2 (https://github.com/calacademyresearch/excerptByIDs) to create a new FastQ file consisting of only the Illumina reads with strong BLATq scores. These files were combined into a single set of all BLAT "hits" using the Unix "cat" command. We then used the assembler SPAdes 3.9.0 (Bankevich et al., 2012) to perform an initial de novo assembly of reads in the hit file. We improved upon this assembly by using the genome assembly program PRICE version 1.2 (Ruby et al., 2013), which iteratively extends the assembly beginning with the assembled contigs from SPAdes, and extending using the pairedend Illumina read data (the entire HiSeq paired-end data as well as the unmerged MiSeq data). See Data S1 for the assembly Bash shell script and options and parameters.

The assembled contigs from PRICE were loaded into Geneious (versions 8.0 through 11.0.2). Within Geneious, we used BLAST to identify which contigs contained the Pitohui sequences. We created a BLAST database consisting of all of the assembled PRICE contigs, and we used each of the Corvus $\mathrm{Na}_{\mathrm{v}} 1.4$ exons to query the BLAST database of contigs using MegaBLAST. The top hits for each exon suggested which assembled contigs contained the $\mathrm{Na}_{\mathrm{v}} 1.4$ sequence, and typically several to all of the exons were found on the same contig. Assuming that the exon splice patterns were identical in crow and Pitohui, we aligned each of the crow $\mathrm{Na}_{\mathrm{v}} 1.4$ exon sequences to the top-hit Pitohui contig, and we annotated the matching exon regions as the Pitohui SCN4A exons.

This assembly and annotation pipelines were repeated for primary $\mathrm{Na}_{\mathrm{V}} \mathrm{s} \mathrm{Na} 1.5$-subunit (SCN5A) and the $\mathrm{Na}_{\mathrm{V}} \beta$-subunit (SCN2B).

\section{Cloning of poison frog $\mathrm{Na}_{\mathrm{v}} \mathrm{s}$}

Skeletal muscle was harvested from captive $P$. terribilis and $D$. tinctorius (Josh's Frogs) after euthanasia in accordance with University of California, San Francisco Institutional Animal Care 
and Use Committee (UCSF IACUC) protocol AN136799. Total RNA and total DNA were extracted using TRIzol reagent (Thermo Fisher Scientific). Total RNA was reverse transcribed into cDNA using the SuperScript III First-Strand Synthesis System (Thermo Fisher Scientific). 5' and 3' end sequences of genes encoding for $P$. terribilis and $D$. tinctorius $\mathrm{Na}_{\mathrm{v}} 1.4$ were determined by DNA gel extraction and sequencing after rapid amplification of cDNA ends using the SMARTer RACE $5^{\prime} / 3^{\prime}$ Kit (Takara Bio) and internal primers designed from P. terribilis and D. tinctorius $\mathrm{Na}_{\mathrm{v}} 1.4 \mathrm{~S} 6$ segment sequences (Tarvin et al., 2016). From these $5^{\prime}$ end and $3^{\prime}$ end sequences, new primers were designed from both $5^{\prime}$ and $3^{\prime}$ untranslated regions of each gene and were used to amplify full-length $P$. terribilis and $D$. tinctorius $\mathrm{Na}_{\mathrm{v}} 1.4$ genes by PCR using Phusion HF (New England Biolabs). PCR products were gel extracted and sequenced to determine the full-length $P$. terribilis and $D$. tinctorius $\mathrm{Na}_{\mathrm{V}} 1.4$ gene sequences. Direct cloning of the full-length PCR products of $P$. terribilis and D. tinctorius $\mathrm{Na}_{\mathrm{v}} 1.4$ channel genes into pCDNA3.1 proved problematic, resulting in unstable constructs prone to deletion. The codon-optimized genes were synthesized for expression in human embryonic kidney cells (HEK293; GenScript) but were also found to be prone to recombination upon insertion into pCDNA3.1. Finally, the gene sequences were redesigned to differ as much as possible from the original genes, synthesized (GenScript), and cloned into pCDNA3.1. This strategy yielded stable constructs.

\section{Subcloning and site-directed mutagenesis}

For electrophysiology experiments, Homo sapiens (Hs) Nav1.4 (GenBank accession no. NM_000334.4), human $\mathrm{Na}_{v} \beta 1$ (GenBank accession no. NM_001037.5), Pum Nav1.4, Pum $\mathrm{Na}_{\mathrm{v}} \beta 2$, Pum Nav1.5, P. terribilis (Pt) Na 1.4 , and D. tinctorius (Dt) Nav 1.4 were subcloned into pCDNA3.1 and Rattus norvegicus $(R n) \mathrm{Na}_{\mathrm{v}} 1.4$ (GenBank accession no. Y17153.1) was subcloned into pZem228. All mutants were made using the QuikChange Site-Directed Mutagenesis Kit (Agilent) and validated by complete sequencing of the genes encoding for the proteins of interest.

\section{Patch-clamp electrophysiology}

HEK293 cells and Chinese hamster ovary ( $\mathrm{CHO}$ ) cells were grown at $37^{\circ} \mathrm{C}$ and $5 \% \mathrm{CO}_{2}$ in culture medium (Dulbecco's modified Eagle's medium for HEK293 cells or Kaighn's modified Ham's F-12 medium for CHO cells) supplemented with $10 \%$ FBS, $10 \%$ L-glutamine, and antibiotics (100 $\mathrm{IU} \mathrm{ml}^{-1}$ penicillin and $100 \mathrm{mg} \mathrm{ml}^{-1}$ streptomycin). HEK293 cells were transfected (in 35-mm-diameter wells) using Lipofectamine 2000 (Invitrogen) and plated onto coverslips coated with Matrigel (BD Biosciences). Human and Pitohui $\mathrm{Na}_{\mathrm{V}} \mathrm{s}$ were coexpressed with enhanced GFP (EGFP) and human $\mathrm{Na}_{\mathrm{v}} \beta 1$ or Pitohui $\mathrm{Na}_{\mathrm{v}} \beta 2$. Poison frog $\mathrm{Na}_{\mathrm{V}} \mathrm{s}$ were coexpressed with EGFP. Transfected cells were identified visually by EGFP expression. A total of $2 \mu \mathrm{g}$ plasmid DNA ( $\left.20 \% \mathrm{Na}_{\mathrm{v}} \alpha, 40 \% \mathrm{Na}_{\mathrm{v}} \beta, 40 \% \mathrm{EGFP}\right)$ was transfected, except for the poison frog $\mathrm{Na}_{\mathrm{v}} \mathrm{s}$, for which a total of $3 \mu \mathrm{g}$ plasmid DNA (70\% Nav $\alpha, 15 \%$ EGFP, $15 \%$ SV40 T antigen) was used to increase current amplitude. For mock transfections, the $\mathrm{Na}_{\mathrm{V}} \alpha$-encoding plasmid was replaced by an empty pcDNA3.1+ plasmid. Experiments designed for studying $\mathrm{Rn} \mathrm{Na}_{\mathrm{V}} \mathrm{l} .4$ constructs were conducted using $\mathrm{CHO}$ cells cultured as described previously (Andresen and Du Bois, 2009). Briefly, cells were grown in Dulbecco's modified Eagle's medium (Gibco) supplemented with $10 \%$ cosmic calf serum (HyClone Laboratories) and $100 \mathrm{U} / \mathrm{ml}$ penicillin-streptomycin (Gibco). Cells were kept in a $5 \% \mathrm{CO}_{2}$ and $96 \%$ relative humidity incubator. $\mathrm{CHO}$ cells were transfected in a 10-cm plate using the calcium phosphate precipitation method and EGFP expression as a marker of transfection.

$\mathrm{Na}^{+}$currents were recorded by whole-cell patch clamping (Hamill et al., 1981) at room temperature $\left(23 \pm 2^{\circ} \mathrm{C}\right) 48-72 \mathrm{~h}$ after transfection. Data collection was performed using an Axopatch 200B amplifier (Molecular Devices) and pCLAMP 9 software (Molecular Devices).

Pipettes were pulled from borosilicate glass capillaries (TW150F-3; World Precision Instruments) and polished with a microforge (MF-900; Narishige) to obtain $1.2-3.5-\mathrm{M} \Omega$ resistances. Whole-cell access resistance was 3-8 $\mathrm{M} \Omega$, pipette capacitance was fully compensated, and $65-80 \%$ of the voltage error due to the series resistance was compensated. For experiments with HEK293 cells, pipette solution contained the following in $\mathrm{mM}$ : $120 \mathrm{Cs}$ methane sulfonate, $8 \mathrm{NaCl}, 10$ EGTA, $2 \mathrm{Mg}$-ATP, and 20 HEPES (pH 7.4 with $\mathrm{CsOH}$ ). Bath solution contained the following in $\mathrm{mM}: 155 \mathrm{NaCl}, 1 \mathrm{CaCl}_{2}, 1 \mathrm{MgCl}_{2}, 5 \mathrm{KCl}$, 10 HEPES, and 10 glucose (pH 7.4 with $\mathrm{NaOH}$ ). For experiments with $\mathrm{CHO}$ cells, pipette solution contained the following in $\mathrm{mM}$ : $125 \mathrm{CsCl}, 40 \mathrm{NaF}, 1 \mathrm{EDTA}$, and $20 \mathrm{HEPES}$ (pH 7.4 with $\mathrm{CsOH}$ ). Bath solution contained the following in $\mathrm{mM}: 160 \mathrm{NaCl}, 2 \mathrm{CaCl}_{2}$, and 20 HEPES (pH 7.4 with $\mathrm{NaOH}$ ).

For experiments with human, bird, and frog channels, voltage-dependent activation was assessed by stimulating the cells with a multistep depolarization protocol from -90 to $+50 \mathrm{mV}$ using $5-\mathrm{mV}$ increments, a $-100-\mathrm{mV}$ holding potential, and a sweep-to-sweep interval duration of $2 \mathrm{~s}$. Voltage-dependent steady-state inactivation was assessed by stimulating the cells with a 500-ms prepulse depolarization from -110 to $0 \mathrm{mV}$ in 5$\mathrm{mV}$ steps, followed by a 20 -ms step to $0 \mathrm{mV}$, and repolarization to the holding potential, $-100 \mathrm{mV}$; sweep-to-sweep interval duration was $4 \mathrm{~s}$. To examine BTX effects, cells were stimulated upon BTX exposure by applying at least 120 step pulses from -120 to $0 \mathrm{mV}$ at $2-\mathrm{Hz}$ frequency in order to facilitate BTX access into the channel pore because BTX is known to preferentially interact with the open state of $\mathrm{Na}_{\mathrm{v}} \mathrm{s}$ (Tanguy and Yeh, 1991). For experiments with rat $\mathrm{Na}_{\mathrm{v}} 1.4$, voltage-dependent activation was assessed by stimulating the cells with a multistep depolarization protocol from -120 to $+50 \mathrm{mV}$ using $5-\mathrm{mV}$ increments and a $-120-\mathrm{mV}$ holding potential. Voltage-dependent steady-state inactivation was assessed by stimulating the cells with a $150-\mathrm{ms}$ prepulse depolarization from -140 to $0 \mathrm{mV}$ in $5-\mathrm{mV}$ steps, followed by a $50-\mathrm{ms}$ step to $0 \mathrm{mV}$, and repolarization to the holding potential, $-120 \mathrm{mV}$. Equilibration of BTX was accomplished with persistent activation of channels by applying a 24-ms step depolarization from -120 to $0 \mathrm{mV}$ at a frequency of $2 \mathrm{~Hz}$ over the course of $8 \mathrm{~min}$. Leak currents were subtracted using a $\mathrm{P} / 4$ protocol during data acquisition. Data analysis was performed using Clampfit 10.6 (Axon Instruments).

Activation curves were obtained by fitting the data with the following single or double Boltzmann equations: $\mathrm{I}=\mathrm{I}_{\max } /\{1+\exp$ 
$\left.\left[\left(\mathrm{V}_{1 / 2}-\mathrm{V}_{\mathrm{m}}\right) / \mathrm{k}\right]\right\}$ or $\mathrm{I}=\left\{\mathrm{I}_{\max 1} /\left[1+\exp \left(\left\{\mathrm{V}_{1 / 2,1}-\mathrm{V}_{\mathrm{m}}\right\} / \mathrm{k}_{1}\right)\right]\right\}+\left\{\mathrm{I}_{\max 2} /\right.$ $\left.\left[1+\exp \left(\left\{\mathrm{V}_{1 / 2,2}-\mathrm{V}_{\mathrm{m}}\right\} / \mathrm{k}_{2}\right)\right]\right\}$, where $\mathrm{I}_{\max }$ is the maximal current after normalization to the driving force, $V_{1 / 2}$ is the halfactivation potential, $\mathrm{V}_{\mathrm{m}}$ is the membrane potential, and $\mathrm{k}$ is the slope factor. Inactivation curves were obtained by fitting the data with the following single Boltzmann equation: $\mathrm{I}=\mathrm{I}_{\max } /\{1+$ $\left.\exp \left[\left(\mathrm{V}_{\mathrm{m}}-\mathrm{V}_{1 / 2}\right) / \mathrm{k}\right]\right\}$, where $\mathrm{I}_{\max }$ is the absolute value of the maximal current at the test pulse, $\mathrm{V}_{1 / 2}$ is the half-inactivation potential, $\mathrm{V}_{\mathrm{m}}$ is the membrane potential, and $\mathrm{k}$ is the slope factor. Current density was determined as the ratio between current amplitude and the membrane capacitance. In cells transfected with $\mathrm{Na}_{V}$ constructs, green cells having no apparent $\mathrm{Na}_{\mathrm{V}}$ currents were extremely rare and therefore were not included in current density assessment. All cells with a whole-cell access resistance $>8 \mathrm{M} \Omega$ or a leak current more negative than $-200 \mathrm{pA}$ were excluded.

\section{Two-electrode voltage-clamp electrophysiology}

Two-electrode voltage-clamp recordings were performed on defolliculated stages V-VI Xenopus laevis oocytes harvested (under UCSF IACUC protocol AN178461) 1-2 d after microinjection with mRNA. Linearized Pitohui (Pum), Pt, or Dt Nav1.4 cDNA was translated into capped mRNA using the mMESSAGE mMACHINE T7 Transcription Kit (Invitrogen). Xenopus oocytes were injected with 0.5-2 ng, 3-6 ng, or 10-30 ng of Pum $\mathrm{Na}_{\mathrm{v}} 1.4$, Pt Na 1.4 , or Dt Na 1.4 mRNA, respectively. Two-electrode voltage-clamp experiments were performed 1-2 $\mathrm{d}$ after injection. Data were acquired using a GeneClamp 500B amplifier (MDS Analytical Technologies) controlled by pClamp software (Molecular Devices) and digitized at $1 \mathrm{kHz}$ using a Digidata 1332A digitizer (MDS Analytical Technologies).

Oocytes were impaled with borosilicate recording microelectrodes (0.3-3.0-M $\Omega$ resistance) backfilled with $3 \mathrm{M} \mathrm{KCl}$. Sodium currents were recorded using a bath solution (RS) containing the following in $\mathrm{mM}: 96 \mathrm{NaCl}, 1 \mathrm{CaCl}_{2}, 1 \mathrm{MgCl}_{2}, 2 \mathrm{KCl}$, and 5 HEPES ( $\mathrm{pH} 7.5$ with $\mathrm{NaOH}$ ) supplemented with antibiotics (50 $\mu \mathrm{g} \mathrm{ml}^{-1}$ gentamicin, $100 \mathrm{IU} \mathrm{ml}^{-1}$ penicillin, and $100 \mu \mathrm{g} \mathrm{ml}{ }^{-1}$ streptomycin) and $2.5 \mathrm{mM}$ sodium pyruvate.

For studying the competition between tricaine and BTX, $0.5 \mathrm{mM}$ tricaine was applied by continuous perfusion in the bath solution to assess channel block. BTX was applied from the intracellular side of the membrane by injecting oocytes with $50 \mathrm{nl}$ of $2 \mathrm{mM}$ BTX. After BTX injection, oocytes were stimulated by applying 1,000 step pulses of $60 \mathrm{~ms}$ each, from -120 to $0 \mathrm{mV}$ at $2 \mathrm{~Hz}$ frequency, in order to facilitate BTX access into the channel pore.

To determine STX and TTX dose-response curves, solutions containing test concentrations of each toxin were applied in series by perfusion to oocytes expressing Pum Nav1.4, Pt Nav1.4, or $\mathrm{Dt} \mathrm{Na}_{\mathrm{v}}$ 1.4. $\mathrm{IC}_{50}$ values were calculated from the ratio of peak currents in the presence and absence of toxin, based on the following equation: $\frac{I_{x}}{I_{0}}=\frac{\left(I_{\max }-I_{\min }\right)}{\left(1+\frac{x}{C_{50}}\right)}$, where $I_{\mathrm{x}}$ is the current amplitude at the toxin concentration $x, \mathrm{I}_{\mathrm{o}}$ is the current amplitude in absence of toxin, and $I_{\max }$ and $I_{\min }$ are the maximum and minimum peak current amplitudes, respectively, and $\mathrm{IC}_{50}$ is the half-maximal inhibitory concentration.
To determine the effects of Sxph on Pt Na 1.4 STX responses, Rana catesbeiana Sxph was expressed from a pFastBacl vector (Invitrogen) in Sf9 cells and purified as described previously (Yen et al., 2019). Sxph concentration was determined by measuring $\mathrm{A}_{280 \mathrm{~nm}}$ using an extinction coefficient of $96,365 \mathrm{M}^{-1} \mathrm{~cm}^{-1}$ calculated using the ExPASY server (https://web.expasy.org/ protparam/). For experiments in which Sxph:STX were premixed before being applied to Xenopus oocytes expressing $P t$ $\mathrm{Na}_{\mathrm{V}}$, varied Sxph:STX ratios were made by adding purified Sxph from a $100 \mu \mathrm{M}$ Sxph stock solution $(150 \mathrm{mM} \mathrm{NaCl}$ and $10 \mathrm{mM}$ HEPES, pH 7.4) to $100 \mathrm{nM} \mathrm{STX}$ in (RS) at least 10 min before perfusion. In the order of addition experiments, following recording channel behavior in the absence of the toxins, toxin concentrations to achieve $\sim 90 \%$ block, $100 \mathrm{nM} \mathrm{STX}$ or $300 \mathrm{nM}$ TTX, in RS was applied to the channels before Sxph to the desired concentration was then added directly to a 1-ml recording chamber containing the toxin. For all [Sxph]:[STX] ratios, the concentration of the stock Sxph solution added to the chamber was adjusted so that the volume of the added Sxph solution was $<1 \%$ of the total volume of the recording chamber.

All toxin effects were assessed with $60-\mathrm{ms}$ depolarization steps from -120 to $0 \mathrm{mV}$ with a holding potential of $-120 \mathrm{mV}$ and a sweep-to-sweep duration of $10 \mathrm{~s}$.

Recordings were conducted at room temperature $\left(23 \pm 2^{\circ} \mathrm{C}\right)$. Leak currents were subtracted using a P/4 protocol during data acquisition. Data analysis was performed using Clampfit 10.6 (Axon Instruments) and a custom software developed in the Igor environment (Wavemetrics).

\section{Toxin challenge experiments}

Frogs for the toxin challenge experiments were obtained from the following sources: Polypedates leucomystax, P. terribilis, and D. tinctorius (Josh's Frogs); Xenopus (Nasco); and Mantella aurantiaca (Indoor Ecosystems). All experiments were performed in accordance with UCSF IACUC protocol AN136799.

Frogs were held at room temperature $\left(23 \pm 2{ }^{\circ} \mathrm{C}\right)$ and anesthetized with a $0.15 \%$ tricaine (MS-222) bath before toxin injections. Once under anesthesia, as judged by immobility and lack of response to foot pinching, frogs were weighed in order to calculate the appropriate amount of toxin to be administered at 20 times the $\mathrm{LD}_{50}$ based on the values calculated for mice as follows: BTX, $2 \mu \mathrm{g} / \mathrm{kg}$ (Albuquerque et al., 1971); STX, $10 \mu \mathrm{g} / \mathrm{kg}$ (Wiberg and Stephenson, 1960); and TTX, $12.5 \mu \mathrm{g} / \mathrm{kg}$ (Lago et al., 2015). BTX, STX, and TTX were delivered using $40 \mathrm{ng}, 200 \mathrm{ng}$, and $250 \mathrm{ng}$ of toxin, respectively, per gram of animal weight. The upper right hind leg was injected with either control, PBS, or toxin-containing solution under an SMZ645 binocular microscope (Nikon) using a 30-gauge PrecisionGlide needle (BD Biosciences). BTX, STX, or TTX dissolved in PBS was injected at the appropriate concentration to deliver 20 times the $\mathrm{LD}_{50}$. The total volume of injection was $100 \mu \mathrm{l}$ in Xenopus and $10 \mu \mathrm{l}$ in other frogs due to their smaller size. The choice of intramuscular injection was to avoid internal organ damage. Frogs were allowed to recover in a separate container and monitored constantly for signs of recovery, paralysis, or other adverse symptoms. For Xenopus, the recovery container was filled with deionized water and inclined in a way that the frogs could recover on the dry 
surface of the container base. Postrecovery activity was then assessed by the ability of the frogs to move from the dry to the water-containing surface because Xenopus are primarily aquatic animals. For all other frogs, postrecovery activity was assessed by monitoring the ability of the animals to put themselves right side up from a supine position in their recovery containers. The monitoring period was up to $24 \mathrm{~h}$ after injection; and three animals were tested for each condition.

\section{Online supplemental material}

Fig. $\mathrm{S} 1$ shows Pitohui and poison frog $\mathrm{Na}_{\mathrm{V}} 1.4$ sequences. Fig. S2 shows the Pitohui $\mathrm{Na}_{\mathrm{v}} 1.5$ sequence. Fig. S3 shows that Pitohui $\mathrm{Na}_{\mathrm{V}} 1.5$ and $\mathrm{Na}_{\mathrm{V}} 1.4: \mathrm{Na}_{\mathrm{V}} \beta 2$ complexes are BTX sensitive. Fig. S4 shows that poison frog $\mathrm{Na}_{\mathrm{V}} 1.4 \mathrm{~s}$ expressed in $\mathrm{CHO}$ cells and Xenopus oocytes are BTX sensitive. Fig. S5 shows the functional costs of DIV-S6 Asn mutation in $R n \mathrm{Na}_{\mathrm{V}} 1.4$. Fig. S6 shows the functional cost of DIV-S6 Asn mutation in Pum $\mathrm{Na}_{\mathrm{v}} 1.4$ and $\mathrm{Hs}$ $\mathrm{Na}_{\mathrm{V}}$ 1.4. Fig. S7 shows the functional cost of DIV-S6 $\mathrm{N} \rightarrow \mathrm{T} \mathrm{mu-}$ tation in poison frog $\mathrm{Na}_{\mathrm{V}} 1.4 \mathrm{~s}$. Fig. $\mathrm{S} 8$ shows functional studies of S6 Asn mutants that support asymmetric properties of the channel pore. Table S1 lists $\mathrm{Na}_{\mathrm{V}}$ inactivation parameters. Table S2 lists human $\rightarrow$ poison frog $\mathrm{Na}_{\mathrm{V}} 1.4$ amino acid variants. Table S3 shows the recovery time from anesthesia. Data S1 provides gene assembly scripts.

\section{Results}

Pitohui poison birds and poison frogs have BTX-sensitive $\mathrm{Na}_{\mathrm{v}} \mathrm{s}$ Pitohui is one of only a few bird genera known to carry BTX (Dumbacher et al., 1992; Dumbacher et al., 2000; Menon and Dumbacher, 2014) and has BTX levels in its skeletal and cardiac muscles that should alter $\mathrm{Na}_{\mathrm{V}}$ function ( $\sim 5$ and $\sim 20 \mu \mathrm{M}$, respectively; Dumbacher et al., 2009; MacKenzie et al., 2021 Preprint). To investigate possible mechanisms of BTX resistance, we used a Pitohui genomic DNA library to identify and assemble genes for Pum skeletal muscle $\mathrm{Na}_{\mathrm{v}} 1.4$ (Fig. S1) and cardiac Pum $\mathrm{Na}_{\mathrm{V}} 1.5$ (Fig. S2). Primary sequence alignment showed extensive similarities between Pum $\mathrm{Na}_{v} 1.4$, Pum $\mathrm{Na}_{\mathrm{v}} 1.5$, and other vertebrate homologues ( $73 \%$ amino acid identity; Figs. S1 and S2), including hallmark $\mathrm{Na}_{\mathrm{V}}$ features such as a selectivity filter aspartate-glutamate-lysine-alanine (DEKA) motif, canonical RXXR repeats in S4 in all four voltage sensor domains, and the isoleucine-phenylalanine-methionine (IFM) motif responsible for fast inactivation (Catterall et al., 2020).

Whole-cell patch-clamp electrophysiology of Pum Nav1.4 and Pum Na 1.5 transfected into HEK293 cells demonstrated that both have fast voltage-dependent activation followed by a fast and complete voltage-dependent inactivation typical of $\mathrm{Na}_{\mathrm{V}} \mathrm{S}$ (Fig. 1, a and b; Fig. S3, a and b; Table 1; and Table S1), similar to Hs $\mathrm{Na}_{\mathrm{v}} 1.4$ recorded under identical conditions (Fig. 1, c and d; Table 1; and Table S1). Because $\mathrm{Na}_{\mathrm{V}} \mathrm{s}$ can harbor resistance mutations to other small-molecule toxins (Arbuckle et al., 2017; Almabruk et al., 2018; Geffeney et al., 2002; Bricelj et al., 2005), we anticipated that the Pitohui Navs might be BTX resistant. Surprisingly, application of $10 \mu \mathrm{M}$ BTX, a concentration comparable to that found in Pitohui muscle (Dumbacher et al., 2009), drastically altered the function of both Pum $\mathrm{Na}_{\mathrm{V}} \mathrm{s}$, yielding typical BTX-induced functional consequences: a hyperpolarized shift in the voltage dependency of activation $\left(\Delta \mathrm{V}_{1 / 2 \text { BTX }}=-33.6 \pm\right.$ 1.2 and $-37.4 \pm 1.8 \mathrm{mV}$ for Pum $\mathrm{Na}_{\mathrm{V}} 1.4$ and Pum $\mathrm{Na}_{\mathrm{V}} 1.5$, respectively), reduced inactivation, and enhanced tail currents (Khodorov, 1985; Logan et al., 2016; Fig. 1, a and b; Fig. S3, a and b; and Table 1). The BTX-induced activation curve follows a double Boltzmann function in which the first and second components arise from BTX-bound and unmodified channels, respectively (Du et al., 2011). Notably, the BTX-induced changes were equivalent to those elicited by BTX application to $H s \mathrm{Na}_{\mathrm{V}} 1.4\left(\Delta \mathrm{V}_{1 / 2} \mathrm{BTX}=-35.9 \pm\right.$ $1.8 \mathrm{mV}$; Fig. $1 \mathrm{~d}$ and Table 1$). \mathrm{Na}_{\mathrm{V}} \mathrm{s}$ are often coexpressed with auxiliary $\beta$-subunits that can alter their biophysical (Calhoun and Isom, 2014) and pharmacological (Gilchrist et al., 2014; Zhang et al., 2013) properties. To test whether this subunit could affect BTX resistance, we identified the Pum gene encoding for a transmembrane protein bearing the key features of $\mathrm{Na}_{\mathrm{v}} \mathrm{\beta} 2$ (Das et al., 2016; Fig. S3 c). Cotransfection of Pum $\mathrm{Na}_{\mathrm{v}} \beta 2$ with Pum $\mathrm{Na}_{\mathrm{V}} 1.4$ had no impact on channel biophysical properties or on BTX responses (Fig. S3, d and e; Table 1; and Table S1). Thus, Pum $\mathrm{Na}_{\mathrm{V}} 1.4$ alone and Pum $\mathrm{Na}_{\mathrm{V}} 1.4$ in combination with Pum $\mathrm{Na}_{\mathrm{v}} \mathrm{\beta 2}$ failed to show evidence of BTX-resistant channels. Together, these data demonstrate that even though Pitohui carry BTX in their skeletal muscles and heart (Dumbacher et al., 2009), their skeletal and cardiac $\mathrm{Na}_{\mathrm{V}} \mathrm{s}$ are BTX sensitive. Thus, autoresistance cannot originate from altered BTX sensitivity in the two most likely targets exposed to lethal BTX levels.

Poison frogs in the genus Phyllobates (family Dendrobatidae) are the most well-known BTX carriers (Albuquerque et al., 1971; Santos et al., 2016; Albuquerque et al., 1973). A number of studies have identified amino acid substitutions hypothesized to contribute to poison frog $\mathrm{Na}_{\mathrm{V}}$ BTX resistance (Tarvin et al., 2016; Márquez et al., 2019; Wang and Wang, 2017). We cloned poison frog $\mathrm{Na}_{\mathrm{V}} 1.4$ from the skeletal muscle from captivity-raised members of two representative poison frog species, one that carries high BTX levels in the wild, Phyllobates terribilis (Pt Nav1.4) (Tarvin et al., 2016; Daly et al., 1980; Myers et al., 1978), and one not known to carry BTX, Dendrobates tinctorius ( Dt $\mathrm{Na}_{\mathrm{v}} 1.4$ ) (Daly et al., 1987). Consistent with evolutionary relationships between the two species (Tarvin et al., 2016; Márquez et al., 2019), Pt Nav1.4 and $D t \mathrm{Na}_{\mathrm{v}} 1.4$ were highly similar to each other ( 95\% amino acid identity) and other vertebrate $\mathrm{Na}_{V} \mathrm{~s}$ ( $73 \%$ amino acid identity), and bore all $\mathrm{Na}_{\mathrm{V}}$ hallmark features (Fig. S1). Importantly, their DIS6 and DIVS6 sequences were identical to those reported previously (Tarvin et al., 2016) with the remarkable absence in Pt $\mathrm{Na}_{\mathrm{V}} 1.4$ of the proposed BTX resistance mutation DIVS6 $\mathrm{N} \rightarrow \mathrm{T}$ (Pt Na 1.4 Asn1600, Pt Na 1.4 N1584T [rat numbering]; Wang and Wang, 2017; Fig. S1; Table S2). Genomic DNA sequencing covering the Pt Nav1.4 DIVS6 yielded nucleotide sequences identical to those obtained from cDNA and cross-validated the absence of the DIVS6 $\mathrm{N} \rightarrow \mathrm{T}$ substitution. These findings are consistent with the observation that the DIVS6 N1600T substitution has a very low frequency among P. terribilis (Márquez et al., 2019). Besides the prior reported amino acid variants (Tarvin et al., 2016), Pt Nav1.4 and Dt $\mathrm{Na}_{\mathrm{V}} 1.4$ differed from bird, human, and rat $\mathrm{Na}_{\mathrm{V}} 1.4$ at an additional 93 positions distributed throughout the channel (Fig. 2 and Table S2). Although we could readily sequence the Pt $\mathrm{Na}_{\mathrm{V}} 1.4$ and $\mathrm{Dt}$ 


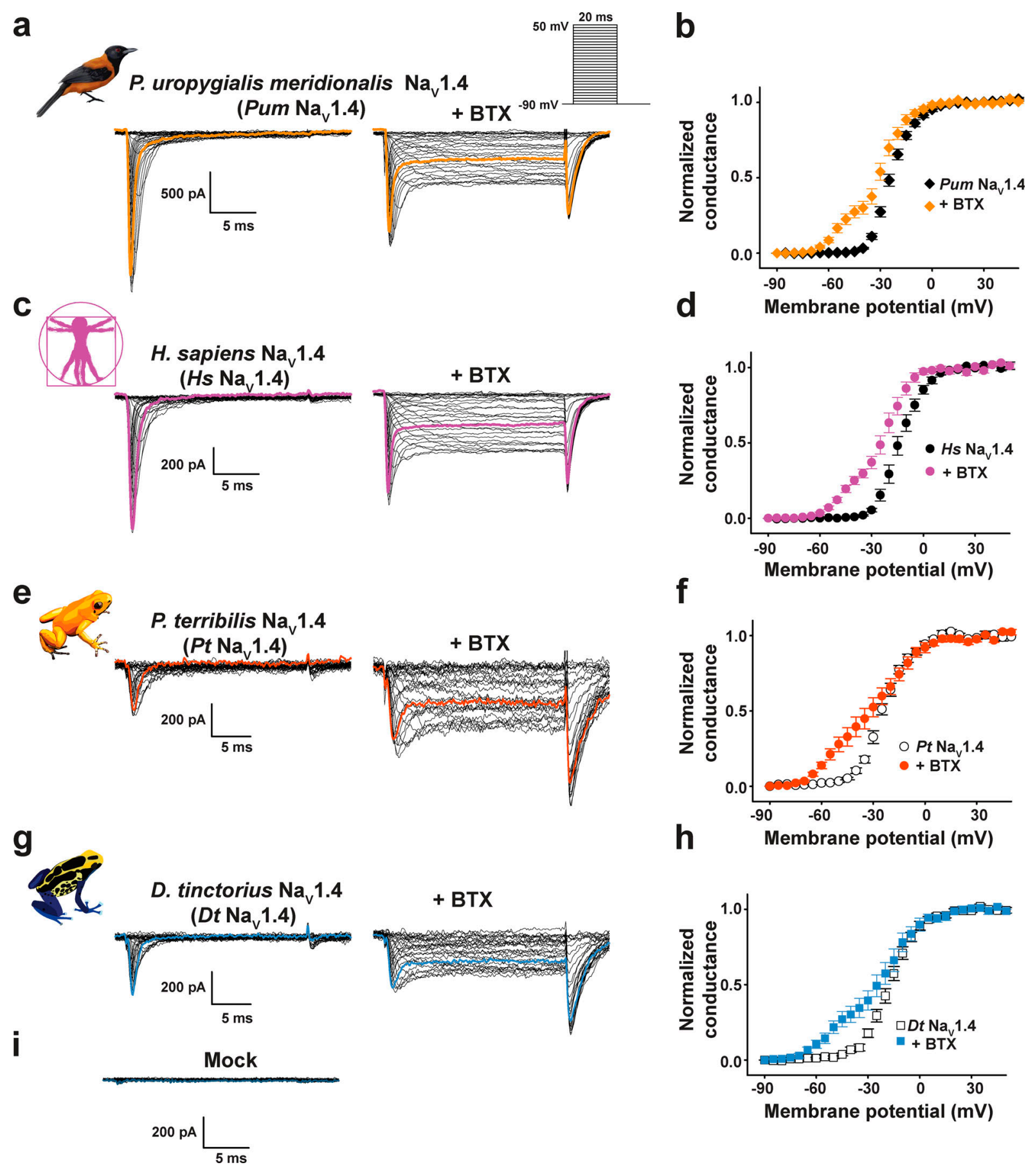

Figure 1. Pitohui and poison frog Nav1.4 channels are BTX sensitive. (a, c, e, and g) Exemplar current recordings for Pum Nav1.4 (a), Hs Nav1.4 (c), Pt Nav1.4 (e), and Dt Nav1.4 (g) expressed in HEK293 cells in the absence (left) or presence (right) of $10 \mu M$ BTX. Trace at $0 \mathrm{mV}$ is highlighted in each panel. Currents were evoked with the shown multistep depolarization protocol (inset in a). (b, d, f, and h) G-V relationships in the presence or absence of $10 \mu \mathrm{M}$ BTX for Pum Nav1.4 (black diamonds), +BTX (orange diamonds; b), Hs Nav1.4 (black circles), +BTX (purple circles; d), Pt Nav1.4 (white circles), +BTX (dark orange circles; f), and Dt Nav1.4 (white squares), +BTX (blue squares; h). (i) Exemplar current recordings from mock-transfected HEK293 cells using the protocol from a.

$\mathrm{Na}_{\mathrm{V}} 1.4$ genes, both proved prone to recombination upon passage through Escherichia coli, rendering the native DNA sequences impossible to handle. To solve this problem, we redesigned the codon usage to preserve the amino acid sequence of both. These redesigned genes were well behaved and allowed us to conduct electrophysiological characterization of $P t \mathrm{Na}_{\mathrm{V}} 1.4$ and $D t \mathrm{Na}_{\mathrm{V}} 1.4$ in mammalian and amphibian expression systems.
Whole-cell patch-clamp electrophysiology of HEK293 cells transfected with Pt $\mathrm{Na}_{\mathrm{V}} 1.4$ and $\mathrm{Dt} \mathrm{Na}_{\mathrm{V}} 1.4$ yielded voltagedependent channels that matched the properties of Pum and Hs $\mathrm{Na}_{\mathrm{v}} 1.4 \mathrm{~s}$ (Fig. 1, e-h; Table 1; and Table S1). Strikingly, both poison frog $\mathrm{Na}_{\mathrm{V}} \mathrm{s}$ had the same response to $10 \mu \mathrm{M}$ BTX as Pum and $\mathrm{Hs} \mathrm{Na} \mathrm{V}_{\mathrm{V}} \mathrm{l} .4$ (Fig. 1, e-h; $\Delta \mathrm{V}_{1 / 2}$ BTX $=-30.0 \pm 2.1$ and $-37.9 \pm$ $2.0 \mathrm{mV}$ for $\mathrm{Pt} \mathrm{Na}_{\mathrm{V}} 1.4$ and $\mathrm{Dt} \mathrm{Na}_{\mathrm{V}} 1.4$, respectively). Even though 


\begin{tabular}{|c|c|c|c|c|c|c|c|c|}
\hline Channel & & Current density $(\mathrm{pA} / \mathrm{pF})^{\mathrm{a}}(\mathrm{pA} / \mathrm{pg})^{\mathrm{b}}$ & $V_{1 / 2}-I(m V)$ & 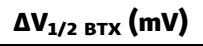 & $k_{\text {act }}-1(\mathrm{mV})$ & $V_{1 / 2}-I I(m V)$ & $k_{\text {act }}-1 I(m V)$ & $n$ \\
\hline \multirow[t]{16}{*}{ Bird } & Pum $\mathrm{Na}_{\mathrm{v}} 1.4$ & $119.5 \pm 11.8$ & $-23.4 \pm 1.0$ & & $5.9 \pm 0.3$ & & & 20 \\
\hline & $+B T X$ & & $-57.0 \pm 0.7$ & $-33.6 \pm 1.2$ & $3.8 \pm 0.6$ & $-26.0 \pm 1.7$ & $5.9 \pm 0.8$ & 9 \\
\hline & Pum Nav1.4 + Pum $\mathrm{Na}_{v} \beta 2$ & $86.5 \pm 12.8$ & $-24.9 \pm 1.3$ & & $6.2 \pm 0.5$ & & & 15 \\
\hline & $+\mathrm{BTX}$ & & $-59.9 \pm 1.9$ & $-35.0 \pm 2.3$ & $3.5 \pm 0.5$ & $-28.0 \pm 1.4$ & $5.7 \pm 0.6$ & 7 \\
\hline & Pum $\mathrm{Na}_{\mathrm{v}} 1.5$ & $17.1 \pm 3.5$ & $-22.4 \pm 1.6$ & & $8.6 \pm 0.3$ & & & 9 \\
\hline & $+\mathrm{BTX}$ & & $-59.8 \pm 0.8$ & $-37.4 \pm 1.8$ & $5.5 \pm 1.9$ & $-25.0 \pm 2.3$ & $11.3 \pm 0.7$ & 8 \\
\hline & Pum Nav1.4 N432T (DI) & $107.5 \pm 26.9$ & $-20.2 \pm 1.9$ & & $6.7 \pm 0.5$ & & & 7 \\
\hline & $+\mathrm{BTX}$ & & $-51.0 \pm 0.9$ & $-30.8 \pm 2.1$ & $4.4 \pm 0.4$ & $-9.9 \pm 6.1$ & $7.4 \pm 1.4$ & 10 \\
\hline & Pum Nav1.4 N830T (DII) & $8.1 \pm 1.5$ & $-22.4 \pm 1.0$ & & $9.2 \pm 0.5$ & & & 16 \\
\hline & $+\mathrm{BTX}$ & & $-54.0 \pm 1.7$ & $-31.6 \pm 2.0$ & $7.6 \pm 1.0$ & $-22.9 \pm 1.8$ & $5.2 \pm 0.9$ & 9 \\
\hline & Pum Nav1.4 N1306T (DIII) & $103.7 \pm 29.4$ & $-26.7 \pm 1.0$ & & $6.4 \pm 0.3$ & & & 10 \\
\hline & + BTX & & $-63.6 \pm 1.0$ & $-36.9 \pm 1.4$ & $3.7 \pm 0.6$ & $-24.8 \pm 1.2$ & $8.5 \pm 1.3$ & 5 \\
\hline & Pum Nav1.4 N1609T (DIV) & $24.6 \pm 10.8$ & $-2.9 \pm 1.1$ & & $9.6 \pm 1.0$ & & & 9 \\
\hline & + BTX & & $-14.3 \pm 3.0$ & $-11.4 \pm 3.2$ & $9.7 \pm 2.1$ & $\mathrm{~N} / \mathrm{A}$ & N/A & 5 \\
\hline & Pum Nav1.4 N1609A (DIV) & $28.9 \pm 4.6$ & $-3.8 \pm 1.3$ & & $10.7 \pm 0.4$ & & & 21 \\
\hline & $+B T X$ & & $-45.1 \pm 2.2$ & $-41.3 \pm 2.6$ & $9.1 \pm 0.8$ & $-9.6 \pm 2.0$ & $8.6 \pm 1.1$ & 14 \\
\hline \multirow[t]{4}{*}{ Human } & Hs Nav1.4 & $70.9 \pm 13.8$ & $-13.3 \pm 1.6$ & & $6.1 \pm 0.4$ & & & 13 \\
\hline & $+\mathrm{BTX}$ & & $-49.2 \pm 0.9$ & $-35.9 \pm 1.8$ & $5.0 \pm 0.4$ & $-19.0 \pm 1.9$ & $5.2 \pm 0.5$ & 9 \\
\hline & Hs Nav1.4 N1591T (DIV) & $31.7 \pm 13.4$ & $3.6 \pm 2.2$ & & $10.9 \pm 1.1$ & & & 4 \\
\hline & $+\mathrm{BTX}$ & & $-10.6 \pm 5.0$ & $-14.2 \pm 5.5$ & $9.7 \pm 0.6$ & $\mathrm{~N} / \mathrm{A}$ & $\mathrm{N} / \mathrm{A}$ & 6 \\
\hline \multirow[t]{4}{*}{ Rat } & $\mathrm{Rn} \mathrm{Na} 1.4$ & $445.0 \pm 125.1$ & $-23.1 \pm 0.3$ & & $7.3 \pm 0.3$ & & & 4 \\
\hline & $+\mathrm{BTX}$ & & $-68.7 \pm 0.2$ & $-45.6 \pm 0.4$ & $4.0 \pm 0.1$ & & & 4 \\
\hline & Rn Nav1.4 N1584T (DiV) & $43.2 \pm 40.1$ & $-5.1 \pm 0.5$ & & $8.6 \pm 0.3$ & & & 6 \\
\hline & $+\mathrm{BTX}$ & & $-45.4 \pm 2.7$ & $-40.3 \pm 2.8$ & $9.6 \pm 1.1$ & $-17.0 \pm 1.2$ & $13.0 \pm 0.9$ & 6 \\
\hline \multirow[t]{16}{*}{ Poison frog } & Pt $\mathrm{Na}_{\mathrm{v}} 1.4$ & $26.2 \pm 5.9$ & $-24.3 \pm 1.4$ & & $7.6 \pm 0.3$ & & & 6 \\
\hline & Oocytes & $669.7 \pm 120.4$ & $-16.2 \pm 2.0$ & & $4.3 \pm 0.6$ & & & 11 \\
\hline & + BTX & & $-54.3 \pm 1.6$ & $-30.0 \pm 2.1$ & $6.3 \pm 0.8$ & $-20.0 \pm 2.2$ & $9.1 \pm 1.5$ & 9 \\
\hline & + BTX oocytes & & $-49.3 \pm 2.5$ & $-33.1 \pm 3.2$ & $4.8 \pm 0.7$ & & & 8 \\
\hline & Pt Nav1.4 (N1600T) (DIV) & $24.1 \pm 3.9$ & $-23.8 \pm 1.2$ & & $9.0 \pm 0.3$ & & & 10 \\
\hline & $+\mathrm{BTX}$ & & $-54.6 \pm 2.2$ & $-30.8 \pm 2.5$ & $5.6 \pm 0.8$ & $-19.0 \pm 6.7$ & $11.7 \pm 2.0$ & 6 \\
\hline & Dt Nav1.4 & $11.1 \pm 1.8$ & $-17.1 \pm 1.6$ & & $7.7 \pm 0.4$ & & & 13 \\
\hline & $\mathrm{CHO}$ cells & $18.7 \pm 4.4$ & $-9.7 \pm 1.5$ & & $8.0 \pm 0.4$ & & & 11 \\
\hline & oocytes & $108.1 \pm 24.3$ & $-19.6 \pm 2.5$ & & $5.1 \pm 0.6$ & & & 10 \\
\hline & $+\mathrm{BTX}$ & & $-55.0 \pm 1.2$ & $-37.9 \pm 2.0$ & $5.8 \pm 1.4$ & $-17.4 \pm 2.7$ & $8.2 \pm 0.8$ & 6 \\
\hline & +BTX CHO cells & & $-39.3 \pm 1.9$ & $-29.6 \pm 2.4$ & $6.7 \pm 0.5$ & $-0.2 \pm 2.1$ & $8.5 \pm 0.9$ & 7 \\
\hline & +BTX oocytes & & $-57.4 \pm 5.6$ & $-37.8 \pm 6.1$ & $5.2 \pm 0.7$ & & & 5 \\
\hline & Dt Nav1.4 (N1600T) (DIV) & $10.0 \pm 2.0$ & $-17.2 \pm 1.2$ & & $10.7 \pm 0.9$ & & & 4 \\
\hline & $\mathrm{CHO}$ cells & $13.4 \pm 1.4$ & $-5.5 \pm 1.2$ & & $8.0 \pm 0.4$ & & & 12 \\
\hline & $+\mathrm{BTX}$ & & $-55.1 \pm 1.4$ & $-37.8 \pm 1.8$ & $6.0 \pm 0.5$ & $-18.0 \pm 3.1$ & $9.8 \pm 1.3$ & 4 \\
\hline & +BTX CHO cells & & $-40.1 \pm 2.4$ & $-34.6 \pm 2.7$ & $5.9 \pm 0.8$ & $1.4 \pm 3.1$ & $7.0 \pm 1.0$ & 7 \\
\hline
\end{tabular}

Current densities for mock-transfected HEK293 and CHO cells were $1.3 \pm 0.2$ and $1.3 \pm 0.3 \mathrm{pA} / \mathrm{pF}, n=10$ and 14 , respectively. $V_{1 / 2}-I$ and $V_{1 / 2}-\|$ are the halfactivation potential. $\mathrm{k}_{\mathrm{act}} \mathrm{l}$ an $\mathrm{k}_{\mathrm{act}} \mathrm{Il}$ are the slope factors. Values having "I" only indicate those fit by a single Boltzmann equation. Values having "I" and "II" indicate in cases where the data are fit by a double Boltzmann equation.

avalues for mammalian cells.

bValues for oocytes. 

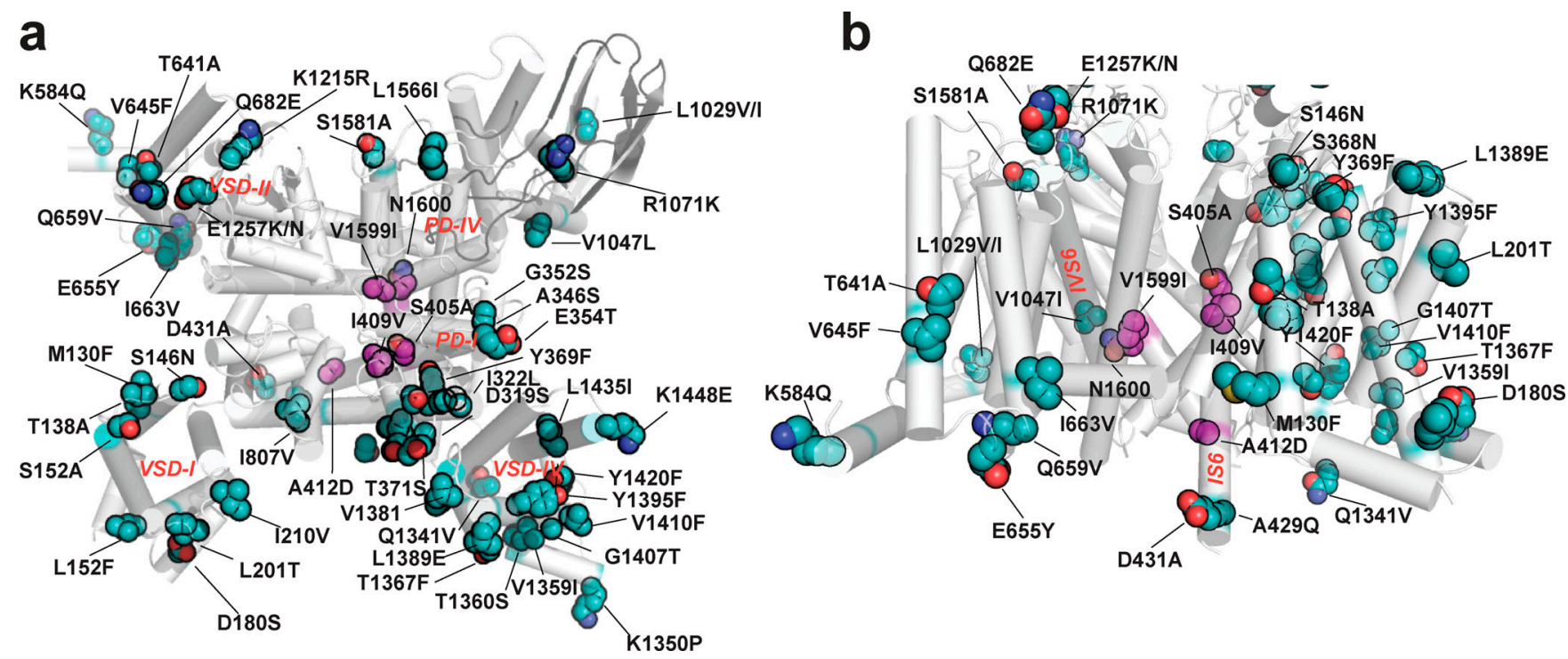

Figure 2. Structural context for poison frog $\mathrm{Na}_{\mathbf{v}}$ amino acid changes. (a and b) Locations of poison frog Nav amino acid variants reported here (cyan) and shared with Tarvin et al. (2016) (magenta). Variants are denoted human residue:residue number:frog variant using Pt Nav1.4 numbering from Fig. S1. Residues are mapped on human Nav1.4 (Protein Data Bank accession no. 6ADF; Pan et al., 2018). Nav1.4 (white).

the expression levels of both frog channels were lower than those for the Pitohui or human channels, rendering their biophysical characterization less accurate, we found no evidence for $\mathrm{Na}_{\mathrm{v}} \mathrm{s}$ in mock-transfected cells (Fig. $1 \mathrm{i}$ and Table 1). We further examined the response of $\mathrm{Dt} \mathrm{Na} \mathrm{V}_{\mathrm{v}} \mathrm{l} .4$ in a second system, $\mathrm{CHO}$ cells, and found similarly low, BTX-responsive $\mathrm{Na}_{\mathrm{V}}$ currents that were absent from mock-transfected cells (Fig. S4, a, b, e, and f; and Table 1), giving confidence that the measured activity indeed arises from the frog $\mathrm{Na}_{\mathrm{v}} \mathrm{s}$. Hence, these results demonstrate that these poison frog channels are not resistant to BTX and rule out the possibility that the $>90$ amino acid differences between poison frog and human channels, including the previously proposed changes in DIS6 and DIVS6 (Tarvin et al., 2016), could confer BTX resistance. Notably, the response of the Pt Nav1.4 to BTX reveals a BTX sensitivity evoked by a BTX concentration $(10 \mu \mathrm{M})$ that is well below that found in wild P. terribilis ( 170 $\mu \mathrm{M}$; Myers et al., 1978).

Because expression of amphibian channels in an amphibian cell could provide a more native-like context, we also expressed $P t \mathrm{Na}_{\mathrm{v}} 1.4$ and $\mathrm{Dt} \mathrm{Na}_{\mathrm{v}} 1.4$ in Xenopus oocytes and examined their function by two-electrode voltage clamping. Both channels had biophysical parameters that matched those measured in mammalian cells (Fig. S4, g-j; and Table 1). Furthermore, BTX application caused the strong hallmark functional modification observed for all of the other channels we studied (Fig. 1; Fig. S3, a, b, d, and e; and Fig. S4, a-d), including voltage-dependent activation shifts comparable to those measured in mammalian cells $\left(\Delta \mathrm{V}_{1 / 2}\right.$ втх $=-33.1 \pm 3.2$ and $-30.0 \pm 2.1$ and $-37.8 \pm 6.1$ and $-37.9 \pm 2.0 \mathrm{mV}$ for Pt Nav 1.4 and Dt Nav 1.4 expressed in Xenopus oocytes and HEK293 cells, respectively). The shift was more complete in oocytes (cf. Fig. 1, f and h; and Fig. S4, h and j). This result likely originates from the fact that, for technical reasons, due to the large extracellular solution volumes used in the oocyte experiments that would require prohibitively large quantities of BTX, this toxin was injected into the oocytes rather than applied by bath application as it was for mammalian cells. Our observation that $\mathrm{Na}_{\mathrm{V}}$ s from two classes of BTX-carrying animals, Pitohui and P. terribilis, are not BTX resistant challenges the idea that $\mathrm{Na}_{\mathrm{V}}$ mutation is the BTX autoresistance strategy as suggested for poison frogs such as P. terribilis (Tarvin et al., 2016; Wang and Wang, 2017).

\section{DIVS6 $\mathrm{N} \rightarrow \mathrm{T}$ mutation fails to confer BTX resistance to poison frog $\mathrm{Na}_{\mathrm{v}} \mathrm{s}$}

Because the DIVS6 $\mathrm{N} \rightarrow \mathrm{T}$ mutation was absent from $\mathrm{Na}_{\mathrm{V}}$ s of BTXbearing species, we wondered whether the observation that DIVS6 $\mathrm{N} \rightarrow \mathrm{T}$ could confer BTX resistance to rat $\mathrm{Na}_{\mathrm{v}} 1.4$ (Wang and Wang, 2017) was impacted by the $>90$ amino acid differences between poison frog and mammalian $\mathrm{Na}_{\mathrm{V}} \mathrm{s}$ (Fig. 2 and Table S2). Therefore, we placed the DIVS6 $\mathrm{N} \rightarrow \mathrm{T}$ mutation in poison bird, human, and poison frog $\mathrm{Na}_{\mathrm{V}} 1.4 \mathrm{~s}$ (Pum $\mathrm{Na}_{\mathrm{V}} 1.4$ N1609T, Hs Nav1.4 N1591T, Pt Nav1.4 N1600T, and Dt Nav1.4 N6100T) and measured its effects on channel function and BTX sensitivity. Consistent with studies of rat Nav1.4 DIVS6 $\mathrm{N} \rightarrow \mathrm{T}$ (Wang and Wang, 2017), DIVS6 $\mathrm{N} \rightarrow \mathrm{T}$ eliminated the ability of BTX to block inactivation and induce large tail currents in Pum $\mathrm{Na}_{v} 1.4$ and $\mathrm{Hs} \mathrm{Na} \mathrm{v}_{\mathrm{V}} \mathrm{l}$ (Fig. 3, a-d). Nevertheless, the bird and human $\mathrm{Na}_{\mathrm{V}} 1.4 \mathrm{~s}$ were not rendered completely BTX resistant. Application of $10 \mu \mathrm{M}$ BTX shifted the voltage-dependent activation of both channels, making them more easily opened by voltage $\left(\Delta \mathrm{V}_{1 / 2}\right.$ BTX $=-11.4 \pm 3.2$ and $-14.2 \pm 5.5 \mathrm{mV}$ for Pum Nav 1.4 N1609T and Hs Nav 1.4 N1591T, respectively; Fig. 3, b and d; and Table 1). Furthermore, the BTX-induced double Boltzmann was lost (Fig. 3, b and d), suggesting an enhanced BTX affinity. Due to its limited effectiveness in blocking the effects of BTX in the bird and human channels, we revisited the consequences of the DIVS6 $\mathrm{N} \rightarrow \mathrm{T}$ mutation in Rn Nav1.4. Similar to the bird and human channel results, DIVS6 $\mathrm{N} \rightarrow$ T reduced but did not eliminate $R n \mathrm{Na}_{\mathrm{v}} 1.4$ BTX sensitivity (Fig. S5, a-d). Application of $10 \mu \mathrm{M}$ 


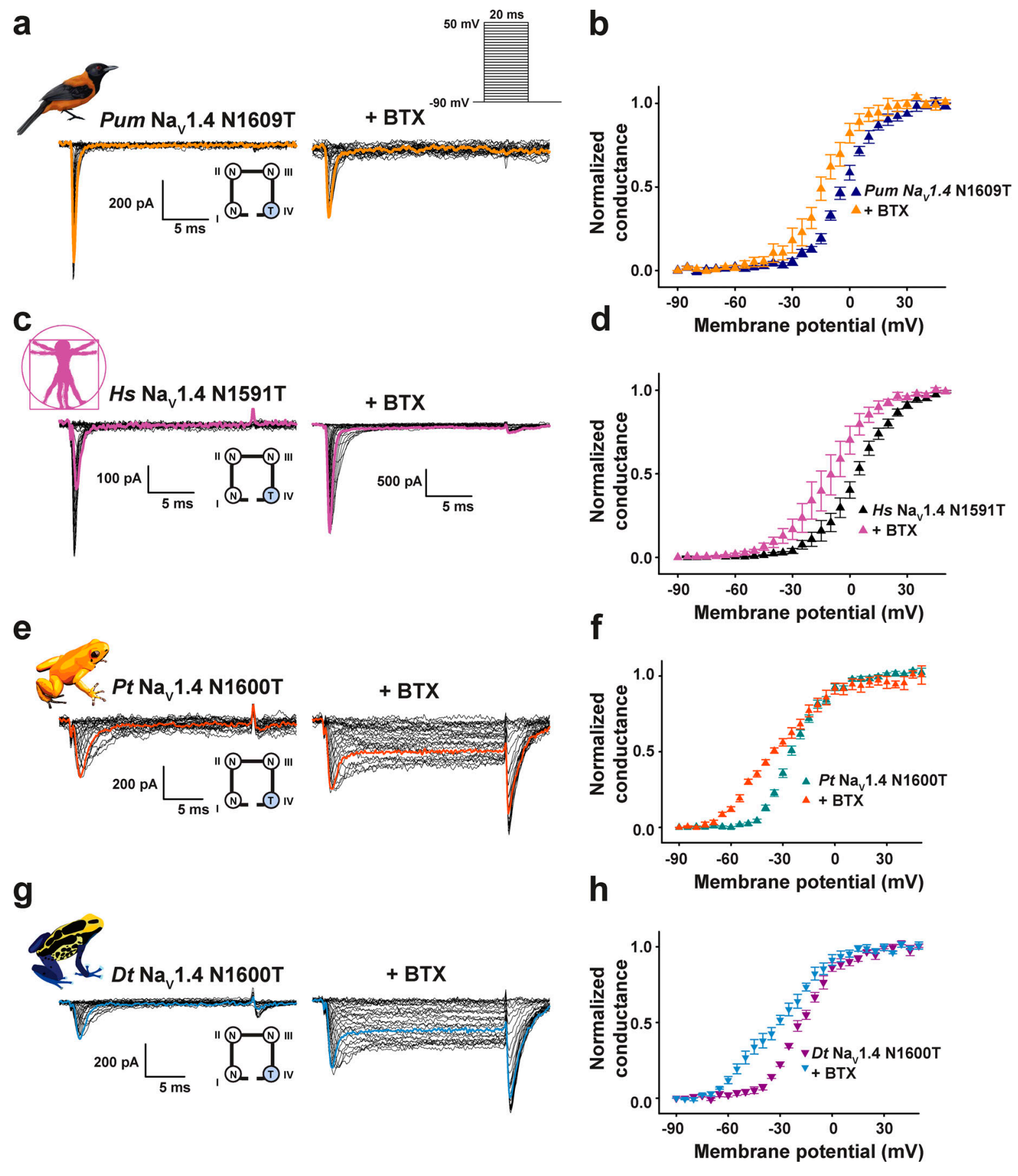

Figure 3. DIVS6 $\mathrm{N} \rightarrow$ T mutation reduces BTX sensitivity of Pitohui and human but not poison frog $\mathrm{Na}_{\mathbf{v}} \mathbf{1 . 4 s .}$ (a, c, e, and g) Exemplar current recordings for Pum Nav1.4 N1609T (a), Hs Nav1.4 N1591T (c), Pt Nav1.4 N1600T (e), and Dt Nav1.4 N1600T (g) expressed in HEK293 cells in the absence (left) or presence (right) of $10 \mu \mathrm{M}$ BTX. Trace at $0 \mathrm{mV}$ is highlighted in each panel. Currents were evoked with the shown multistep depolarization protocol (inset in a). Cartoon shows a diagram of the identities of the S6 Asn for each construct. (b, d, f, and h) G-V relationships for Pum Nav1.4 N1609T (dark blue triangles), +BTX (orange triangles; b), Hs Nav1.4 N1591T (black triangles), +BTX (magenta triangles; d), Pt Nav1.4 N1600T (teal triangles), +BTX (dark orange triangles; f), and Dt Nav1.4 N1600T (magenta downward triangles), +BTX (cyan downward triangles; h) in the presence or absence of $10 \mu M$ BTX.

BTX shifted the voltage-dependent activation of both $R n$ Nav1.4 and $R n \mathrm{Na}_{\mathrm{V}} 1.4 \mathrm{~N} 1584 \mathrm{~T}$, making them more easily opened by voltage $\left(\Delta \mathrm{V}_{1 / 2}\right.$ втх $=-45.6 \pm 0.4$ and $-40.3 \pm 2.8 \mathrm{mV}$ for $R n \mathrm{Na}_{\mathrm{V}} 1.4$ and $R n \mathrm{Na}_{\mathrm{v}} 1.4 \mathrm{~N} 1584 \mathrm{~T}$, respectively; Fig. S5, b and d; and Table 1). Thus, DIVS6 $\mathrm{N} \rightarrow \mathrm{T}$ was unable to mitigate the effects of BTX completely in any $\mathrm{Na}_{\mathrm{v}}$ orthologue.
In all three contexts, DIVS6 $\mathrm{N} \rightarrow \mathrm{T}$ also affected channel biophysical properties (Fig. S5, e-g; Fig. S6, a-h; Tables 1 and 2; and Table S1). DIVS6 $\mathrm{N} \rightarrow$ T rendered Pum Nav1.4, $\mathrm{Hs} \mathrm{Na} \mathrm{N}_{\mathrm{v}} 1.4$, and $\mathrm{Rn}$ $\mathrm{Na}_{\mathrm{V}} 1.4$ more difficult to open, shifting the activation voltage dependence to depolarizing potentials $\left(\Delta \mathrm{V}_{1 / 2}=+20.5 \pm 1.5,+16.9\right.$ \pm 2.7 , and $+18.0 \pm 0.6 \mathrm{mV}$ for Pum $\mathrm{Na}_{\mathrm{v}} 1.4$ N1609T, Hs Nav1.4 
Table 2. Comparison of the functional effects of S6 mutations

\begin{tabular}{|c|c|c|c|c|}
\hline Channel & $\begin{array}{l}\text { BTX } \\
\text { resistant? }\end{array}$ & $\begin{array}{l}\text { Activation shift? } \Delta \mathrm{V}_{1 / 2} \text { act } \\
(\mathrm{mV})\end{array}$ & $\begin{array}{l}\text { Inactivation shift? } \Delta V_{1 / 2} \text { inact } \\
(\mathrm{mV})\end{array}$ & $\begin{array}{l}\text { Decrease in current density? } \\
\text { (fold change) }\end{array}$ \\
\hline Pum Nav1.4 N432T (DI) & No & No & No & No \\
\hline Pum Nav1.4 N830T (DII) & No & No & Yes; $-10.8 \pm 1.6$ & Yes; 14.8 \\
\hline Pum Nav1.4 N1306T (DIII) & No & No & No & No \\
\hline Pum Nav1.4 N1609T (DIV) & Yes & Yes; $+20.5 \pm 1.5$ & Yes; $-10.3 \pm 2.1$ & Yes; 4.9 \\
\hline Pum Nav1.4 N1609A (DIV) & No & Yes; $+19.6 \pm 1.6$ & Yes; $-13.4 \pm 1.6$ & Yes; 4.1 \\
\hline Hs Nav1.4 N1591T (DIV) & Yes & Yes; $+16.9 \pm 2.7$ & Yes; $-9.8 \pm 1.2$ & Yes; 2.2 \\
\hline $\mathrm{Rn} \mathrm{Na}_{\mathrm{V}} 1.4 \mathrm{~N} 1584 \mathrm{~T}$ (DIV) & Yes & Yes $;+18.0 \pm 0.6$ & Yes; $-27.0 \pm 0.4$ & Yes; 10.3 \\
\hline Pt Nav1.4 (N1600T) (DIV) & No & No & Yes; $-7.7 \pm 0.9$ & No* \\
\hline Dt Nav1.4 (N1600T) (DIV) & No & No & Yes; $-9.8 \pm 1.9$ & No* \\
\hline
\end{tabular}

Data represent measurements in transfected HEK293 cells. ${ }^{*}$, substantial current density loss in Xenopus oocytes. $\Delta V_{1 / 2}$ act $=V_{1 / 2}$, act mutant $-V_{1 / 2}$, act wT. $\Delta \mathrm{V}_{1 / 2}$ inact $=\mathrm{V}_{1 / 2 \text {, inact mutant }}-\mathrm{V}_{1 / 2, \text { inact }} \mathrm{WT}$.

N1591T, and Rn Nav1.4 N1584T, respectively; Fig. S5 e; Fig. S6, b and f; and Tables 1 and 2), and made the channels easier to inactivate, shifting the voltage dependence of steady-state inactivation toward hyperpolarizing potentials $\left(\Delta \mathrm{V}_{1 / 2}\right.$ inact $=-10.3 \pm$ 2.1, $-9.8 \pm 1.2$, and $-27.0 \pm 0.4 \mathrm{mV}$ for Pum Nav1.4 N1609T, Hs $\mathrm{Na}_{\mathrm{V}} 1.4 \mathrm{~N} 1591 \mathrm{~T}$, and $\mathrm{Rn} \mathrm{Na}_{\mathrm{V}} 1.4 \mathrm{~N} 1584 \mathrm{~T}$, respectively; Fig. S5 f; Fig. S6, c and g; Table 2; and Table S1). Furthermore, DIVS6 $\mathrm{N} \rightarrow \mathrm{T}$ diminished Pum Na 1.4 N1609T, Hs Na 1.4 N1591T, and Rn $\mathrm{Na}_{\mathrm{V}} 1.4 \mathrm{~N} 1584 \mathrm{~T}$ current densities by $79 \%, 55 \%$, and $90 \%$, respectively (Fig. S5, a, c, and g; Fig. S6, a, d, e, and h; and Tables 1 and 2). Thus, the DIVS6 $\mathrm{N} \rightarrow \mathrm{T}$ change incurs a substantial functional cost.

To probe the DIVS6 Asn site further, we examined the consequences of mutation to alanine in Pum $\mathrm{Na}_{\mathrm{V}} 1.4$. Pum $\mathrm{Na}_{\mathrm{V}} 1.4$ N1609A phenocopied the biophysical changes measured for $\mathrm{N} 1609 \mathrm{~T}$, producing channels that were more difficult to open $\left(\Delta \mathrm{V}_{1 / 2}=+19.6 \pm 1.6 \mathrm{mV}\right)$ and easier to inactivate $\left(\Delta \mathrm{V}_{1 / 2}\right.$ inact $=$ $-13.4 \pm 1.6 \mathrm{mV}$ ) and that had current density reduced by $76 \%$ (Fig. S6, a-d; Tables 1 and 2; and Table S1), in agreement with the reduced channel activity reported for the corresponding $R n$ $\mathrm{Na}_{\mathrm{V}} 1.4$ mutant (Wang et al., 1997; Sheets et al., 2015). These biophysical changes match those of the BTX-resistant Pum $\mathrm{Na}_{\mathrm{V}} 1.4$ N1609T; however, Pum $\mathrm{Na}_{\mathrm{V}} 1.4$ N1609A retained all of the classical BTX responses such as reduction of inactivation, enhanced tail current, and a leftward shift of the activation voltage dependence (Fig. S6, i and j; and Tables 1 and 2). The failure of the N1609A to diminish BTX sensitivity shows that the reduction of BTX sensitivity in Pum Nav1.4 N1609T, Hs Nav1.4 N1591T, and $R n \mathrm{Na}_{\mathrm{V}} 1.4 \mathrm{~N} 1584 \mathrm{~T}$ is a specific effect of the threonine mutation and not a consequence of the changes in channel biophysical properties or current density reduction (Table 2).

To our surprise, placing DIVS6 $\mathrm{N} \rightarrow \mathrm{T}$ in both poison frog $\mathrm{Na}_{\mathrm{V}} 1.4 \mathrm{~s}$ failed to blunt the effects of BTX on channel activation and inactivation (Fig. 3, e-h; $\Delta \mathrm{V}_{1 / 2}$ втX $=-30.0 \pm 2.1$ and $-30.8 \pm$ $2.5 \mathrm{mV}$ for Pt Nav1.4 and Pt Na 1.4 N1600T, respectively, and $-37.9 \pm 2.0$ and $-37.8 \pm 1.8$ for $D t \mathrm{Na}_{\mathrm{V}} 1.4$ and $\mathrm{Dt} \mathrm{Na}_{\mathrm{V}} 1.4 \mathrm{N1600T}$, respectively). Similar results were obtained for $\mathrm{Dt} \mathrm{Na}_{\mathrm{V}} 1.4$ N1600T measured in a second expression system, CHO cells (Fig.
S4, c, d, and f). Hence, even though the DIVS6 $\mathrm{N} \rightarrow \mathrm{T}$ change reduces Pum $\mathrm{Na}_{\mathrm{V}} 1.4$, Hs $\mathrm{Na}_{\mathrm{V}} 1.4$, and $\mathrm{Rn} \mathrm{Na}_{\mathrm{V}} 1.4$ BTX responses (Fig. 3, a-d; and Fig. S5, a-d), this same change fails to affect the BTX sensitivity of poison frog $\mathrm{Na}_{\mathrm{V}}$ s. Unlike its effects in Pum, Hs, and $\mathrm{Rn} \mathrm{Na}_{\mathrm{V}} \mathrm{s}$, DIVS6 $\mathrm{N} \rightarrow \mathrm{T}$ did not cause major changes in poison frog $\mathrm{Na}_{\mathrm{V}}$ biophysical properties, shifting only the inactivation voltage dependence by $-10 \mathrm{mV}$ while leaving the activation voltage dependence and current density unchanged (Fig. S7, a-c; Tables 1 and 2; and Table S1). Additionally, expression of Pt $\mathrm{Na}_{\mathrm{V}} 1.4 \mathrm{~N} 1600 \mathrm{~T}$ and $\mathrm{Dt} \mathrm{Na}_{\mathrm{V}} 1.4$ N1600T in Xenopus oocytes revealed dramatic reductions in channel activity (Fig. S7, d-h). This 10 -fold reduction in current amplitude prevented measurement of channel biophysical properties and BTX responses, especially because in the case of the latter, the intracellular injection of BTX necessary for the oocyte experiments induces a leak current that is similar to the amplitude of the N1600T mutants. Nevertheless, these results reveal that DIVS6 $\mathrm{N} \rightarrow \mathrm{T}$ is detrimental to function and may interfere with channel folding and maturation in a manner that is accentuated at lower temperatures, such as those used to store the oocytes. This contextdependent loss of function indicates that the DIVS6 $\mathrm{N} \rightarrow \mathrm{T}$ variant exacts a functional cost that, together with its ineffectiveness in endowing poison frog $\mathrm{Na}_{\mathrm{V}} \mathrm{s}$ with BTX resistance, challenges the idea that DIVS6 $\mathrm{N} \rightarrow \mathrm{T}$ could serve as an effective BTX autoresistance mechanism.

\section{Cost of the conserved $\mathrm{N} \rightarrow \mathrm{T}$ mutation is context dependent}

The varied outcomes of DIVS6 $\mathrm{N} \rightarrow \mathrm{T}$ on BTX sensitivity among the poison bird, human, rat, and poison frog $\mathrm{Na}_{\mathrm{V}} \mathrm{s}$ highlight the importance of context in determining the functional consequences of mutations. Because the equivalent residue is conserved in all four S6 helices (Figs. S1 and S2), we systematically introduced S6 N $\rightarrow \mathrm{T}$ into each of the Pum $\mathrm{Na}_{\mathrm{V}} 1.4 \mathrm{~S} 6$ segments and measured channel properties and BTX responses to investigate the question of context-dependent effects further (Fig. 4). Whole-cell patch-clamp recordings from HEK293 cells transfected with these mutant channels revealed clear, domain-specific differences. Contrasting the effect of DIVS6 $\mathrm{N} \rightarrow \mathrm{T}$ (Fig. S6 b), voltage-dependent activation 
of channels having the $\mathrm{N} \rightarrow \mathrm{T}$ mutation in DI, DII, or DIII (Pum Na 1.4 N432T [DI], Pum Na 1.4 N830T [DII], and Pum Nav1.4 $\mathrm{N} 1306 \mathrm{~T}$ [DIII]) was unchanged relative to WT $\left(\mathrm{V}_{1 / 2}=-20.2 \pm 1.9\right.$, $-22.4 \pm 1.0,-26.7 \pm 1.0$, and $-23.4 \pm 1.0 \mathrm{mV}$ for Pum Nav1.4 N432T [DI], Pum Na 1.4 N830T [DII], Pum Na 1.4 N1306T [DIII], and Pum $\mathrm{Na}_{\mathrm{v}} 1.4$, respectively; Fig. 4, a-j; Fig. S8, a and b; and Tables 1 and 2). By contrast, we found varied effects on steady-state inactivation. DI and DIII changes showed WT-like behavior, whereas the DII mutant had an $\sim 10-\mathrm{mV}$ hyperpolarizing shift $\left(\mathrm{V}_{1 / 2}\right.$ inact $=-61.2$ $\pm 1.6,-75.0 \pm 0.9,-65.3 \pm 1.0$, and $-64.2 \pm 1.3 \mathrm{mV}$ for Pum $\mathrm{Na}_{\mathrm{V}} 1.4$ N432T [DI], Pum Nav1.4 N830T [DII], Pum Nav1.4 N1306T [DIII], and Pum $\mathrm{Na}_{\mathrm{V}} 1.4$, respectively; Fig. S8 c, Table 2, and Table S1). All three had strong BTX responses similar to WT $\left(\Delta \mathrm{V}_{1 / 2 \text { BTX }}=-30.8 \pm\right.$ 2.1, $-31.6 \pm 2.0,-36.9 \pm 1.4$, and $-33.6 \pm 1.2 \mathrm{mV}$ for Pum $\mathrm{Na}_{\mathrm{V}} 1.4$ N432T [DI], Pum Nav1.4 N830T [DII], Pum Na 1.4 N1306T [DIII], and Pum $\mathrm{Na}_{\mathrm{v}} 1.4$, respectively; Fig. 4 and Tables 1 and 2). Thus, the only site where the conserved S6 $\mathrm{N} \rightarrow \mathrm{T}$ change affects BTX responses is in DIVS6, in line with its proposed contribution to the BTX binding site (Wang and Wang, 2017).

As with the biophysical changes, the effects on current density from placing the $\mathrm{N} \rightarrow \mathrm{T}$ change in different channel domains were not uniform. The DIS6 and DIIIS6 $\mathrm{N} \rightarrow$ T mutants had current densities matching WT (Fig. 4, a, c, and g; Fig. S8, a and $\mathrm{d}$; and Tables 1 and 2), whereas, DIIS6 $\mathrm{N} \rightarrow \mathrm{T}$ lowered the current density and was more detrimental to channel activity than DIVS6 N1609T or N1609A (Fig. 4, a and e; Fig. S8, a and d; and Tables 1 and 2). Together, these data show that there is no correlation between changes in channel biophysical properties and the acquisition of BTX resistance and are in line with the results from DIVS6 $\mathrm{N} \rightarrow \mathrm{T}$ and $\mathrm{N} \rightarrow \mathrm{A}$ mutants (Figs. 3, S6, and S7, and Table 2).

Consideration of the conserved S6 asparagine structural locale provides insight into the context-dependent effects. The two $\mathrm{S} 6$ sites where $\mathrm{N} \rightarrow \mathrm{T}$ has no impact on channel biophysics, BTX responses, or current density, DIS6 and DIIIS6, occupy positions that are partially exposed to the channel inner pore (Fig. S8, e and f). By contrast, the two positions that affect channel biophysics and current density, DIIS6 and DIVS6, interact with the S4-S5 linkers (Pan et al., 2018; Fig. S8, e and f), and altering these buried sites comes with substantial functional costs. Hence, DIVS6 $\mathrm{N} \rightarrow$ T carries major disadvantages for protecting animals such as Pitohui and poison frogs against BTX autointoxication.

\section{Toxin-free poison frogs have BTX- and STX-sensitive $\mathrm{Na}_{\mathrm{v}}$ s but are resistant to both toxins}

The surprising observation that $\mathrm{Na}_{\mathrm{V}}$ s from BTX-carrying birds and frogs remain BTX sensitive raised the question whether the species from which we cloned the channels were actually BTX resistant. Because of difficulties in obtaining live animals, we were unable to investigate Pitohui BTX resistance. Captivityraised poison frogs lack BTX because this toxin is acquired in the wild from their diet (Daly et al., 1994b; Daly et al., 1994a). Thus, it was possible that the toxin-free poison frogs used to clone $\mathrm{Na}_{\mathrm{V}} \mathrm{s}$ were not BTX resistant due to the absence of selective pressure from the toxin, a possibility underscored by the high functional cost of DIVS6 N $\rightarrow$ T (Fig. 3, e-h; Fig. S7; Tables 1 and 2; and Table S1). To test whether captivity-raised poison frogs were BTX resistant, we conducted a series of toxin challenge experiments using five different frog species: two nonpoisonous frogs (Xenopus and Polypedates leucomystax), two captivity-raised dendrobatid poison frogs that carry alkaloid toxins in the wild ( $P$. terribilis, BTX; and D. tinctorius, HTX and PTX), and an unrelated captivity-raised Malagasy poison frog that carries PTX rather than BTX in the wild ( $M$. aurantiaca) and that represents an independent evolutionary origin of chemical defenses (Daly et al., 2005; Daly et al., 2008; Garraffo et al., 1993). We challenged these animals with three different toxins that target $\mathrm{Na}_{\mathrm{V}} \mathrm{s}$ : BTX and two guanidinium toxins that act by a pore-blocking mechanism, STX (Thottumkara et al., 2014; Durán-Riveroll and Cembella, 2017) and TTX (Durán-Riveroll and Cembella, 2017).

We assessed the duration of recovery from anesthesiainduced paralysis after intramuscular injection of each toxin at 20 times the lethal dose based on values for mice $\left(L_{50}\right)$ by monitoring how long it took the frog to show clear motor activity relative to injection of a PBS control. After BTX injection, Xenopus and P. leucomystax displayed an accelerated recovery from anesthesia that was at least two times faster than that with PBS injections (PBS and BTX recovery times: $29 \pm 1 \mathrm{~min}$ and $15 \pm$ $5 \mathrm{~min}$ and $169 \pm 12 \mathrm{~min}$ and $70 \pm 20 \mathrm{~min}$ for Xenopus and Phyllobates leucomystax, respectively; Fig. 5, a, b, and f; and Table S3). After the initial recovery, BTX was ultimately lethal to Xenopus (Fig. 5, a and f). By contrast, BTX injection did not change the anesthesia recovery time or kill any of the poison frogs, regardless of whether they carry BTX in the wild (P. terribilis) or are naturally BTX free but harbor other alkaloid toxins ( $D$. tinctorius, M. aurantiaca; Fig. 5, c-f; and Table S3). Reponses to STX also revealed differences between nonpoisonous and poisonous frogs. STX injection was lethal to Xenopus and P. leucomystax (Fig. 5, a, b, and f), whereas all three poison frogs fully recovered from anesthesia after STX injections (Fig. 5, c-f). TTX was lethal to Xenopus (Fig. 5, a and f). Although TTX caused extended paralysis in all other tested frogs, it was not lethal (Fig. 5, a-f; and Table S3). Thus, all tested poisonous frogs showed resistance to all three toxins, whereas nonpoisonous frogs were vulnerable to either BTX and STX (P. leucomystax) or all three toxins (Xenopus; Fig. $5 \mathrm{f}$ ).

The striking differences in BTX-induced accelerated recovery from anesthesia between the nonpoisonous and poisonous species was unexpected. Studies of eukaryotic and prokaryotic $\mathrm{Na}_{V} \mathrm{~S}$ suggest that BTX and local anesthetics, such as the tricaine used for frog anesthesia, have overlapping binding sites within the channel pore (Finol-Urdaneta et al., 2019; Wang and Wang, 1992; Wang et al., 1994; Wang and Wang, 1994). We considered that the differences in BTX-dependent accelerated recovery from anesthesia were a physiological manifestation of this molecular competition and indicated that BTX was engaging the target channels in nonpoisonous frogs but not in poisonous frogs. Hence, we tested whether tricaine and BTX produced competing effects on $\mathrm{Pt} \mathrm{Na} \mathrm{V}_{\mathrm{V}} 1.4$ and $\mathrm{Dt} \mathrm{Na} \mathrm{V}_{\mathrm{V}} 1.4$. Consistent with its anesthetic effects on the frogs, $0.5 \mathrm{mM}$ tricaine inhibited both poison frog $\mathrm{Na}_{\mathrm{V}} \mathrm{s}$ and had similar effects on the Pum $\mathrm{Na}_{\mathrm{V}} 1.4$ control (Fig. 6, $\mathrm{a}-\mathrm{c}$ and $\mathrm{g})$. Subsequent BTX injection into the same tricaine- 
a
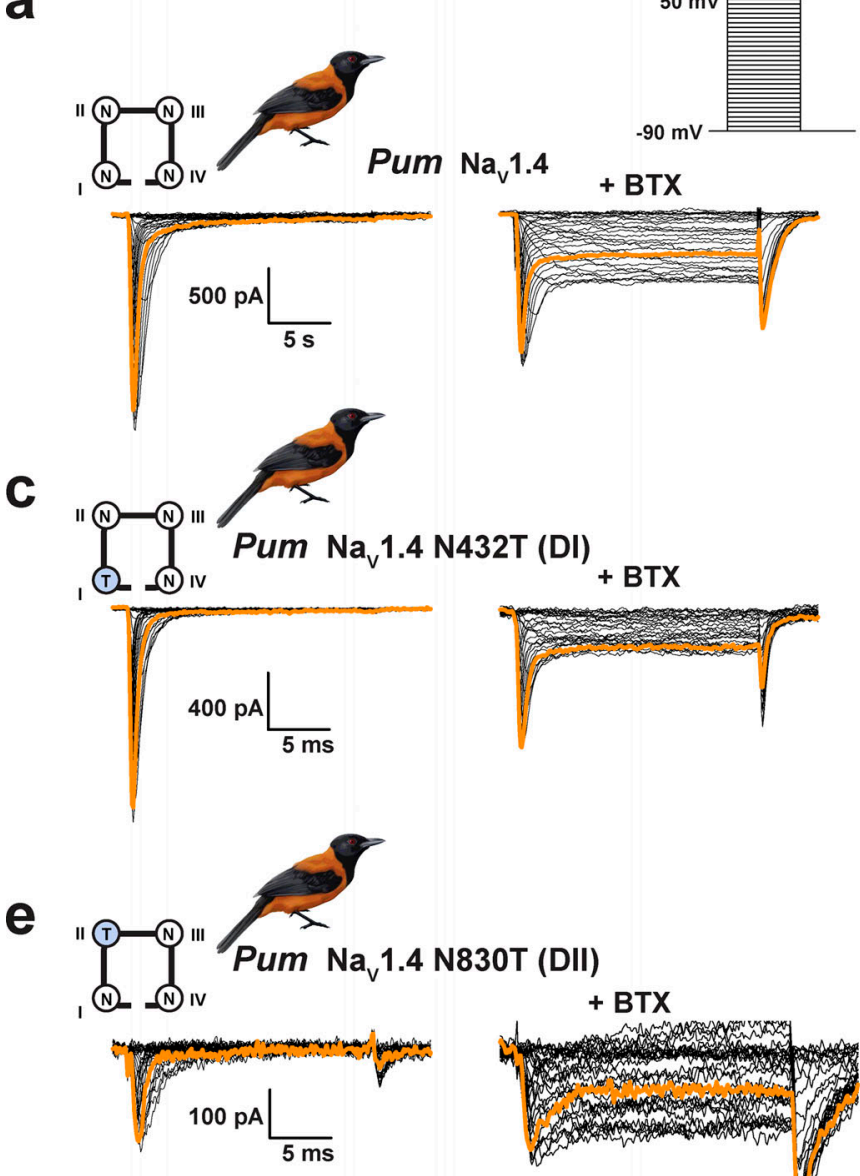

9

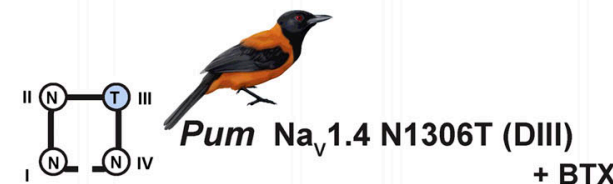

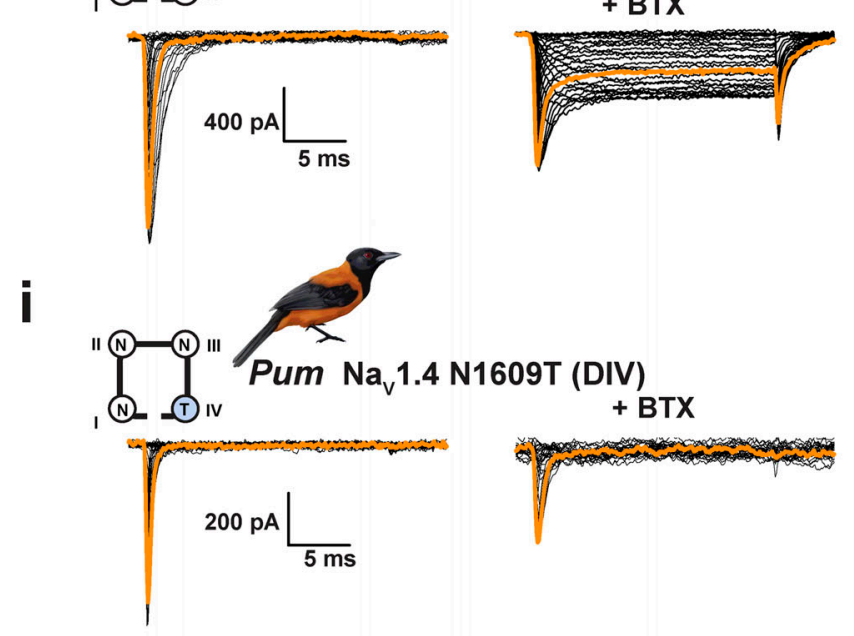

b
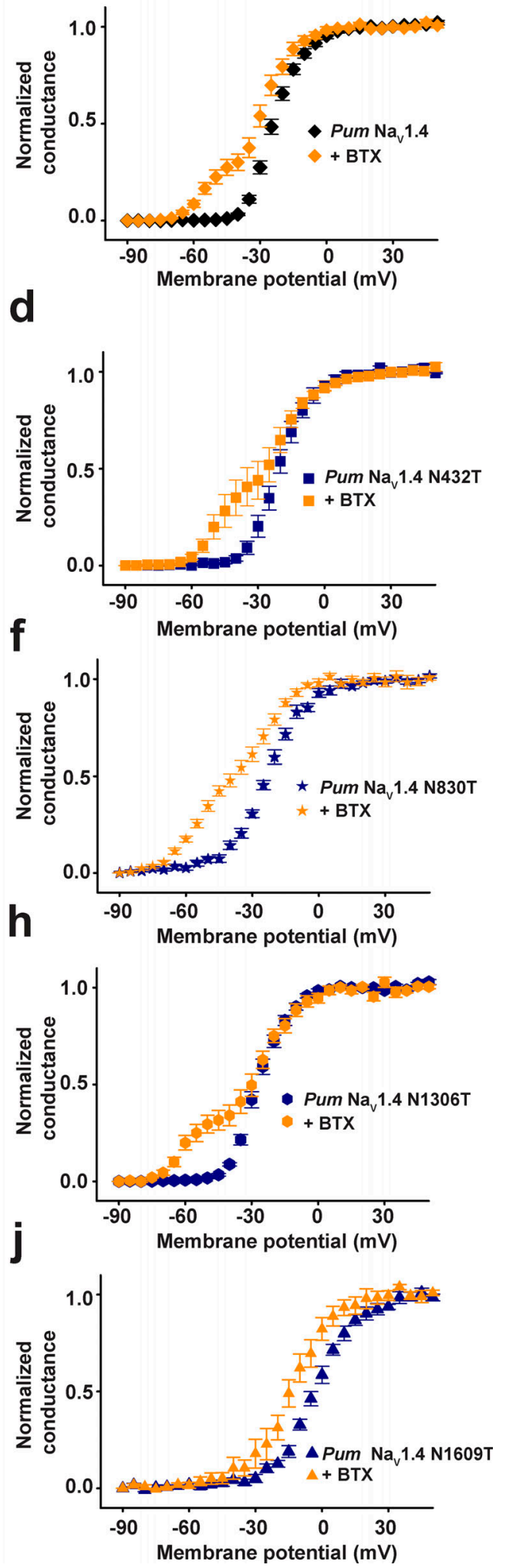

Figure 4. Sodium channel modulation by BTX is associated with an asymmetry in the inner pore. (a, c, e, g, and i) Exemplar current recordings for Pum Nav1.4 (a), Pum Nav1.4 N432T (c), Pum Nav1.4 N830T (e), Pum Nav1.4 N1306T (g), and Pum Nav1.4 N1609T (i) expressed in HEK293 cells in the absence (left) or presence (right) of $10 \mu \mathrm{M}$ BTX. Trace at $0 \mathrm{mV}$ is highlighted in each panel. Currents were evoked with the shown multistep depolarization protocol (inset in a). Cartoon shows a diagram of the identities of the S6 Asn for each construct. (b, d, f, h, and j) G-V relationships in the presence or absence of $10 \mu M$ BTX for Pum 
Nav1.4 (black diamonds), +BTX (orange diamonds; b), Pum Nav1.4 N432T (dark blue squares), +BTX (orange squares; d), Pum Nav1.4 N830T (dark blue stars), +BTX (orange stars; f), Pum Nav1.4 N1306T (dark blue hexagons), +BTX (orange hexagons; h), and Pum Nav1.4 N1609T (dark blue triangles), +BTX (orange triangles; j). Data in a and b are from Fig. 1 , a and b.

treated oocytes caused complete relief of the tricaine block (Fig. 6, a-c and g), in line with a direct competition between tricaine and BTX. By contrast, in the absence of tricaine, this dramatic BTX-induced increase in peak current was absent (Fig. 6, d-f and h). These data demonstrate that the poison frog $\mathrm{Na}_{\mathrm{V}} \mathrm{S}$ are competent for BTX-tricaine competition. Hence, the differences in BTX-induced accelerated recovery from anesthesia reflect the direct competition of the two compounds on the channel in the nonpoisonous frogs and suggest that the poisonous frogs have a means to prevent BTX from engaging their $\mathrm{Na}_{\mathrm{V}} \mathrm{s}$.

The poison frog STX resistance we observed could be explained by a lack of $\mathrm{Na}_{\mathrm{V}}$ sensitivity to this toxin. To test this possibility, we compared the responses of Pt $\mathrm{Na}_{\mathrm{V}} 1.4, \mathrm{Dt} \mathrm{Na} \mathrm{N}_{\mathrm{V}} 1.4$, and Pum Nav1.4 as a control to STX and TTX because the former had minimal effect on the poison frogs, whereas the latter caused potent paralysis (Fig. 5 and Table S3). Extracellular application of increasing STX concentrations inhibited all three $\mathrm{Na}_{V} \mathrm{~s}$ with a nanomolar response that matched that of other $\mathrm{Na}_{\mathrm{V}} \mathrm{s}$ (Thomas-Tran and Du Bois, 2016; Thottumkara et al., 2014; Andresen and Du Bois, 2009; $\mathrm{IC}_{50}=12.6 \pm 1.4 \mathrm{nM}, 14.6 \pm 0.6 \mathrm{nM}$, and $7.3 \pm 0.5 \mathrm{nM}$ for Pt Nav1.4, Dt Nav1.4, and Pum $\mathrm{Na}_{\mathrm{v}} 1.4$, respectively; Fig. 7, a-d). Pt $\mathrm{Na}_{\mathrm{V}} 1.4$ and $\mathrm{Dt} \mathrm{Na}_{\mathrm{V}} 1.4$ and the control Pum $\mathrm{Na}_{\mathrm{v}} 1.4$ also had nanomolar TTX responses, similar to $\mathrm{Hs}$ $\mathrm{Na}_{\mathrm{v}} 1.4$ (Chahine et al., 1994; $\mathrm{IC}_{50}=21.3 \pm 1.0 \mathrm{nM}, 40.8 \pm 1.8 \mathrm{nM}$, and $6.2 \pm 0.4 \mathrm{nM}$ for Pt Nav $1.4, D t \mathrm{Na}_{\mathrm{v}} 1.4$, and Pum Nav 1.4 , respectively; Fig. 7, e-h). Thus, the ability of the poison frogs to resist STX does not arise from their $\mathrm{Na}_{V}$ s having some unusual resistance to the toxin (Figs. 5 and $7 \mathrm{~d}$ and Table S3). The resistance of poison frogs to the effects of BTX and STX contrasts with the effects of TTX and is not consistent with the high sensitivity of their Nav1.4s to all three toxins. These findings suggest that mechanisms such as toxin sequestration may prevent BTX and STX from reaching their target $\mathrm{Na}_{\mathrm{V}} \mathrm{S}$.

\section{An amphibian "toxin sponge" protein protects $\mathrm{Na}_{v} \mathrm{~s}$ from toxin action}

The toxin challenge experiments indicated that BTX and STX were unable to affect poison frog $\mathrm{Na}_{\mathrm{V}} \mathrm{s}$, even though the channels are perfectly sensitive to both toxins (Figs. 5 and $7 \mathrm{~d}$, and Table S3). Although there is yet no known BTX binding protein, a high-affinity soluble $91 \mathrm{kD}$ STX-binding protein from frog
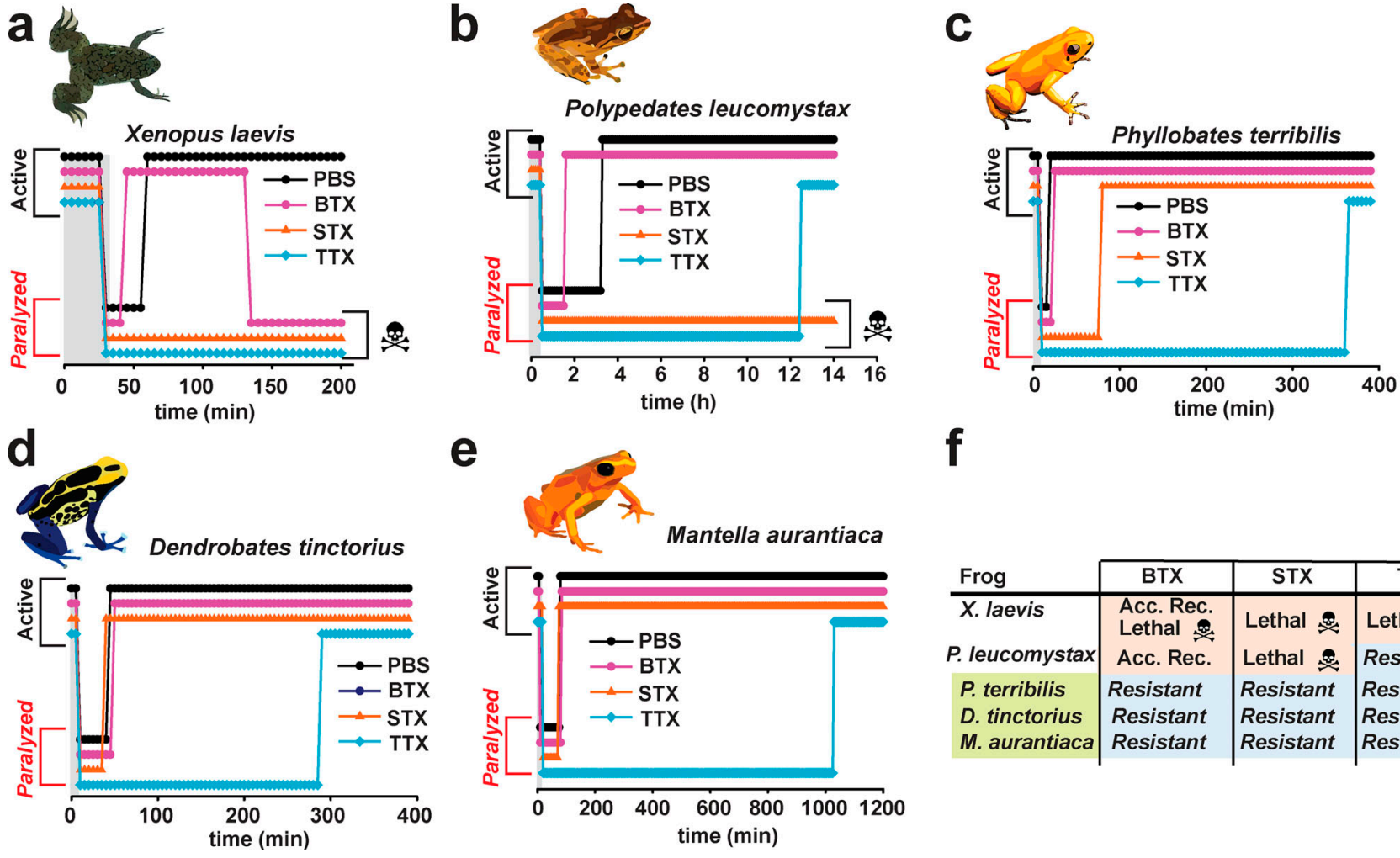

Figure 5. Captivity-raised poison frogs are resistant to BTX and STX. (a-e) Challenge experiments for Xenopus (a), P. leucomystax (b), P. terribilis (c), D. tinctorius (d), and M. aurantiaca (e) with PBS (black circles), BTX (magenta circles), STX (orange triangles), or TTX (cyan diamond) injection. Gray area shows the period of anesthesia application. Active and paralyzed states of the frogs are indicated. (f) Summary of the sensitivity of the indicated species to BTX, STX, and TTX. Acc. Rec., accelerated recovery from anesthesia; Resistant, no toxin-induced death. 
a

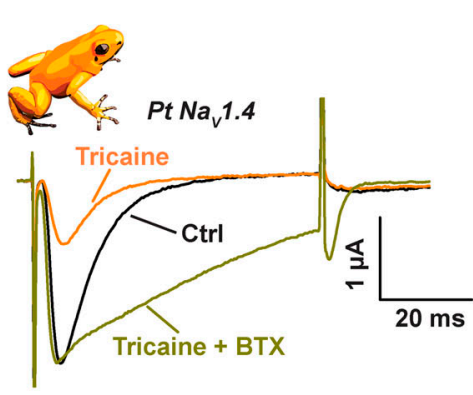

d

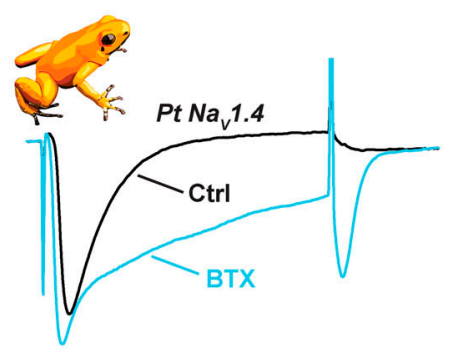

b

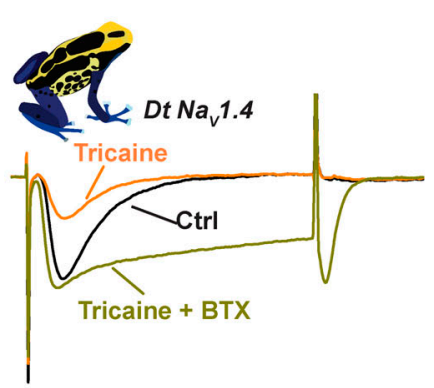

e

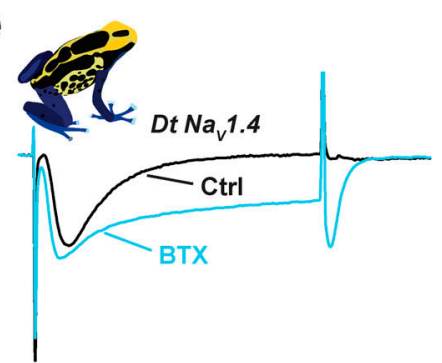

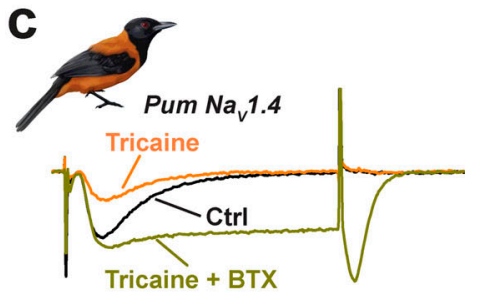

f

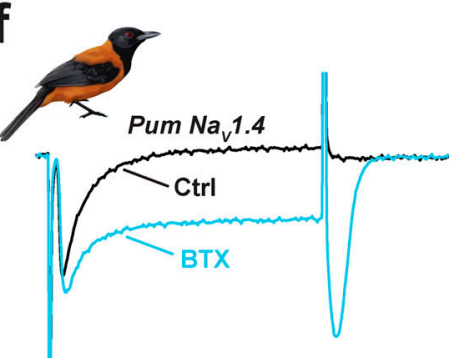

g

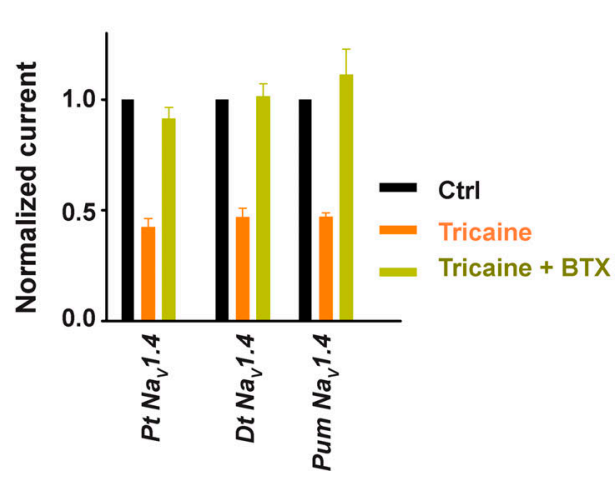

h

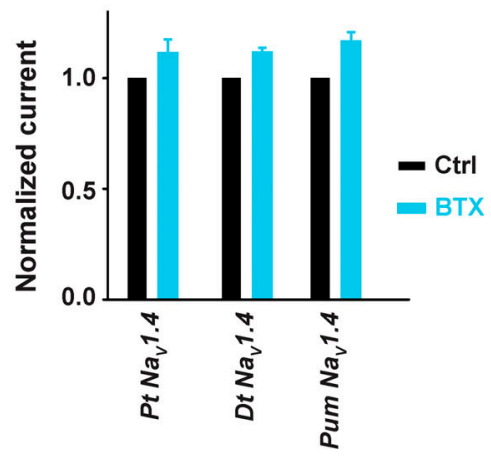

Figure 6. BTX competes with anesthetic agent tricaine in $\mathrm{Na}_{\mathbf{V}}$ s from poisonous species. (a-c) Exemplar two electrode voltage clamp (TEVC) recordings at $0 \mathrm{mV}$ in control (black), after $0.5 \mathrm{mM}$ tricaine application (orange), and after BTX injection (dark green) into the same Xenopus oocytes expressing Pt Nav1.4 (a), Dt Nav1.4 (b), and Pum Nav1.4 (c). BTX injection was performed after tricaine block of sodium current, and the recordings of the BTX effect were made while the oocyte was still exposed to tricaine. (d-f) Exemplar TEVC recordings at $0 \mathrm{mV}$ before (black) or after BTX injection (light blue) into the same Xenopus oocytes expressing Nav1.4 from the indicated poisonous species. ( $g$ and $\mathbf{h}$ ) Average peak current amplitudes normalized to the corresponding control peak current amplitude for tricaine and BTX (g) and BTX alone (h).

plasma, Sxph, has been well characterized and shown to bind STX but not TTX (Mahar et al., 1991; Yen et al., 2019; Llewellyn and Moczydlowski, 1994; Morabito and Moczydlowski, 1994). Hence, we asked whether Sxph, which has a $K_{d}$ for STX that is comparable to that of the channel (Mahar et al., 1991; Doyle et al., 1982; Llewellyn and Moczydlowski, 1994), would be capable of protecting $\mathrm{Na}_{\mathrm{V}} \mathrm{s}$ from the action of STX. Application of solutions preequilibrated with different Sxph:STX molar ratios showed that Sxph was able to protect completely $P t \mathrm{Na}_{\mathrm{V}}$ expressed in Xenopus oocytes from STX inhibition once the ratio reached 2: 1 Sxph:STX (Fig. 8, a and b). Furthermore, application of Sxph to cells expressing Pt $\mathrm{Na}_{\mathrm{V}}$ s that had been preblocked with STX yielded the same result and demonstrated that Sxph is able to compete effectively with the channel for the toxin (Fig. 8, c-e; and Fig. S9, a-f). Importantly, Sxph had no effect against the related guanidinium toxin TTX (Fig. 8, e and f; and Fig. S9, $g$ and h), a toxin that does not bind Sxph (Mahar et al., 1991). Hence, these experiments demonstrate that high-affinity toxin sponge proteins are able to prevent the actions of small-molecule toxins that target $\mathrm{Na}_{\mathrm{V}} \mathrm{s}$ and lend further support to the idea that toxin sequestration mechanisms may act to protect poisonous animals from autointoxication.

\section{Discussion}

Poisonous organisms that use toxins as defensive molecules must avoid autointoxication. Such resistance has been proposed to arise from three strategies: (1) acquisition of target protein toxin resistance mutations, (2) toxin sequestration, and (3) enhanced detoxification or elimination capacity (Almabruk et al., 2018; Arbuckle et al., 2017). Support for the first mechanism includes prominent examples of TTX-resistant $\mathrm{Na}_{\mathrm{V}} \mathrm{S}$ in toxinbearing species and their predators (Hanifin and Gilly, 2015; Jost et al., 2008; Geffeney et al., 2002; Geffeney et al., 2005; McGlothlin et al., 2016), STX-resistant $\mathrm{Na}_{\mathrm{V}} \mathrm{s}$ in mollusks (Bricelj et al., 2005), and epibatidine-resistant nicotinic acetylcholine 
a
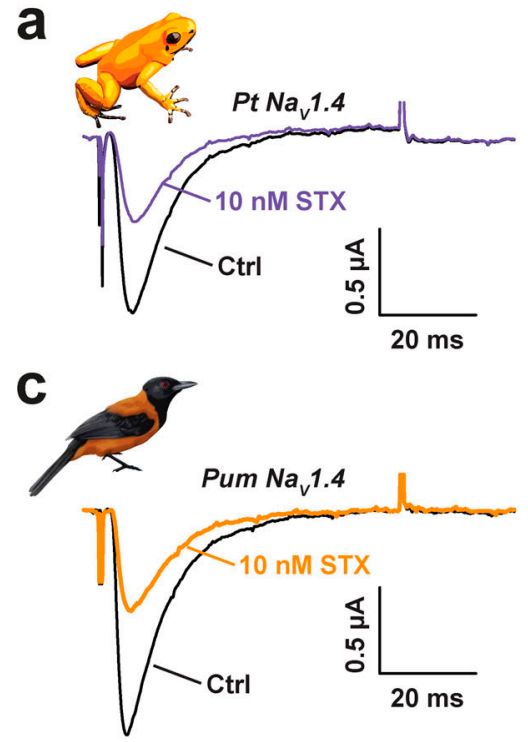

e
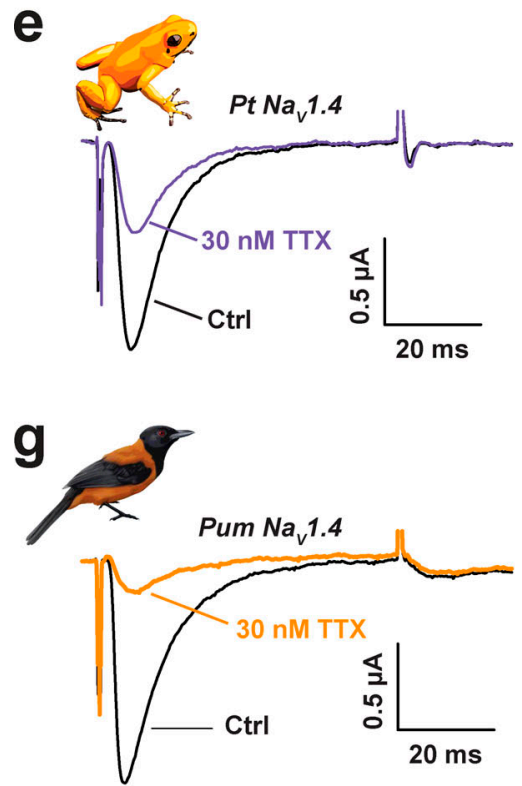

b

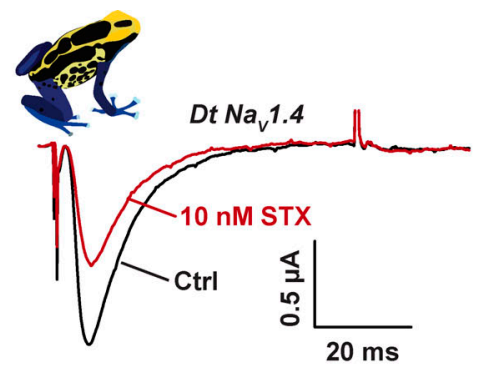

d

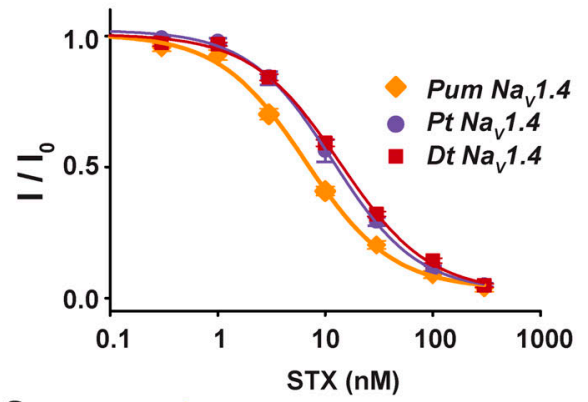

f

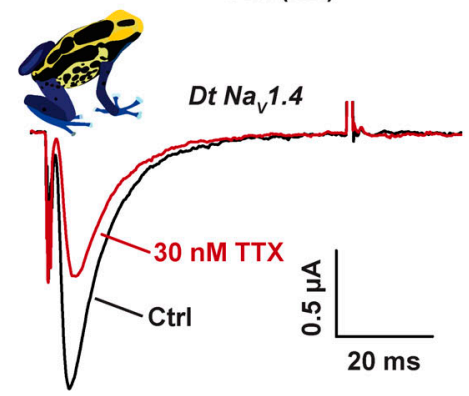

h

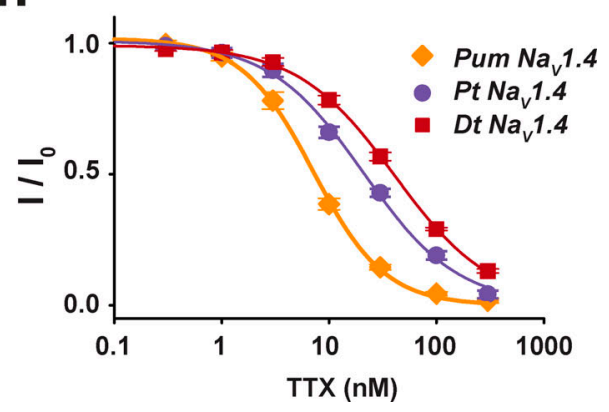

Figure 7. $\mathrm{Na}_{\mathbf{v}} \mathbf{1 . 4 \mathrm { s }}$ from poisonous animals are STX and TTX sensitive. (a-c) Exemplar two-electrode voltage-clamp (TEVC) recordings at $0 \mathrm{mV}$ before (black) and after $10 \mathrm{nM} \mathrm{STX}$ application to Xenopus oocytes expressing $P t$ Nav1.4 (purple; a), Dt Nav1.4 (red; b), or Pum Nav1.4 (orange; c). (d) STX dose-response curves for Pt Nav1.4 (purple circles), Dt Nav1.4 (red squares), and Pum Nav1.4 (orange diamonds). Curves show fits to the Hill equation. $I_{50}=12.6 \pm 1.4 \mathrm{nM}, 14.6 \pm 0.6 \mathrm{nM}$, and $7.3 \pm$ $0.5 \mathrm{nM}$ for Pt Nav1.4, Dt Nav1.4, and Pum $\mathrm{Na}_{\vee} 1.4$, respectively. Error bars are SEM. $n=4$. (e-g) Exemplar TEVC recordings at $0 \mathrm{mV}$ before (black) and after $30 \mathrm{nM}$ TTX application to Xenopus oocytes expressing Pt Nav1.4 (purple; e), Dt Nav1.4 (red; f), or Pum Nav1.4 (orange; g). (h) TTX dose-response curves for Pt Nav1.4 (purple circles), Dt Nav1.4 (red squares), and Pum Nav1.4 (orange diamonds). Curves show fits to the Hill equation. $I C_{50}=21.3 \pm 1.0 \mathrm{nM}, 40.8 \pm 1.8$ $\mathrm{nM}$, and $6.2 \pm 0.4 \mathrm{nM}$ for Pt Nav1.4, Dt Nav1.4, and Pum Nav1.4, respectively. Error bars are SEM. $n=5-6$. receptors in poison frogs (Tarvin et al., 2017). Because of these examples and the suggestion that the $\mathrm{Na}_{\mathrm{V}}$ DIVS6 $\mathrm{N} \rightarrow$ T mutation might confer BTX resistance to poison frogs (Wang and Wang, 2017), we expected to find toxin-resistant mutants in poison bird and frog $\mathrm{Na}_{\mathrm{V}} \mathrm{s}$. Instead, we found multiple lines of evidence demonstrating that $\mathrm{Na}_{\mathrm{V}} \mathrm{s}$ from both poison birds and frogs are highly sensitive to BTX and lack the DIVS6 $\mathrm{N} \rightarrow \mathrm{T}$ change. Furthermore, even though the DIVS6 $\mathrm{N} \rightarrow$ T mutation alters the BTX responses of bird, human, and rat $\mathrm{Na}_{\mathrm{V}} 1.4 \mathrm{~s}$ (Fig. 3, a-d; and Fig. S5, a-d), it failed to have any effect on the BTX sensitivity of poison frog $\mathrm{Na}_{\mathrm{V}} \mathrm{s}$ (Fig. 3, e-h), a result that highlights the importance of vetting putative toxin resistance mutations in the context of the native channel (Tarvin et al., 2017).

How amino acid changes compensate for mutations that alter function is complex and can arise from effects at positions that are far apart in the protein structure (Thomas et al., 2010; Wang et al., 2002; Bigman and Levy, 2020; Tokuriki et al., 2008). There are $>90$ amino acid differences between the poison frog and human $\mathrm{Na}_{\mathrm{V}} 1.4 \mathrm{~s}$ (Fig. 2 and Table S2), and it is not obvious which variants in the frog $\mathrm{Na}_{\mathrm{V}}$ s suppress the ability of DIVS6 $\mathrm{N} \rightarrow \mathrm{T}$ to affect BTX responses. The importance of context is further evident from the fact that even though the Asn position is conserved in all four $\mathrm{Na}_{\mathrm{V}}$ pore domain subunits, the functional consequences of the $\mathrm{N} \rightarrow \mathrm{T}$ change are domain dependent (Fig. 4 and Table 2). These factors, together with the absence of DIVS6 $\mathrm{N} \rightarrow \mathrm{T}$ in BTX-bearing birds and frogs (Figs. S1 and S2; Márquez et al., 2019; Tarvin et al., 2016) and its ineffectiveness in poison frog $\mathrm{Na}_{\mathrm{V}} \mathrm{s}$, rule out the target alteration hypothesis for BTX resistance.

Endowing a protein with a new function through mutation often incurs a cost, particularly with respect to protein stability 

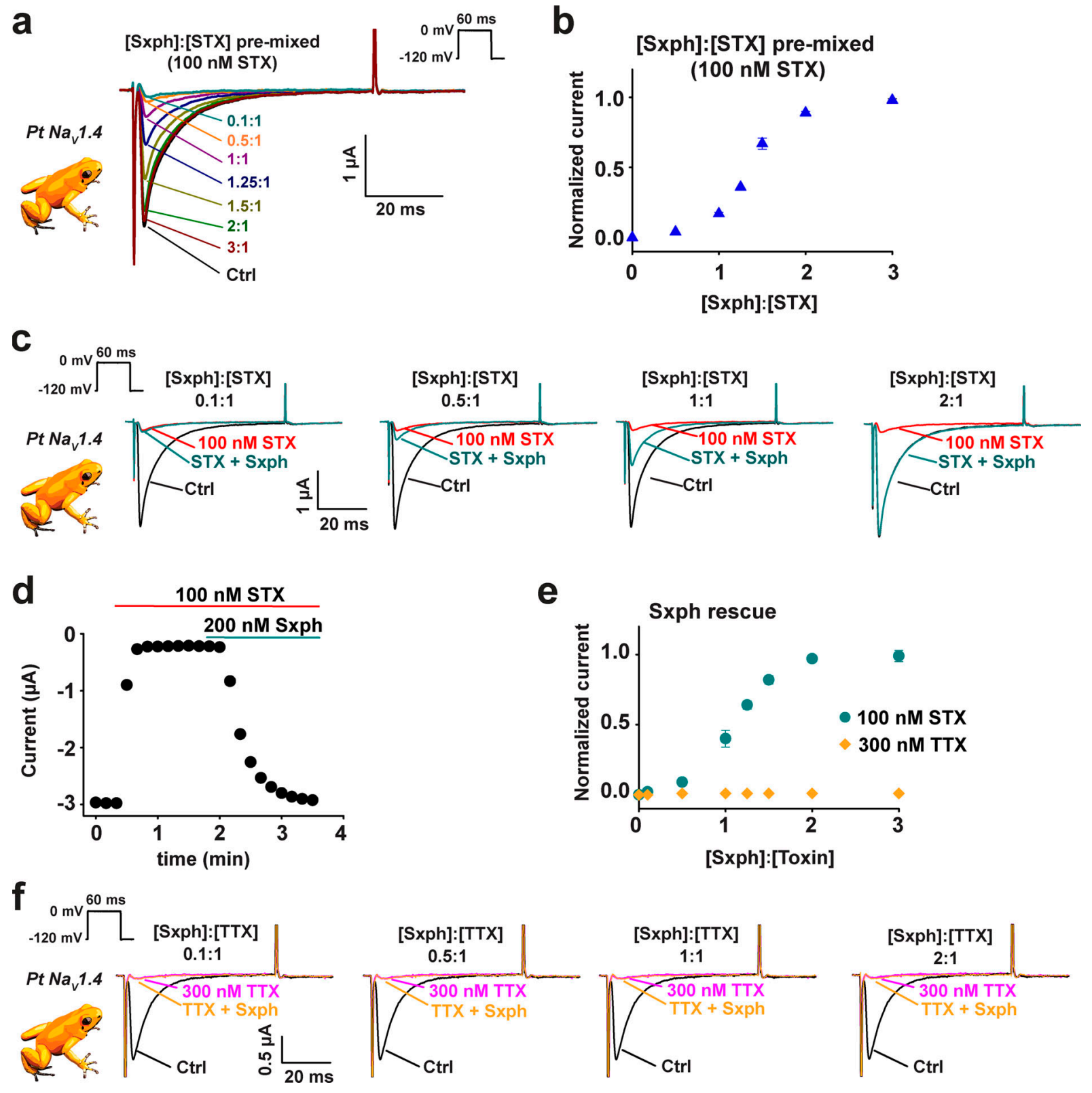

Figure 8. Sxph rescues $\mathbf{P t} \mathbf{N a} \mathbf{1} \mathbf{1 . 4}$ from STX block. (a) Exemplar two-electrode voltage-clamp (TEVC) recordings of Pt Nav1.4 expressed in Xenopus oocytes in the presence of $100 \mathrm{nM} \mathrm{STX}$ and [Sxph]:[STX] in the indicated molar ratios. Ctrl (black) shows response in the absence of STX. Inset shows the stimulation protocol. (b) [Sxph]:[STX] dose response from a. (c) Exemplar TEVC recordings of Pt Nav1.4 before (black) and after (red) application of $100 \mathrm{nM}$ STX and then after application of Sxph at the indicated [Sxph]:[STX] molar ratio (blue-green). Inset shows the protocol. (d) Exemplar TEVC time course showing Pt Nav1.4 peak currents from c after application of $100 \mathrm{nM} \mathrm{STX} \mathrm{(red} \mathrm{bar)} \mathrm{and} 200 \mathrm{nM}$ Sxph (blue-green bar). (e) [Sxph]:[toxin] dose response for $100 \mathrm{nM} \mathrm{STX} \mathrm{(blue-green}$ circles) and $300 \mathrm{nM}$ TTX (orange diamonds). Normalized current in $b$ and e was determined by $I=\left(I_{\text {Sxph }}-I_{\text {Toxin }}\right) /\left(I_{\text {ctrl }}-I_{\text {Toxin }}\right)$, where $I_{\text {Sxph }}$ is the current after application of Sxph:STX mixtures in b or after Sxph addition for $\mathrm{e}, \mathrm{I}_{\text {Toxin }}$ is the current after STX or TTX application, and $I_{\text {trr }}$ is the basal current. (f) Exemplar TEVC recordings of Pt Nav1.4 before (black) and after (magenta) application of $300 \mathrm{nM}$ TTX and then after application of Sxph at the indicated [Sxph]:[TTX] molar ratio (orange). Inset shows the protocol. For all experiments, $n=5$, and error bars indicate SEM.

(Wang et al., 2002; Bigman and Levy, 2020; Tokuriki et al., 2008). Our data show that the DIVS6 $\mathrm{N} \rightarrow \mathrm{T}$ change in bird, human, rat, and frog $\mathrm{Na}_{\mathrm{v}} \mathrm{s}$ carries substantial functional costs that affect every aspect of channel function by inducing changes that render the channels more difficult to open and more readily inactivated and that reduce current density (Table 2), an effect that likely reflects stability penalties that impact channel biogenesis (Baroudi et al., 2002; Solé and Tamkun, 2020; Mercier et al., 2017). These severe pleiotropic functional consequences are in line with the role of this conserved Asn site in coupling the pore to the voltage sensor domain in $\mathrm{Na}_{\mathrm{V}} \mathrm{s}$ (Sheets et al., 2015). Similar perturbations of $\mathrm{Na}_{\mathrm{V}}$ inactivation and reduction of current levels have profound physiological consequences (Chen et al., 2002) and are linked to a variety of channelopathies (Loussouarn et al., 2016), underscoring the organism-level fitness problems incurred by changes in $\mathrm{Na}_{\mathrm{v}}$ biophysical properties. These substantial fitness 
costs, as well as the inability of the DIVS6 $\mathrm{N} \rightarrow \mathrm{T}$ mutation to affect the BTX responses of poison frog $\mathrm{Na}_{\mathrm{V}} \mathrm{s}$, are consistent with the low frequency of this variant in P. terribilis (Márquez et al., 2019) and its absence from the BTX-bearing P. aurotaenia poison frog (Tarvin et al., 2016). Other studies of ion channel toxin resistance mutants have uncovered various degrees of functional costs that may be compensated by amino acid changes at additional sites in the channel (Lee et al., 2011; Tarvin et al., 2017). Hence, the effectiveness of developing a toxin-resistant channel via mutation is highly dependent on the cost for evolving this new function and the extent to which functional costs can be mitigated by additional changes.

Poison frogs lacking the $\mathrm{Na}_{\mathrm{V}} 1.4$ DIVS6 $\mathrm{N} \rightarrow \mathrm{T}$ change withstand BTX levels that affect nonpoisonous frogs (Fig. 5 and Table S3), in line with previous studies (Daly et al., 1980). In nonpoisonous frogs, we find clear in vivo physiological antagonism between the channel blocker, tricaine, and the channel opener, BTX. This result indicates that both compounds access their target $\mathrm{Na}_{\mathrm{V}} \mathrm{s}$. By contrast, this antagonism is absent in poison frogs (Fig. 5 and Table S3), even though it can occur at the molecular level of the channel (Fig. 6). Furthermore, the resistance of poison frogs to BTX and STX contrasts with the effects of TTX and is not consistent with the high sensitivity of their $\mathrm{Na}_{\mathrm{v}} 1.4 \mathrm{~s}$ to all three toxins (Fig. 1, e-h; Fig. 5; and Fig. 7). Together these observations suggest that poison frogs have a means to prevent BTX and STX engaging the target $\mathrm{Na}_{\mathrm{V}} \mathrm{s}$. It is notable that other frogs resist STX poisoning (Prinzmetal et al., 1932; Kao and Fuhrman, 1967; Mahar et al., 1991), and it is thought that the soluble STX-binding protein Sxph (Mahar et al., 1991; Arbuckle et al., 2017; Yen et al., 2019) acts as a toxin sponge to sequester and neutralize the lethal effects of this and possibly other neurotoxins (Mahar et al., 1991; Llewellyn et al., 1997; Arbuckle et al., 2017; Almabruk et al., 2018; Caty et al., 2019; O'Connell et al., 2021).

If BTX-bearing animals do not use BTX-resistant $\mathrm{Na}_{\mathrm{V}} \mathrm{s}$ to avoid autointoxication, how do they survive? Apart from the absence of BTX-resistant $\mathrm{Na}_{\mathrm{V}} \mathrm{s}$, the diversity among $>800$ poison frog alkaloid toxins (Daly et al., 2005), the seasonal and geographical variation of these toxins, and their ability to affect multiple ion channels (Santos et al., 2016) pose major challenges for evolving toxin-resistant channels. Enhanced detoxification via metabolic toxin destruction would not be useful, because these poisonous organisms need to handle and store the toxins to deploy them against predators. By contrast, sequestration strategies not only offer a general means of toxin protection but also could act in pathways involved in safely transporting and concentrating toxins in key defensive organs such as the skin (Menon and Dumbacher, 2014). The fact that toxin-based chemical defense systems have evolved independently four times in neotropical poison frogs (Dendrobatids; Santos et al., 2016), in Malagasy poison frogs (Garraffo et al., 1993), and in multiple lineages of poisonous birds (including Pitohui and Ifrita; Dumbacher et al., 1992; Dumbacher et al., 2000) supports the idea that such general sequestration mechanisms may underlie toxin autoresistance. Furthermore, there are a number of examples of poison frogs (Tarvin et al., 2016; Márquez et al., 2019) and predators of toxic animals (Feldman et al., 2016) that lack toxin-resistant mutations, raising questions about the generality of the target-based mechanism. Although no BTX-binding proteins have yet been identified, high-affinity toxin-binding proteins for STX in frogs, Sxph (Llewellyn et al., 1997; Mahar et al., 1991; Yen et al., 2019), and STX and TTX in pufferfish, pufferfish STX- and TTX-binding protein, PSTBP (Yotsu-Yamashita et al., 2001; Yotsu-Yamashita et al., 2010), are known and have been proposed to prevent autointoxication through sequestration (Arbuckle et al., 2017). We show that one of these proteins, Sxph, is able not only to protect $\mathrm{Na}_{\mathrm{V}} \mathrm{s}$ from toxin poisoning but also to reverse the action of a high-affinity toxin, STX, on frog $\mathrm{Na}_{V} \mathrm{~s}$ (Fig. 8), a result that underscores the potential for such toxin sponge proteins to act as agents of toxin resistance. Characterizing how such toxin-binding proteins protect hosts from autointoxication, alone or together with specialized toxin transport pathways, should provide new insights into the fundamental mechanisms of toxin autoresistance and expand understanding of how organisms handle a range of chemical insults and may lead to the discovery of antidotes against various toxic agents.

\section{Data availability}

Sequences of Pum Na 1.4 (GenBank accession no. MZ545383), Pum Nav1.5 (GenBank accession no. MZ545384), Pum $\mathrm{Na}_{\mathrm{V}} \beta 2$ (GenBank accession no. MZ545385), Pt Na 1.4 (GenBank accession no. MZ545381), and $D t \mathrm{Na}_{\mathrm{V}} 1.4$ (GenBank accession no. MZ545382) are available from the National Center for Biotechnology Information. Requests for material should be sent to D.L. Minor.

\section{Acknowledgments}

Christopher J. Lingle served as editor.

We thank J. McGlothlin (Virginia Tech) for providing annotated sequences of crow $\mathrm{Na}_{V} \mathrm{~s}, \mathrm{G}$. Loussouarn (l'institut du thorax, Nantes, France) for providing human $\mathrm{Na}_{\mathrm{V}}$ clones, and $\mathrm{K}$. Brejc and D. Julius for comments on the manuscript. We thank the Papua New Guinea National Research Institute and Department of Environment and Conservation for permission to conduct fieldwork, the generous people of Bonua Village for assistance in the field and permission to work on their land.

The National Geographic Society funded the fieldwork (grant 5082-93). This work was supported by National Heart, Lung, and Blood Institute grant R01-HL080050, National Institute on Deafness and Other Communication Disorders grant R01DC007664, and U.S. Department of Defense grant HDTRA-1-19-10040 to D.L. Minor and by National Science Foundation grant NSF-1822025 to L.A. O'Connell. Partial support of this work was from National Institute of General Medical Sciences grant R01GM117263-01A1 to J. Du Bois, an American Ornithological Society Wetmore Research Award to M.E. Kobiela, a National Institute of General Medical Sciences postdoctoral fellowship (F32GM116402) to R.A. Craig, and an American Heart Association postdoctoral fellowship to F. Abderemane-Ali.

J. Du Bois is a cofounder and holds equity shares in SiteOne Therapeutics, Inc., a start-up company interested in developing subtype-selective modulators of sodium channels. The other authors declare no competing financial interests. 
Author contributions: F. Abderemane-Ali, M.E. Kobiela, R.A. Craig, C.E. Garrison, J. Du Bois, J.P. Dumbacher, and D.L. Minor conceived the study and designed the experiments. F. Abderemane-Ali, N.D. Rossen, R.A. Craig, and C.E. Garrison performed patch-clamp electrophysiology experiments and analyzed the data. F. Abderemane-Ali performed de novo $\mathrm{Na}_{\mathrm{V}}$ cloning, molecular biology experiments, two-electrode voltage-clamp electrophysiology experiments, and toxin challenge experiments and analyzed the data. M.E. Kobiela and J.P. Dumbacher constructed and analyzed Pitohui genomes. Z. Chen expressed and purified Sxph. C.M. Colleran conducted mammalian cell culture experiments. J. Du Bois synthesized BTX. J. Du Bois, J.P. Dumbacher, and D.L. Minor analyzed data and provided guidance and support. F. Abderemane-Ali, L.A. O'Connell, J. Du Bois, J.P. Dumbacher, and D.L. Minor wrote the paper.

Submitted: 18 January 2021

Revised: 30 May 2021

Accepted: 1 July 2021

\section{References}

Albuquerque, E.X., J.W. Daly, and B. Witkop. 1971. Batrachotoxin: chemistry and pharmacology. Science. 172:995-1002. https://doi.org/10.1126/science .172 .3987 .995

Albuquerque, E.X., J.E. Warnick, F.M. Sansone, and J. Daly. 1973. The pharmacology of batrachotoxin. V. A comparative study of membrane properties and the effect of batrachotoxin on sartorius muscles of the frogs Phyllobates aurotaenia and Rana pipiens. J. Pharmacol. Exp. Ther. 184:315-329.

Almabruk, K.H., L.K. Dinh, and B. Philmus. 2018. Self-resistance of natural product producers: past, present, and future focusing on self-resistant protein variants. ACS Chem. Biol. 13:1426-1437. https://doi.org/10.1021/ acschembio.8b00173

Andresen, B.M., and J. Du Bois. 2009. De novo synthesis of modified saxitoxins for sodium ion channel study. J. Am. Chem. Soc. 131:12524-12525. https://doi.org/10.1021/ja904179f

Arbuckle, K., R.C. Rodríguez de la Vega, and N.R. Casewell. 2017. Coevolution takes the sting out of it: evolutionary biology and mechanisms of toxin resistance in animals. Toxicon. 140:118-131. https://doi.org/10.1016/j .toxicon.2017.10.026

Bankevich, A., S. Nurk, D. Antipov, A.A. Gurevich, M. Dvorkin, A.S. Kulikov, V.M. Lesin, S.I. Nikolenko, S. Pham, A.D. Prjibelski, et al. 2012. SPAdes: a new genome assembly algorithm and its applications to single-cell sequencing. J. Comput. Biol. 19:455-477. https://doi.org/10.1089/cmb .2012 .0021

Baroudi, G., S. Acharfi, C. Larouche, and M. Chahine. 2002. Expression and intracellular localization of an SCN5A double mutant R1232W/T1620M implicated in Brugada syndrome. Circ. Res. 90:E11-E16. https://doi.org/ 10.1161/hh0102.102977

Bigman, L.S., and Y. Levy. 2020. Proteins: molecules defined by their trade-offs. Curr. Opin. Struct. Biol. 60:50-56. https://doi.org/10.1016/j.sbi.2019.11.005

Bolger, A.M., M. Lohse, and B. Usadel. 2014. Trimmomatic: a flexible trimmer for Illumina sequence data. Bioinformatics. 30:2114-2120. https://doi .org/10.1093/bioinformatics/btu170

Bricelj, V.M., L. Connell, K. Konoki, S.P. Macquarrie, T. Scheuer, W.A. Catterall, and V.L. Trainer. 2005. Sodium channel mutation leading to saxitoxin resistance in clams increases risk of PSP. Nature. 434:763-767. https://doi.org/10.1038/nature03415

Calhoun, J.D., and L.L. Isom. 2014. The role of non-pore-forming $\beta$ subunits in physiology and pathophysiology of voltage-gated sodium channels. Handb. Exp. Pharmacol. 221:51-89. https://doi.org/10.1007/978-3-642 $-41588-3 \_4$

Catterall, W.A. 1977. Activation of the action potential $\mathrm{Na}^{+}$ionophore by neurotoxins. An allosteric model. J. Biol. Chem. 252:8669-8676. https:// doi.org/10.1016/S0021-9258(19)75273-9

Catterall, W.A., M.J. Lenaeus, and T.M. Gamal El-Din. 2020. Structure and pharmacology of voltage-gated sodium and calcium channels. Annu.
Rev. Pharmacol. Toxicol. 60:133-154. https://doi.org/10.1146/annurev -pharmtox-010818-021757

Caty, S.N., A. Alvarez-Buylla, G.D. Byrd, C. Vidoudez, A.B. Roland, E.E. Tapia, B. Budnik, S.A. Trauger, L.A. Coloma, and L.A. O'Connell. 2019. Molecular physiology of chemical defenses in a poison frog. J. Exp. Biol. 222: jeb204149. https://doi.org/10.1242/jeb.204149

Chahine, M., P.B. Bennett, A.L. George Jr., and R. Horn. 1994. Functional expression and properties of the human skeletal muscle sodium channel. Pflugers Arch. 427:136-142. https://doi.org/10.1007/BF00585952

Chen, C., V. Bharucha, Y. Chen, R.E. Westenbroek, A. Brown, J.D. Malhotra, D. Jones, C. Avery, P.J. Gillespie III, K.A. Kazen-Gillespie, et al. 2002. Reduced sodium channel density, altered voltage dependence of inactivation, and increased susceptibility to seizures in mice lacking sodium channel $\beta 2$-subunits. Proc. Natl. Acad. Sci. USA. 99:17072-17077. https:// doi.org/10.1073/pnas.212638099

Daly, J.W., C.W. Myers, J.E. Warnick, and E.X. Albuquerque. 1980. Levels of batrachotoxin and lack of sensitivity to its action in poison-dart frogs (Phyllobates). Science. 208:1383-1385. https://doi.org/10.1126/science.6246586

Daly, J.W., C.W. Myers, and N. Whittaker. 1987. Further classification of skin alkaloids from neotropical poison frogs (Dendrobatidae), with a general survey of toxic/noxious substances in the amphibia. Toxicon. 25: 1023-1095. https://doi.org/10.1016/0041-0101(87)90265-0

Daly, J.W., H. Martin Garraffo, T.F. Spande, C. Jaramillo, and A. Stanley Rand. 1994a. Dietary source for skin alkaloids of poison frogs (Dendrobatidae)? J. Chem. Ecol. 20:943-955. https://doi.org/10.1007/BF02059589

Daly, J.W., S.I. Secunda, H.M. Garraffo, T.F. Spande, A. Wisnieski, and J.F. Cover Jr. 1994b. An uptake system for dietary alkaloids in poison frogs (Dendrobatidae). Toxicon. 32:657-663. https://doi.org/10.1016/0041 -0101(94)90335-2

Daly, J.W., T.F. Spande, and H.M. Garraffo. 2005. Alkaloids from amphibian skin: a tabulation of over eight-hundred compounds. J. Nat. Prod. 68: 1556-1575. https://doi.org/10.1021/np0580560

Daly, J.W., H.M. Garraffo, T.F. Spande, L.A. Giddings, R.A. Saporito, D.R Vieites, and M. Vences. 2008. Individual and geographic variation of skin alkaloids in three species of Madagascan poison frogs (Mantella). J. Chem. Ecol. 34:252-279. https://doi.org/10.1007/s10886-007-9396-9

Das, S., J. Gilchrist, F. Bosmans, and F. Van Petegem. 2016. Binary architecture of the Nav1.2- $\beta 2$ signaling complex. eLife. 5:e10960. https://doi.org/10 .7554/eLife.10960

Doyle, D.D., M. Wong, J. Tanaka, and L. Barr. 1982. Saxitoxin binding sites in frog-myocardial cytosol. Science. 215:1117-1119. https://doi.org/10.1126/ science. 6278588

Du, Y., D.P. Garden, L. Wang, B.S. Zhorov, and K. Dong. 2011. Identification of new batrachotoxin-sensing residues in segment IIIS6 of the sodium channel. J. Biol. Chem. 286:13151-13160. https://doi.org/10.1074/jbc.M110.208496

Dumbacher, J.P., B.M. Beehler, T.F. Spande, H.M. Garraffo, and J.W. Daly. 1992. Homobatrachotoxin in the genus Pitohui: chemical defense in birds? Science. 258:799-801. https://doi.org/10.1126/science.1439786

Dumbacher, J.P., T.F. Spande, and J.W. Daly. 2000. Batrachotoxin alkaloids from passerine birds: a second toxic bird genus (Ifrita kowaldi) from New Guinea. Proc. Natl. Acad. Sci. USA. 97:12970-12975. https://doi.org/ 10.1073/pnas.200346897

Dumbacher, J.P., A. Wako, S.R. Derrickson, A. Samuelson, T.F. Spande, and J.W. Daly. 2004. Melyrid beetles (Choresine): a putative source for the batrachotoxin alkaloids found in poison-dart frogs and toxic passerine birds. Proc. Natl. Acad. Sci. USA. 101:15857-15860. https://doi.org/10 $.1073 /$ pnas.0407197101

Dumbacher, J.P., G.K. Menon, and J.W. Daly. 2009. Skin as a toxin storage organ in the endemic New Guinean genus Pitohui. Auk. 126:520-530. https://doi.org/10.1525/auk.2009.08230

Durán-Riveroll, L.M., and A.D. Cembella. 2017. Guanidinium toxins and their interactions with voltage-gated sodium ion channels. Mar. Drugs. 15: 303. https://doi.org/10.3390/md15100303

Feldman, C.R., A.M. Durso, C.T. Hanifin, M.E. Pfrender, P.K. Ducey, A.N Stokes, K.E. Barnett, E.D. Brodie III, and E.D. Brodie Jr. 2016. Is there more than one way to skin a newt? Convergent toxin resistance in snakes is not due to a common genetic mechanism. Heredity. 116:84-91. https://doi.org/10.1038/hdy.2015.73

Finol-Urdaneta, R.K., J.R. McArthur, M.P. Goldschen-Ohm, R. Gaudet, D.B. Tikhonov, B.S. Zhorov, and R.J. French. 2019. Batrachotoxin acts as a stent to hold open homotetrameric prokaryotic voltage-gated sodium channels. J. Gen. Physiol. 151:186-199. https://doi.org/10.1085/jgp 201812278

Garraffo, H.M., J. Caceres, J.W. Daly, T.F. Spande, N.R. Andriamaharavo, and M. Andriantsiferana. 1993. Alkaloids in Madagascan frogs (Mantella): 
pumiliotoxins, indolizidines, quinolizidines, and pyrrolizidines. J. Nat. Prod. 56:1016-1038. https://doi.org/10.1021/np50097a005

Geffeney, S., E.D. Brodie Jr., P.C. Ruben, and E.D. Brodie III. 2002. Mechanisms of adaptation in a predator-prey arms race: TTX-resistant sodium channels. Science. 297:1336-1339. https://doi.org/10.1126/science .1074310

Geffeney, S.L., E. Fujimoto, E.D. Brodie III, E.D. Brodie Jr., and P.C. Ruben. 2005. Evolutionary diversification of TTX-resistant sodium channels in a predator-prey interaction. Nature. 434:759-763. https://doi.org/10 $.1038 /$ nature03444

Gilchrist, J., B.M. Olivera, and F. Bosmans. 2014. Animal toxins influence voltage-gated sodium channel function. Handb. Exp. Pharmacol. 221: 203-229. https://doi.org/10.1007/978-3-642-41588-3_10

Hague, M.T.J., G. Toledo, S.L. Geffeney, C.T. Hanifin, E.D. Brodie Jr., and E.D. Brodie III. 2018. Large-effect mutations generate trade-off between predatory and locomotor ability during arms race coevolution with deadly prey. Evol. Lett. 2:406-416. https://doi.org/10.1002/evl3.76

Hamill, O.P., A. Marty, E. Neher, B. Sakmann, and F.J. Sigworth. 1981. Improved patch-clamp techniques for high-resolution current recording from cells and cell-free membrane patches. Pflugers Arch. 391:85-100. https://doi.org/10.1007/BF00656997

Hanifin, C.T., and W.F. Gilly. 2015. Evolutionary history of a complex adaptation: tetrodotoxin resistance in salamanders. Evolution. 69:232-244. https://doi.org/10.1111/evo.12552

Hunter, P. 2018. Do not poison thyself: mechanisms to avoid self-toxicity could inspire novel compounds and pathways for synthetic biology and applications for agriculture. EMBO Rep. 19:e46756. https://doi.org/ 10.15252/embr.201846756

Jost, M.C., D.M. Hillis, Y. Lu, J.W. Kyle, H.A. Fozzard, and H.H. Zakon. 2008. Toxin-resistant sodium channels: parallel adaptive evolution across a complete gene family. Mol. Biol. Evol. 25:1016-1024. https://doi.org/10 $.1093 / \mathrm{molbev} / \mathrm{msn} 025$

Kao, C.Y., and F.A. Fuhrman. 1967. Differentiation of the actions of tetrodotoxin and saxitoxin. Toxicon. 5:25-34. https://doi.org/10.1016/0041 $-0101(67) 90114-6$

Kent, W.J. 2002. BLAT-the BLAST-like alignment tool. Genome Res. 12: 656-664. https://doi.org/10.1101/gr.229202

Khodorov, B.I. 1985. Batrachotoxin as a tool to study voltage-sensitive sodium channels of excitable membranes. Prog. Biophys. Mol. Biol. 45:57-148. https://doi.org/10.1016/0079-6107(85)90005-7

Lago, J., L.P. Rodríguez, L. Blanco, J.M. Vieites, and A.G. Cabado. 2015. Tetrodotoxin, an extremely potent marine neurotoxin: distribution, toxicity, origin and therapeutical uses. Mar. Drugs. 13:6384-6406. https:// doi.org $/ 10.3390 / \mathrm{md} 13106384$

Lee, C.H., D.K. Jones, C. Ahern, M.F. Sarhan, and P.C. Ruben. 2011. Biophysical costs associated with tetrodotoxin resistance in the sodium channel pore of the garter snake, Thamnophis sirtalis. J. Comp. Physiol. A Neuroethol. Sens. Neural Behav. Physiol. 197:33-43. https://doi.org/10.1007/ s00359-010-0582-9

Llewellyn, L.E., and E.G. Moczydlowski. 1994. Characterization of saxitoxin binding to saxiphilin, a relative of the transferrin family that displays pH-dependent ligand binding. Biochemistry. 33:12312-12322. https://doi .org/10.1021/bi00206a039

Llewellyn, L.E., P.M. Bell, and E.G. Moczydlowski. 1997. Phylogenetic survey of soluble saxitoxin-binding activity in pursuit of the function and molecular evolution of saxiphilin, a relative of transferrin. Proc. Biol. Sci. 264:891-902. https://doi.org/10.1098/rspb.1997.0124

Logan, M.M., T. Toma, R. Thomas-Tran, and J. Du Bois. 2016. Asymmetric synthesis of batrachotoxin: enantiomeric toxins show functional divergence against NaV. Science. 354:865-869. https://doi.org/10.1126/ science.aag2 2981

Loussouarn, G., D. Sternberg, S. Nicole, C. Marionneau, F. Le Bouffant, G. Toumaniantz, J. Barc, O.A. Malak, V. Fressart, Y. Péréon, et al. 2016. Physiological and pathophysiological insights of Nav1.4 and Nav1.5 comparison. Front. Pharmacol. 6:314. https://doi.org/10.3389/fphar.2015 .00314

MacKenzie, T.M.G., F. Abderemane-Ali, C.E. Garrison, D.L. Minor Jr., and J. $\mathrm{Du}$ Bois. 2021. Differential effects of modified batrachotoxins on voltage-gated sodium channel fast and slow inactivation. ChemRxiv. doi: (Preprint posted February 16, 2021)https://doi.org/10.26434/chemrxiv $.14026406 . v 1$

Mahar, J., G.L. Lukács, Y. Li, S. Hall, and E. Moczydlowski. 1991. Pharmacological and biochemical properties of saxiphilin, a soluble saxitoxinbinding protein from the bullfrog (Rana catesbeiana). Toxicon. 29: 53-71. https://doi.org/10.1016/0041-0101(91)90039-T
Márquez, R., V. Ramírez-Castañeda, and A. Amézquita. 2019. Does batrachotoxin autoresistance coevolve with toxicity in Phyllobates poison-dart frogs? Evolution. 73:390-400. https://doi.org/10.1111/evo.13672

McGlothlin, J.W., M.E. Kobiela, C.R. Feldman, T.A. Castoe, S.L. Geffeney, C.T. Hanifin, G. Toledo, F.J. Vonk, M.K. Richardson, E.D. Brodie Jr., et al. 2016. Historical contingency in a multigene family facilitates adaptive evolution of toxin resistance. Curr. Biol. 26:1616-1621. https://doi.org/10 .1016/j.cub.2016.04.056

Menon, G.K., and J.P. Dumbacher. 2014. A 'toxin mantle' as defensive barrier in a tropical bird: evolutionary exploitation of the basic permeability barrier forming organelles. Exp. Dermatol. 23:288-290. https://doi.org/ 10.1111/exd.12367

Mercier, A., P. Bois, and A. Chatelier. 2017. Sodium channel trafficking. Handb. Exp. Pharmacol. 246:125-145. https://doi.org/10.1007/164_2017_ 47

Morabito, M.A., and E. Moczydlowski. 1994. Molecular cloning of bullfrog saxiphilin: a unique relative of the transferrin family that binds saxitoxin. Proc. Natl. Acad. Sci. USA. 91:2478-2482. https://doi.org/10.1073/ pnas.91.7.2478

Myers, C.W., J.W. Daly, and B. Malkin. 1978. A dangerously toxic new frog (Pyllobates) used by Emberà Indians of Western Colombia, with discussion of blowgun fabrication and dart poisoning. Bull. Am. Mus. Nat. Hist. 161:309-365.

O'Connell, L.A., J.D. O'Connell, J.A. Paulo, S.A. Trauger, S.P. Gygi, and A.W. Murray; LS50: Integrated Science Laboratory Course. 2021. Rapid toxin sequestration modifies poison frog physiology. J. Exp. Biol. 224. jeb230342. https://doi.org/10.1242/jeb.230342

Pan, X., Z. Li, Q. Zhou, H. Shen, K. Wu, X. Huang, J. Chen, J. Zhang, X. Zhu, J. Lei, et al. 2018. Structure of the human voltage-gated sodium channel $\mathrm{Na}_{\mathrm{v}} 1.4$ in complex with $\beta 1$. Science. 362:eaau2486. https://doi.org/10 $.1126 /$ science.aau2486

Prinzmetal, M., H. Sommer, and C.D. Leake. 1932. The pharmacological action of "mussel poison." J. Pharmacol. Exp. Ther. 46:63-73.

Ruby, J.G., P. Bellare, and J.L. Derisi. 2013. PRICE: software for the targeted assembly of components of (meta) genomic sequence data. G3 (Bethesda). 3:865-880. https://doi.org/10.1534/g3.113.005967

Santos, J.C., R.D. Tarvin, and L.A. O'Connell. 2016. A review of chemical defense in poison frogs (Dedrobatidae): ecology, pharmacokinetics, and autoresistance. In Chemical Signals in Vertebrates 13. B. Schulte, T. Goodwin, and M. Ferkin, editors. Springer International Publishing, Cham, Switzerland. 305-337. https://doi.org/10.1007/978-3-319-22026 -0_21

Savitzky, A.H., A. Mori, D.A. Hutchinson, R.A. Saporito, G.M. Burghardt, H.B. Lillywhite, and J. Meinwald. 2012. Sequestered defensive toxins in tetrapod vertebrates: principles, patterns, and prospects for future studies. Chemoecology. 22:141-158. https://doi.org/10.1007/s00049-012 -0112-z

Sheets, M.F., H.A. Fozzard, and D.A. Hanck. 2015. Important role of asparagines in coupling the pore and votage-sensor domain in voltage-gated sodium channels. Biophys. J. 109:2277-2286. https://doi.org/10.1016/j .bpj.2015.10.012

Solé, L., and M.M. Tamkun. 2020. Trafficking mechanisms underlying $\mathrm{Na}_{\mathrm{v}}$ channel subcellular localization in neurons. Channels (Austin). 14:1-17. https://doi.org/10.1080/19336950.2019.1700082

Tanguy, J., and J.Z. Yeh. 1991. BTX modification of Na channels in squid axons. I. State dependence of BTX action. J. Gen. Physiol. 97:499-519. https://doi.org/10.1085/jgp.97.3.499

Tarvin, R.D., J.C. Santos, L.A. O'Connell, H.H. Zakon, and D.C. Cannatella. 2016. Convergent substitutions in a sodium channel suggest multiple origins of toxin resistance in poison frogs. Mol. Biol. Evol. 33:1068-1080. https://doi.org/10.1093/molbev/msv350

Tarvin, R.D., C.M. Borghese, W. Sachs, J.C. Santos, Y. Lu, L.A. O'Connell, D.C. Cannatella, R.A. Harris, and H.H. Zakon. 2017. Interacting amino acid replacements allow poison frogs to evolve epibatidine resistance. Science. 357:1261-1266. https://doi.org/10.1126/science.aan5061

Thomas, V.L., A.C. McReynolds, and B.K. Shoichet. 2010. Structural bases for stability-function tradeoffs in antibiotic resistance. J. Mol. Biol. 396 47-59. https://doi.org/10.1016/j.jmb.2009.11.005

Thomas-Tran, R., and J. Du Bois. 2016. Mutant cycle analysis with modified saxitoxins reveals specific interactions critical to attaining high-affinity inhibition of hNaV1.7. Proc. Natl. Acad. Sci. USA. 113:5856-5861. https:// doi.org/10.1073/pnas.1603486113

Thottumkara, A.P., W.H. Parsons, and J. Du Bois. 2014. Saxitoxin. Angew. Chem. Int. Ed. Engl. 53:5760-5784. https://doi.org/10.1002/anie 201308235 
Tokuriki, N., F. Stricher, L. Serrano, and D.S. Tawfik. 2008. How protein stability and new functions trade off. PLOS Comput. Biol. 4:e1000002. https://doi.org/10.1371/journal.pcbi.1000002

Wang, G.K., and S.Y. Wang. 1992. Inactivation of batrachotoxin-modified $\mathrm{Na}^{+}$ channels in GH3 cells. Characterization and pharmacological modification. J. Gen. Physiol. 99:1-20. https://doi.org/10.1085/jgp.99.1.1

Wang, G.K., and S.Y. Wang. 1994. Binding of benzocaine in batrachotoxinmodified $\mathrm{Na}^{+}$channels. State-dependent interactions. J. Gen. Physiol. 103:501-518. https://doi.org/10.1085/jgp.103.3.501

Wang, S.Y., and G.K. Wang. 2003. Voltage-gated sodium channels as primary targets of diverse lipid-soluble neurotoxins. Cell. Signal. 15:151-159. https://doi.org/10.1016/S0898-6568(02)00085-2

Wang, S.Y., and G.K. Wang. 2017. Single rat muscle $\mathrm{Na}^{+}$channel mutation confers batrachotoxin autoresistance found in poison-dart frog Phyllobates terribilis. Proc. Natl. Acad. Sci. USA. 114:10491-10496. https://doi .org/10.1073/pnas.1707873114

Wang, G.K., W.M. Mok, and S.Y. Wang. 1994. Charged tetracaine as an inactivation enhancer in batrachotoxin-modified $\mathrm{Na}^{+}$channels. Biophys. J. 67:1851-1860. https://doi.org/10.1016/S0006-3495(94)80666-6

Wang, G.K., C. Quan, and S. Wang. 1997. A common local anesthetic receptor for benzocaine and etidocaine in voltage-gated $\mu 1 \mathrm{Na}^{+}$channels. Pflugers Arch. 435:293-302. https://doi.org/10.1007/s004240050515

Wang, X., G. Minasov, and B.K. Shoichet. 2002. Evolution of an antibiotic resistance enzyme constrained by stability and activity trade-offs. J. Mol. Biol. 320:85-95. https://doi.org/10.1016/S0022-2836(02)00400-X
Wiberg, G.S., and N.R. Stephenson. 1960. Toxicologic studies on paralytic shellfish poison. Toxicol. Appl. Pharmacol. 2:607-615. https://doi.org/10 .1016/0041-008X(60)90078-8

Yan, Z., Q. Zhou, L. Wang, J. Wu, Y. Zhao, G. Huang, W. Peng, H. Shen, J. Lei, and N. Yan. 2017. Structure of the $\mathrm{Na}_{\mathrm{v}} 1.4-\beta 1$ complex from electric eel. Cell. 170:470-482.e11. https://doi.org/10.1016/j.cell.2017.06.039

Yen, T.-J., M. Lolicato, R. Thomas-Tran, J. Du Bois, and D.L. Minor Jr. 2019. Structure of the saxiphilin:saxitoxin (STX) complex reveals a convergent molecular recognition strategy for paralytic toxins. Sci. Adv. 5: eaax2650. https://doi.org/10.1126/sciadv.aax2650

Yotsu-Yamashita, M., A. Sugimoto, T. Terakawa, Y. Shoji, T. Miyazawa, and T. Yasumoto. 2001. Purification, characterization, and cDNA cloning of a novel soluble saxitoxin and tetrodotoxin binding protein from plasma of the puffer fish, Fugu pardalis. Eur. J. Biochem. 268:5937-5946. https:// doi.org/10.1046/j.0014-2956.2001.02547.x

Yotsu-Yamashita, M., H. Yamaki, N. Okoshi, and N. Araki. 2010. Distribution of homologous proteins to puffer fish saxitoxin and tetrodotoxin binding protein in the plasma of puffer fish and among the tissues of Fugu pardalis examined by Western blot analysis. Toxicon. 55:1119-1124. https://doi.org/10.1016/j.toxicon.2009.12.021

Zhang, M.M., M.J. Wilson, L. Azam, J. Gajewiak, J.E. Rivier, G. Bulaj, B.M. Olivera, and D. Yoshikami. 2013. Co-expression of $\mathrm{Na}_{\mathrm{v}} \beta$ subunits alters the kinetics of inhibition of voltage-gated sodium channels by poreblocking $\mu$-conotoxins. Br. J. Pharmacol. 168:1597-1610. https://doi.org/ $10.1111 / \mathrm{bph} .12051$ 


\section{Supplemental material}

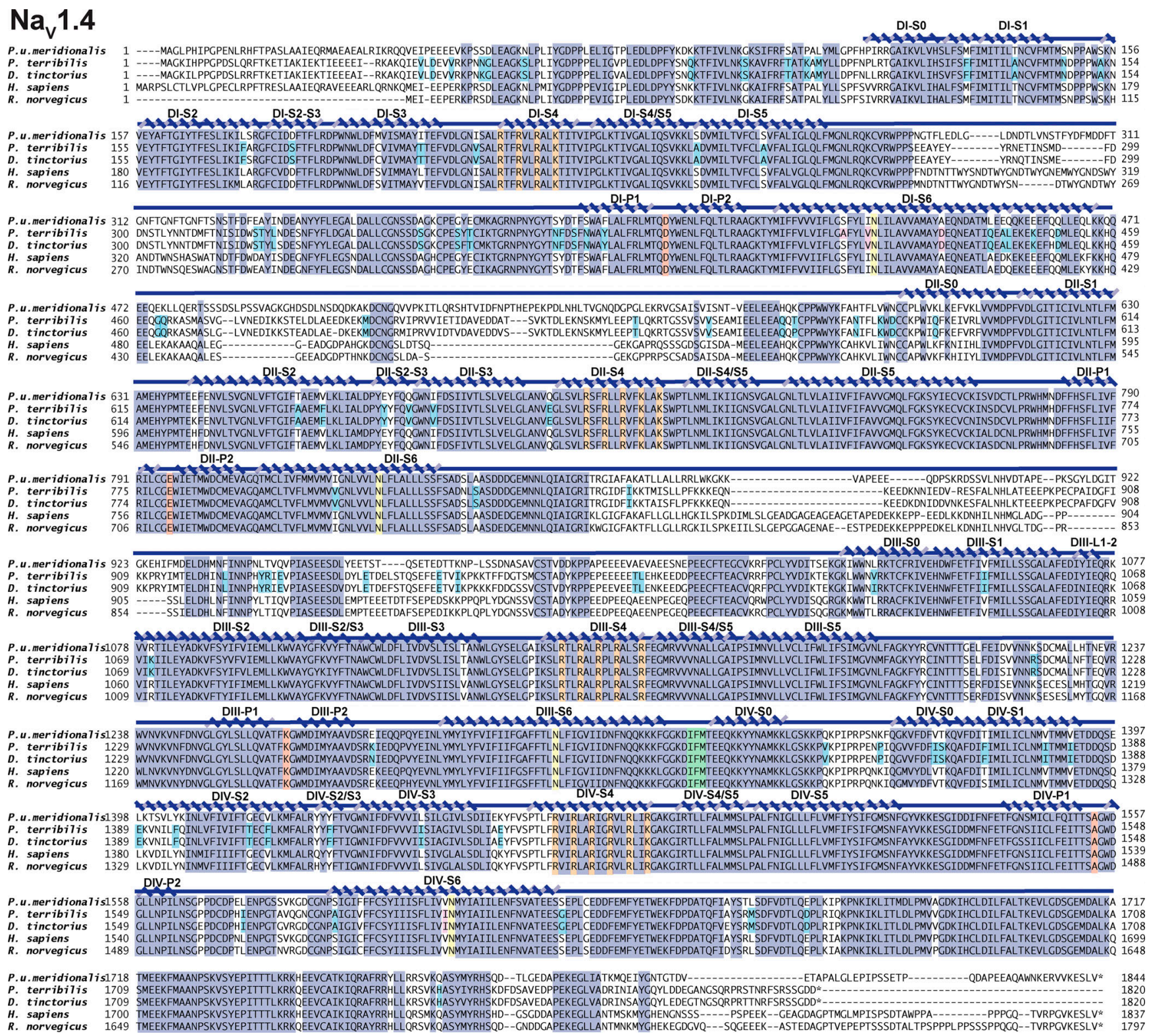

Figure S1. Pitohui and poison frog Nav1.4 sequences. Sequence alignment of Pum Nav1.4, Pt Nav1.4, Dt Nav1.4, Hs Nav1.4 (RefSeq accession no. NP_000325.4), and Rn Nav1.4 (RefSeq accession no. NP_037310.1). Key Nav features are highlighted as follows: selectivity filter DEKA (red), IFM peptide (green), conserved S6 Asn (yellow), S4 voltage sensor arginines (orange), poison frog variants (cyan), and sites highlighted by Tarvin et al. (2016; magenta) are indicated. Conserved residues are highlighted in dark blue. Secondary structure elements were labeled using boundaries from Yan et al. (2017). 
$\mathrm{Na}_{\mathrm{v}} 1.5$

P.u. meridional is $\mathrm{Na}_{v} 1.5$
H. sapiens $\mathrm{Na}_{1} 1.5$

R. norvegicus $\mathrm{Na}_{2} 1.5$

P. u. meridionalis Na 1.5

H. sapiens $\mathrm{Na}_{\mathrm{v}} \mathrm{l} .5$
R. norvegicus

R. norvegicus $\mathrm{Na}_{1} 1.5$
P.u.meridionalis $\mathrm{Na}_{1} 1.4$

P.
H. meridionalis $\mathrm{Na}_{1} 1.5$

H. sapiens $\mathrm{Na}_{v_{1}} 1.5$
R. norvegicus $\mathrm{Na}_{4} 1.5$

R. norvegicus $\mathrm{Na}_{v} \mathrm{l} .5$
P.u.meridionalis $\mathrm{Na}_{v} 1.4$

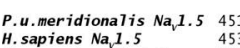

$\begin{array}{ll}\text { H. sapiens } \mathrm{Na}_{\mathbf{r}} \mathbf{1 . 5} & 453 \\ \text { R. norvegicus Na } 1.5 & 454\end{array}$

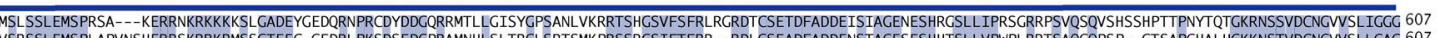

P.u.meridionalis $\mathrm{Na}_{v} 1.5 \quad 608$.

TE

TGALNPDPTSPACLLLPPVIMEKPGTCDLTSPSDEASKKQLLMPHRPSVDHSDEPFQRQRAVSAVSIITSALEELEESHOKCPPCWNHFAVKFLIWDCCPLWLIKKFVKFVVMDPFTDLTITLCIVLNTLFMALEHYKMTKEFDHMLYICNLVFTGIFT

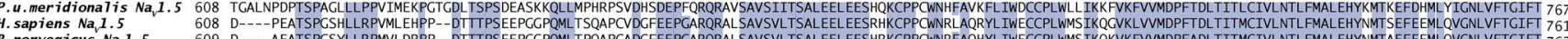

R.norvegicus
P.u.meridionalis Na $_{1} 1.4$
517 DII-S2-S3 DII-S3 DII-S4/S5 DII-S5 DII-P1 DII-P2 P.u. meridionalis
H. sapiens Na 1.5

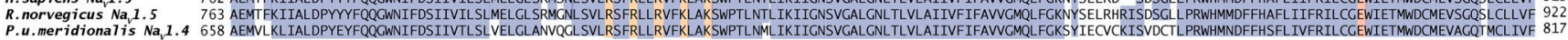

DIIS6

P.u.meridionalis $\mathrm{Na}_{\mathrm{v}} \mathrm{1} .5928$

H. sapiens $N_{2} 1.5$
$R$. norvegicus

DIII-S6

R. norvegicus $\mathrm{Na}_{0} \mathrm{I} .5,923$

ILVMVICNLVVLNLFLALLLSSFSADNL SAPDEDCEMNNLQLAFARINRGLQYTKKAAWNFCCSVLRHPKTTAEKKAM
LLVMVICNLVVLNLFLALLLSSFSADNLTAPDEDREMNNLQLALARIQRGLRFVRTTWDFCCGLLRORPOKPAA-

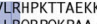

-- LA

作 1082

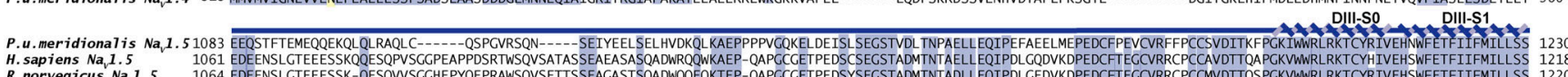

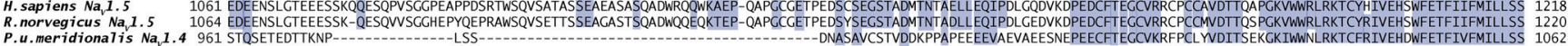
DIII-L1-2 DIIII-S2, DIII-S2/S3 DIII-S3 DIII-S4 DIII-S4/S5

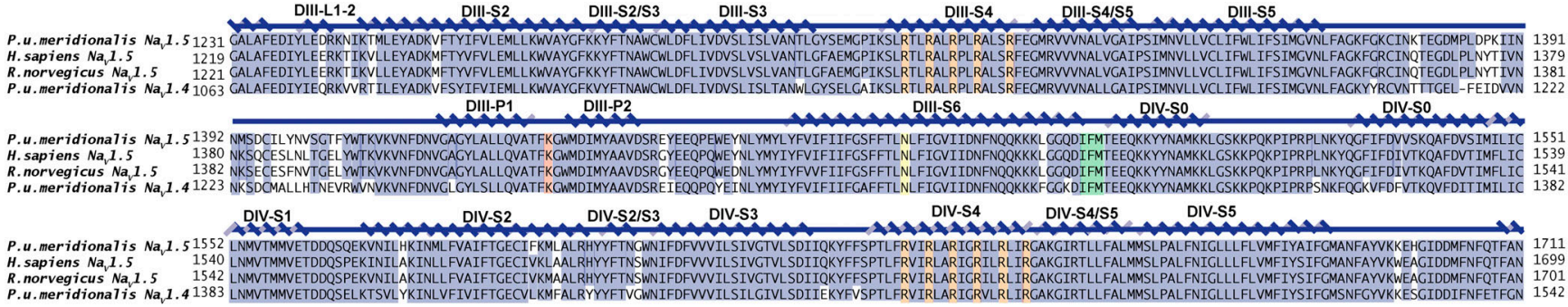

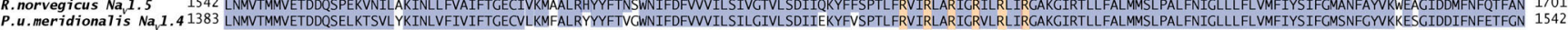

\section{DIV-P1 DIV-P2}

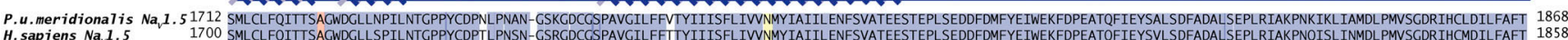

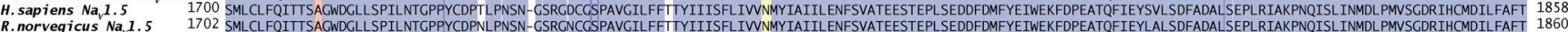

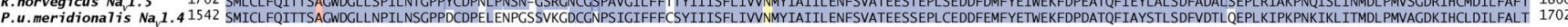
P.u.meridiona7 is Na $_{v} 1.51869$ KRVLGESCEMDALKIOMEEKFMAANPSKISYEPITTTLRRKQEEVSAIVIQRAYRRHLFRRSMKQASYLYRHRTLESSILEDDAPEKEGLIAFMMNENYCRPIDK--SETLSSTSFPPSYDSVTRCTSENLQLKITDLSKSDEAIDCLLSPDKDKESIV* 2027

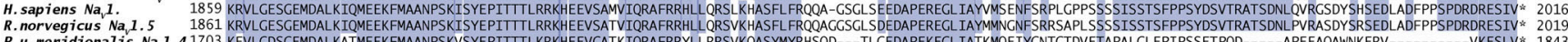

Figure S2. Pitohui Nav1.5 sequence. Sequence alignment of Pum Nav1.5, Hs Nav1.5 (RefSeq accession no. NP_932173.1), Rn Nav1.5 (RefSeq accession no. NP_037257.1), and Pum Nav1.4. Key Nav features are highlighted as follows: selectivity filter DEKA (red), IFM peptide (green), conserved S6 Asn (yellow), and S4 voltage sensor arginines (orange). Conserved residues are highlighted in dark blue. Secondary structure elements were labeled using boundaries from Yan et al. (2017). 

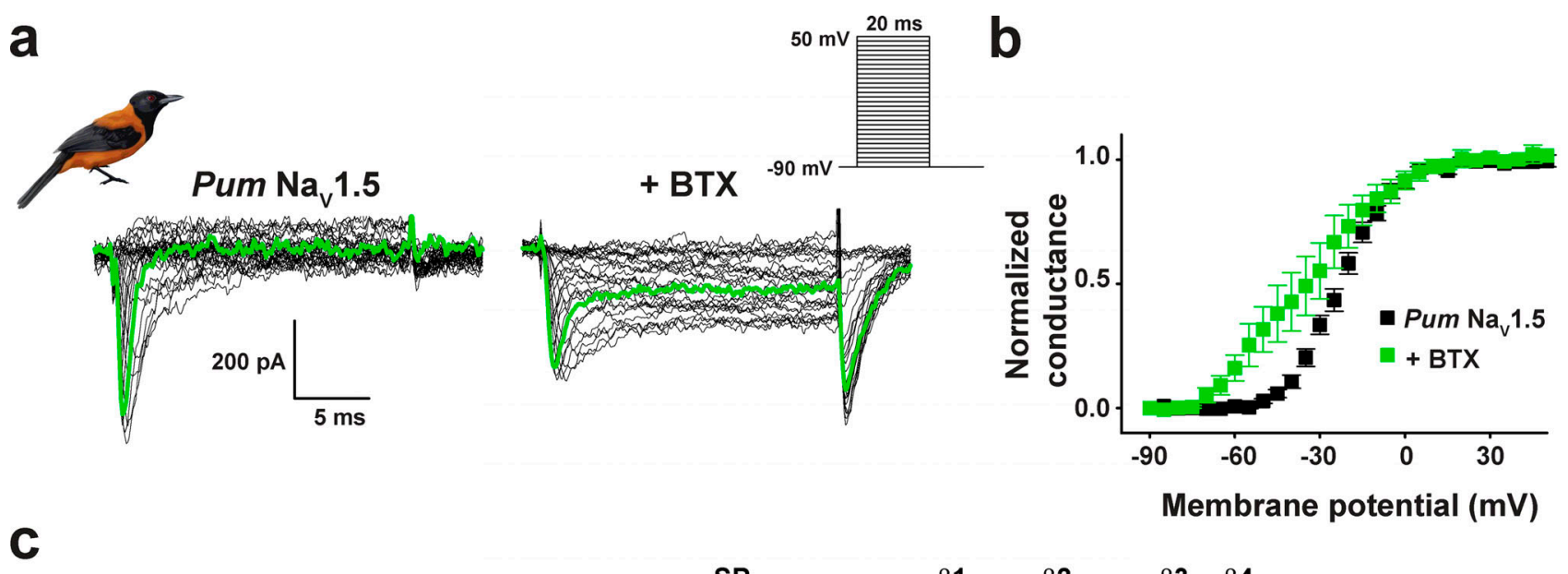
$\begin{array}{ll}\text { P.u.meridonalis } \mathrm{Na} \beta 2 & \text { 1 MSPEAWLPQPTLLLTGLTLLLSLAPPGLGMEVMAPATINALNGSSVKLSCTFNSCYKVEN } 60 \\ \text { H.sapiens } \mathrm{Na}_{v} \beta \mathbf{2} & \text { 1 MHRDAWLPRPAFSLTGLSLFFSLVPPGRSMEVTVPATLNVLNGSDARLPCTFNSCYTVNH } 60 \\ \text { R.morvegicus } \mathrm{Na}_{v} \beta \mathbf{2} & \text { 1 MHRDAWLPRPAFSLTGLSLFFSLVPSGRSMEVTVPTTLSVLNGSDTRLPCTFNSCYTVNH } 60\end{array}$

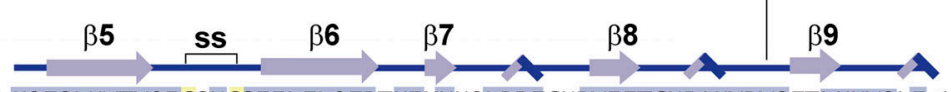

P.u.meridonal is $\mathrm{Na}_{\sqrt{ }} \beta 261$ KQFSLNWTYQECSNCSEELFLQFRTKIMNKQLDRFGNRVEFTGNPAKYDVSFTLKNVQLE 120 H. sapiens $\mathrm{Na}_{4} \beta 2 \quad 61$ KQFSLNWTYQECNNCSEEMFLQFRMKIINLKLERFQDRVEFSGNPSKYDVSVMLRNVQPE 120 R.norvegicus $\mathrm{Na}_{v} \beta 2 \quad 61$ KQFSLNWTYQECSNCSEEMFLQFRMKIINLKLERFGDRVEFSGNPSKYDVSVTLKNVQLE 120

\begin{tabular}{|c|c|c|}
\hline \multirow[b]{2}{*}{$\beta 10$} & \multicolumn{2}{|c|}{ SS } \\
\hline & $\beta 11$ & TM \\
\hline
\end{tabular}

P.u.meridonal is $\mathrm{Na}_{v} \beta 2181$ KCVRRKKQQRLNTDDQKTEEEGKTDGEGNPDEGTK 215

H. sapiens $\mathrm{Na}_{\downarrow} \beta 2 \quad 181$ KCVRRKKEQKLSTDDLKTEEEGKTDGEGNPDDGAK²15

R.norvegicus $\mathrm{Na}_{v} \beta 2 \quad 181$ KCVRRKKEQKLSTDDLKTEEEGKTDGEGNAEDGAK²15
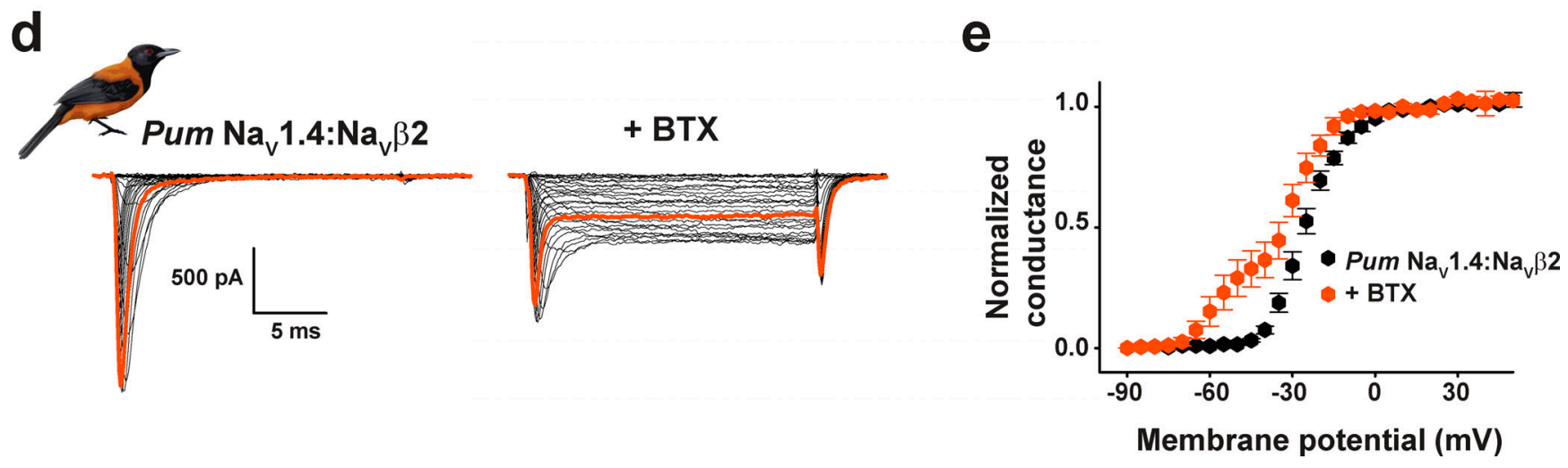

Figure S3. Pitohui Nav1.5 and $\mathrm{Na}_{\mathbf{v}} \mathbf{1 . 4} \mathbf{N} \mathrm{Na}_{\mathbf{v}} \boldsymbol{\beta 2}$ complexes are BTX sensitive. (a) Exemplar current recordings for Pum Nav1.5 expressed in HEK293 cells in the absence (left) or presence (right) of $10 \mu \mathrm{M}$ BTX. Trace at $0 \mathrm{mV}$ is highlighted in each panel. Currents were evoked with the shown multistep depolarization protocol (inset). (b) G-V relationships in the absence (black squares) or presence (green squares) of $10 \mu M$ BTX. (c) Sequence alignment of Nav $\beta 2$ from Pum, Hs (RefSeq accession no. NP_004579.1), and Rn (RefSeq accession no. NP_037009.1). Signal peptide (SP), secondary structural elements from Das et al. (2016), conserved disulfide bond (ss), and transmembrane domain (TM) are indicated. (d) Exemplar current recordings for Pum Nav1.4:Nav 32 expressed in HEK293 cells in the absence (left) or presence (right) of $10 \mu \mathrm{M}$ BTX. Trace at $0 \mathrm{mV}$ is highlighted in each panel. Currents were evoked with the shown multistep depolarization protocol (inset in a). (e) G-V relationships in the absence (black hexagons) or presence (red hexagons) of $10 \mu \mathrm{M}$ BTX. 
a

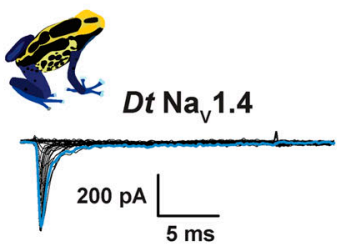

C

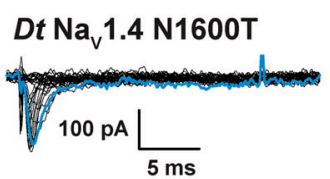

e

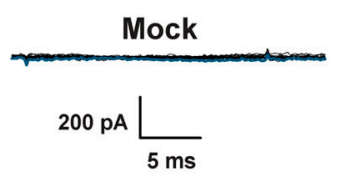

g

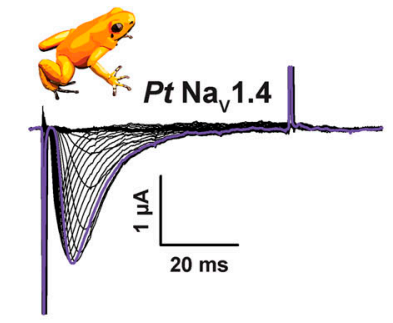

i

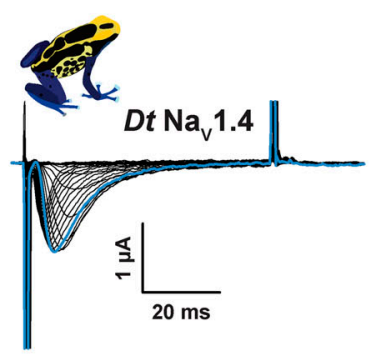

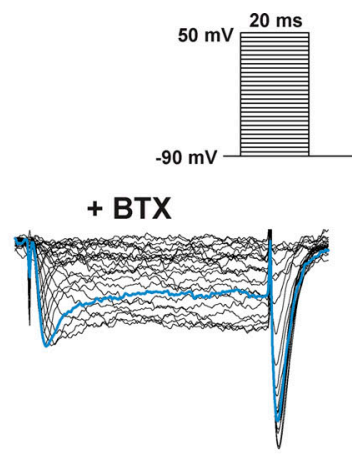

b
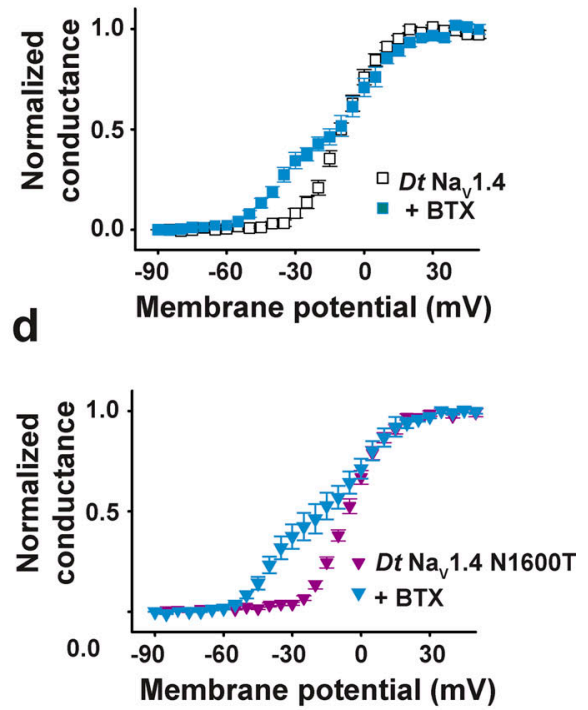

Figure S4. Poison frog Nav1.4s expressed in CHO cells and Xenopus oocytes are BTX sensitive. (a, c, and g) Exemplar current recordings for Dt Nav1.4 (a) and Dt Nav1.4 N1600T (c) expressed in CHO cells in the absence (left) or presence (right) of $10 \mu \mathrm{M}$ BTX. Currents were evoked with the shown multistep depolarization protocol (inset in a). (e) Currents from mock-transfected cells using the same protocol as for a and c. Trace at $0 \mathrm{mV}$ is highlighted in each panel. (b, and d) G-V relationships in the presence or absence of $10 \mu \mathrm{M}$ BTX; Dt Nav1.4 (open squares), +BTX (light blue squares; b); and Dt Nav1.4 N1600T (purple inverted triangles; d), +BTX (light blue inverted triangles; j). (f) Current densities for mock-transfected cells (blue), Dt Nav1.4 (white), and Dt Nav1.4 N1600T (purple). (g and i) Exemplar two-electrode voltage clamp (TEVC) current recordings for Pt Nav1.4 (g) and Dt Nav1.4 (i) expressed in Xenopus oocytes in the absence (left) or presence (right) of $10 \mu \mathrm{M}$ BTX. Trace at $0 \mathrm{mV}$ is highlighted in each panel. Currents were evoked with the shown multistep depolarization protocol (inset in g). (h and j) G-V relationships in the presence or absence of $10 \mu \mathrm{M} \mathrm{BTX,} \mathrm{Pt} \mathrm{Nav1.4} \mathrm{(black} \mathrm{circles),} \mathrm{+BTX} \mathrm{(orange} \mathrm{circles;} \mathrm{for} \mathrm{h);} \mathrm{and} \mathrm{Dt} \mathrm{Nav1.4}$ (light blue squares), +BTX (green squares; j). 


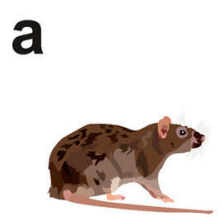

$\operatorname{Rn} \mathrm{Na}_{\mathrm{v}} 1.4$
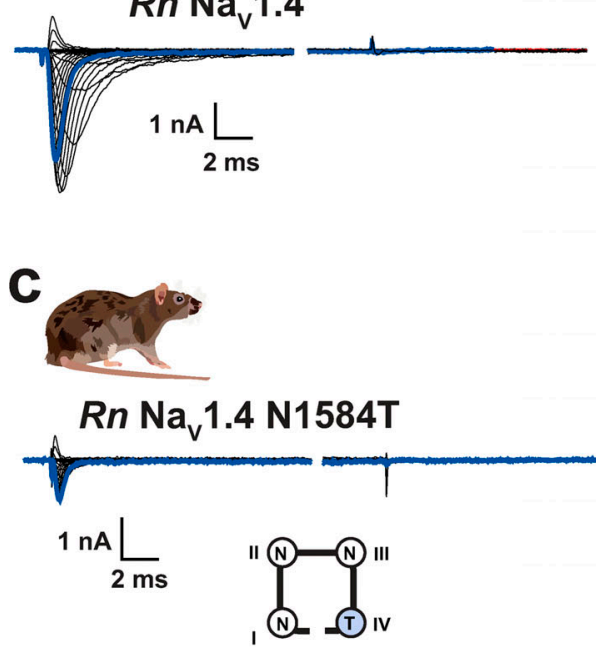

e

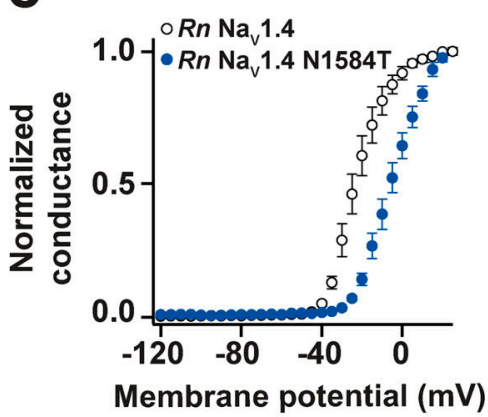

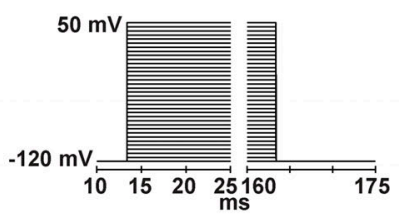

$+\mathrm{BTX}$
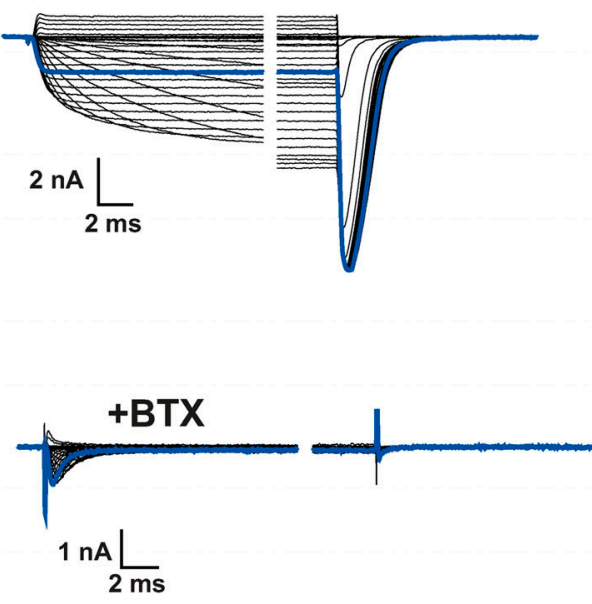

f

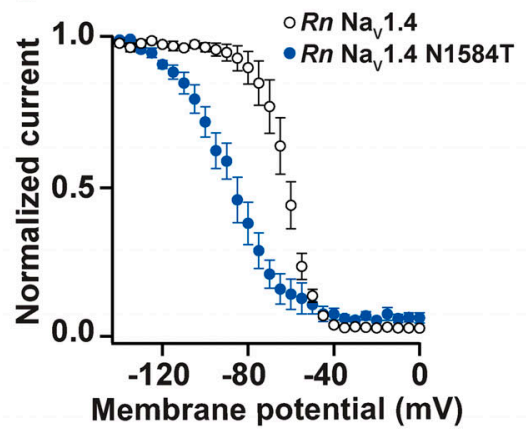

b

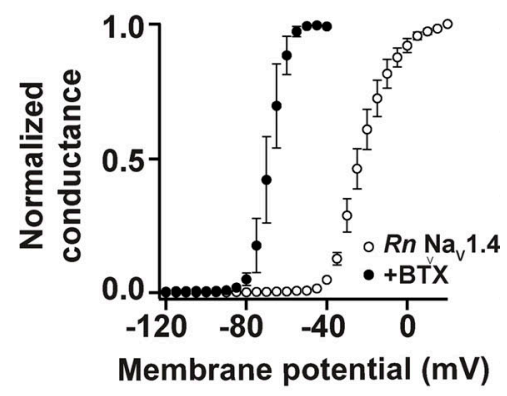

d

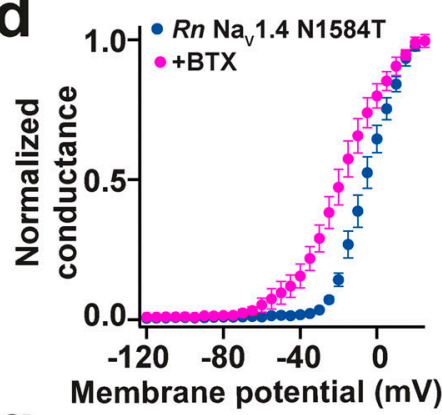

g

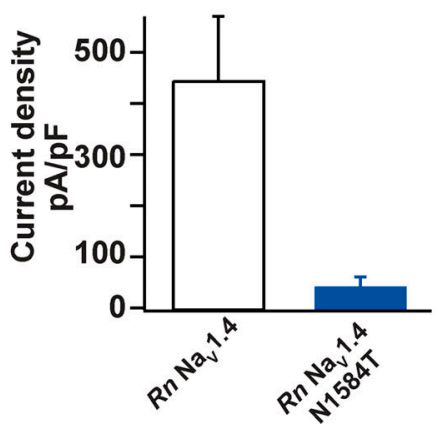

Figure S5. Functional costs of DIV-S6 Asn mutation in Rn Nav1.4. (a and c) Exemplar current recordings for Rn Nav1.4 (a) and Rn Nav1.4 N1584T (c) expressed in $\mathrm{CHO}$ cells in the absence (left) or presence (right) of $10 \mu \mathrm{M} \mathrm{BTX}$. Trace at $0 \mathrm{mV}$ is highlighted in each panel. Currents were evoked with the shown multistep depolarization protocol (inset in a). ( $b$ and d) G-V relationships in the presence or absence of $10 \mu M$ BTX, Rn Nav1.4 (open circles), +BTX (black circles; b); and Rn Nav1.4 N1584T (blue circles), +BTX (magenta circles; d). (e) G-V relationships. (f) Steady-state inactivation voltage dependencies for Rn Nav1.4 (open circles) and Rn Nav1.4 N1584T (blue circles). (g) Current densities for Rn Nav1.4 (white) and Rn Nav1.4 N1584T (blue). 


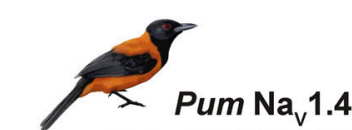

b

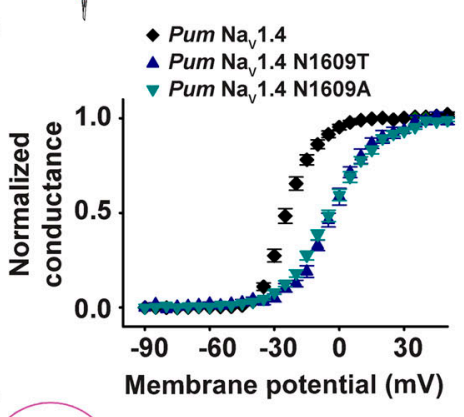

e

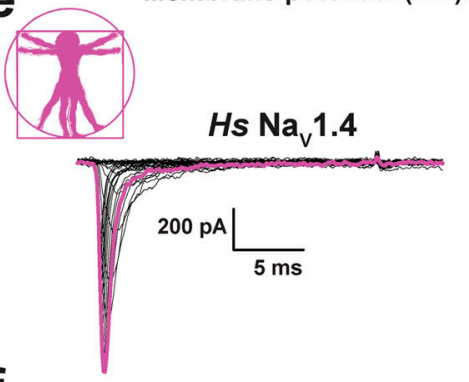

f

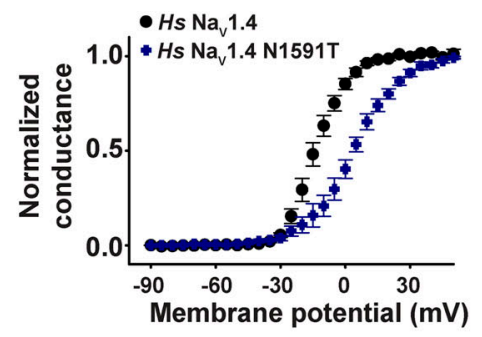

i
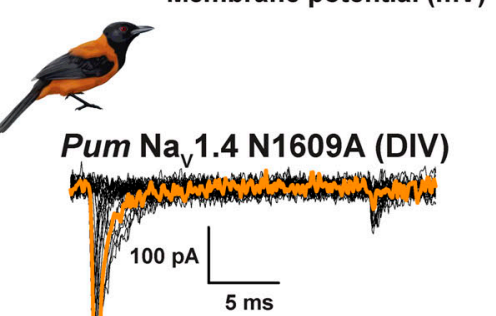

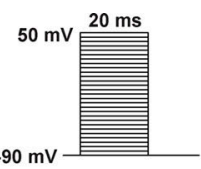

Pum $\mathrm{Na}_{\mathrm{v}} 1.4 \mathrm{~N} 1609 \mathrm{~T}$ (DIV)<smiles>C/C=C\COCO</smiles>

Pum $\mathrm{Na}_{\mathrm{v}} 1.4$ N1609A (DIV)

C
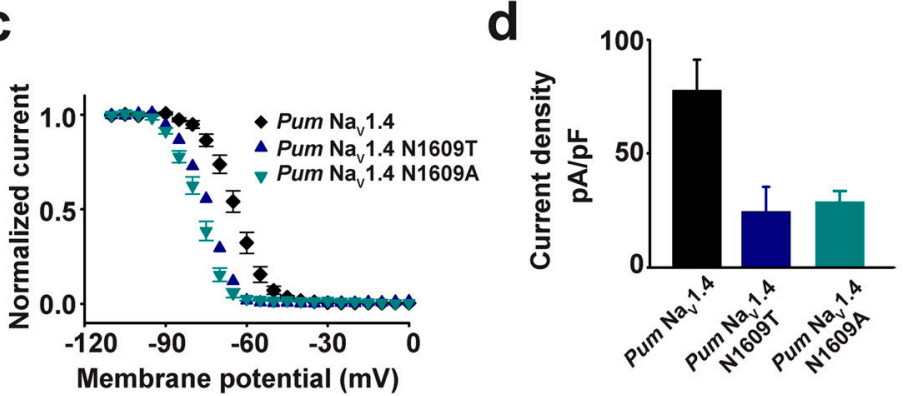

$H s \mathrm{Na}_{\mathrm{v}} 1.4 \mathrm{~N} 1591 \mathrm{~T}$

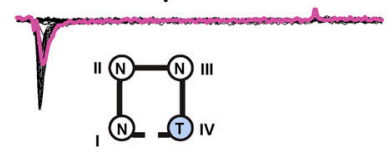

g

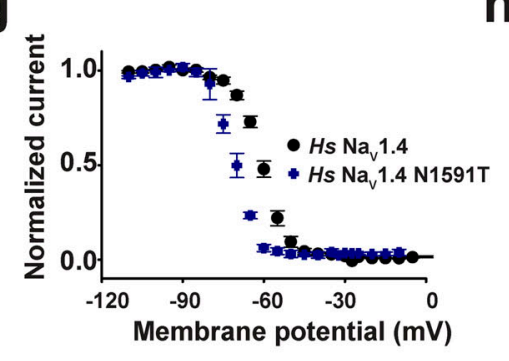

h

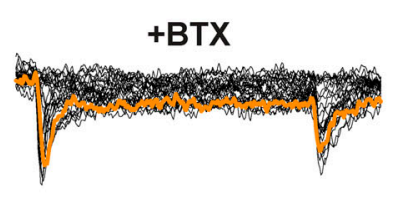

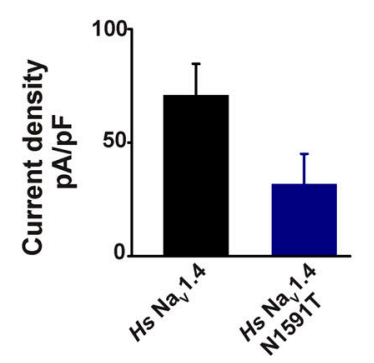

j

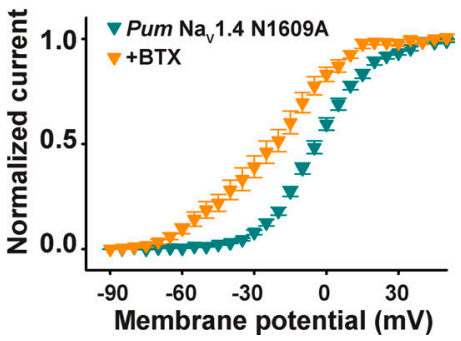

Figure S6. Functional cost of DIV-S6 Asn mutation in Pum Nav1.4 and Hs Nav1.4. (a) Exemplar current recordings for Pum Nav1.4 (left), Pum Nav1.4 N1609T (middle), and Pum Nav1.4 N1609A (right) expressed in HEK293 cells. Trace at 0 mV is highlighted, and currents were evoked with the shown multistep depolarization protocol (inset). Cartoon shows a diagram of the identities of the S6 Asn for the Asn mutants. (b-d) G-V relationships (b). Steady-state inactivation voltage dependencies (c), and current densities (d) for Pum Nav1.4 (black diamonds), Pum Nav1.4 N1609T (blue triangles), and Pum Nav1.4 N1609A (teal inverted triangles). (e) Exemplar current recordings for Hs Nav1.4 (left), Hs Nav1.4 N1591T (right), expressed in HEK293 cells. Trace at 0 mV is highlighted. Currents were evoked with the shown multistep depolarization protocol from a. (f-h) G-V relationships $(\mathrm{f})$, steady-state inactivation voltage dependencies (g), and current densities (h) for Hs Nav1.4 (black circles) and Hs Nav1.4 N1591T (blue diamonds). (i) Exemplar current recordings for Pum Nav1.4 N1609A (left) and in the presence of $10 \mu \mathrm{M}$ BTX (right). (j) G-V relationships for Pum Nav1.4 N1609A (green inverted triangles) and in the presence of $10 \mu \mathrm{M}$ BTX (orange inverted triangles). 
a

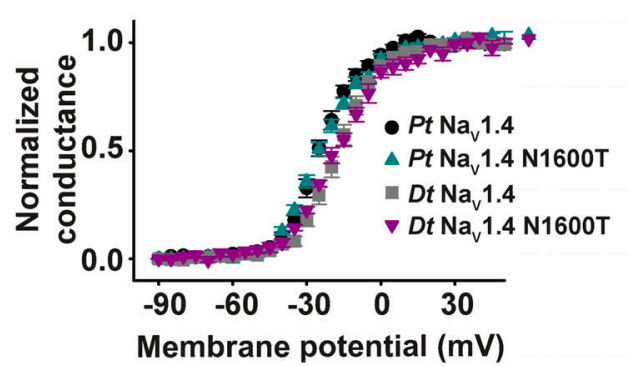

d

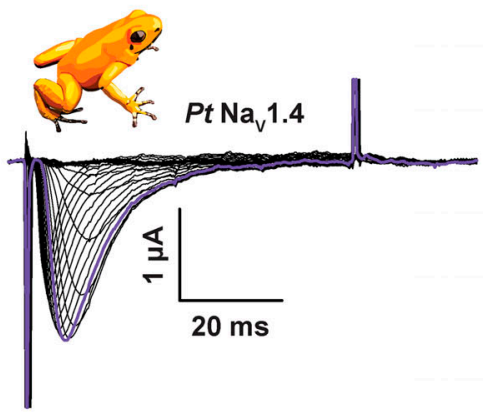

f

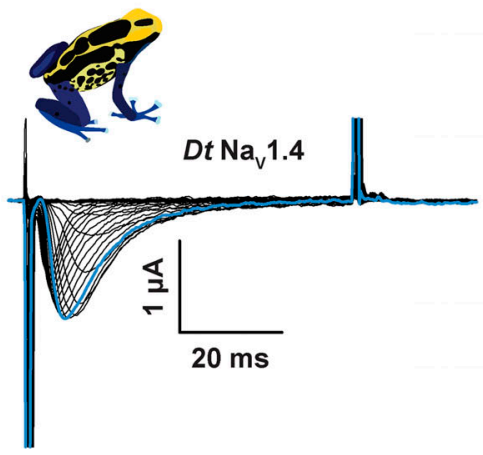

h

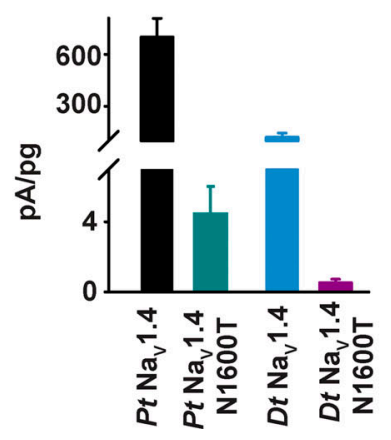

b

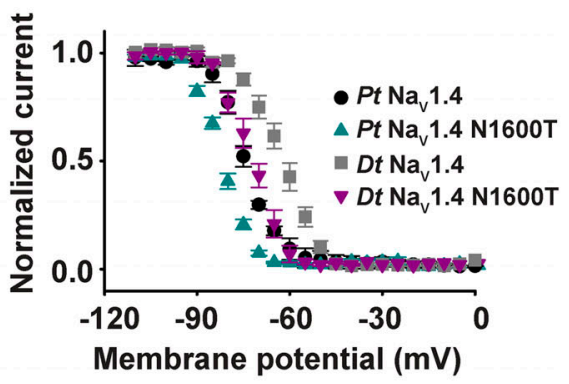

e

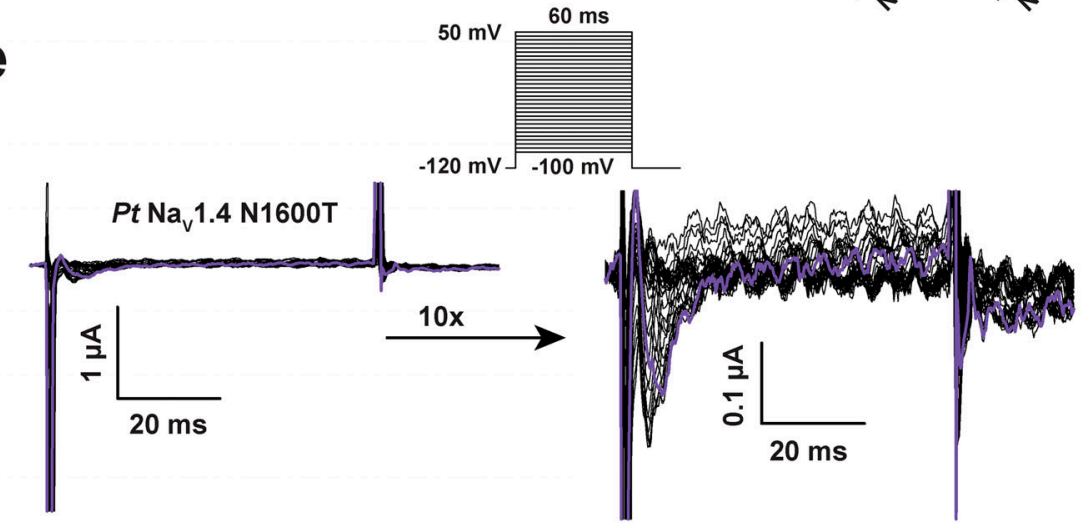

g

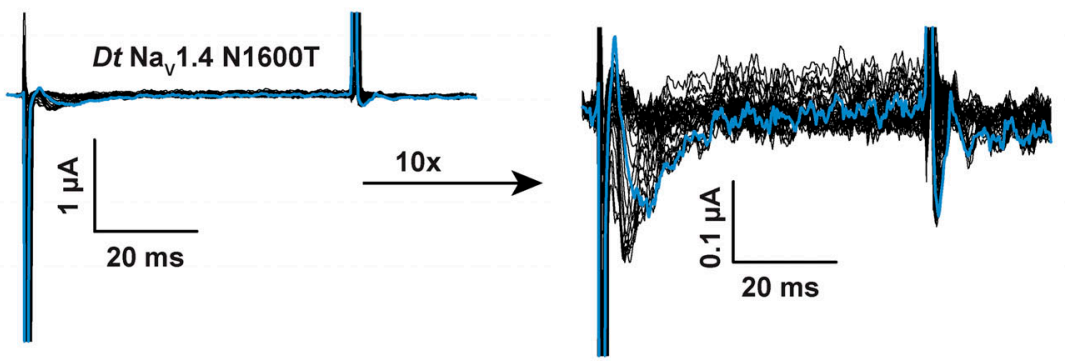

Figure S7. Functional cost of DIV-S6 N $\rightarrow$ T mutation in poison frog Nav1.4s. (a-c) G-V relationships (a), steady-state inactivation voltage dependences (b), and current densities (c) for mock-transfected cells and Pt Nav1.4 (black circles), Pt Nav1.4 N1600T (cyan triangles), Dt Nav1.4 (grey squares), and Dt Nav1.4 N1600T (magenta downward triangles) expressed in HEK293 cells. (d-g) Exemplar current recordings for Pt Nav1.4 (d), Pt Nav1.4 N1600T (e), Dt Nav1.4 (f), and Dt Nav1.4 N1600T (g) expressed in Xenopus oocytes. 10x magnifications of Pt Nav1.4 N1600T and Dt Nav1.4 N1600T traces are shown in e and g, right panels. Trace at $0 \mathrm{mV}$ is highlighted in each panel. Currents were evoked with the shown multistep depolarization protocol (inset in e). (h) Current amplitudes normalized to the amount of injected RNA for the indicated poison frog constructs. 


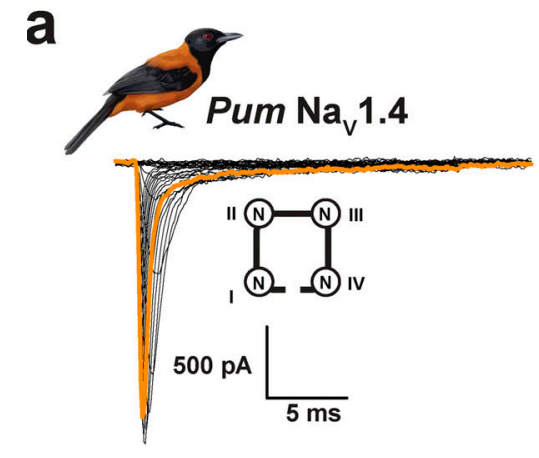

Pum $\mathrm{Na}_{\mathrm{v}} 1.4$ N1306T (DIII)

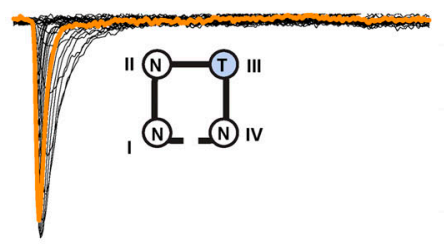

b

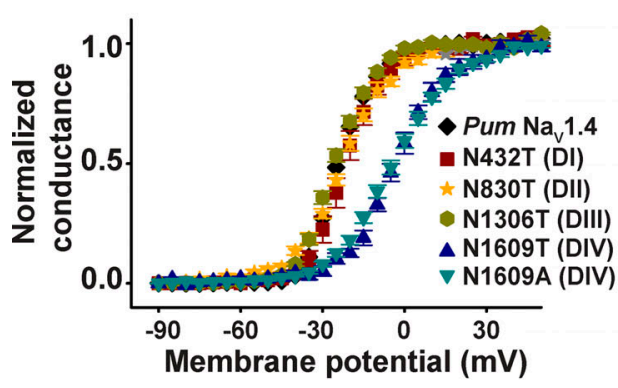

e

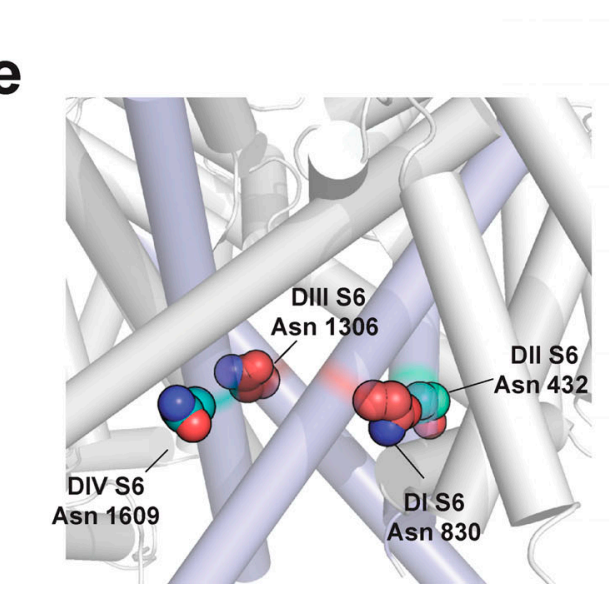

Pum $\mathrm{Na}_{\mathrm{v}} 1.4$ N432T (DI)

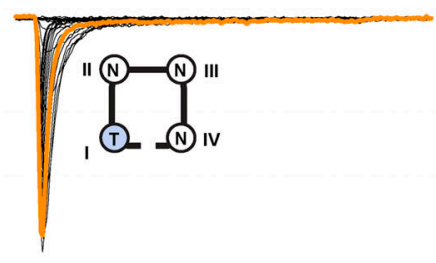

Pum $\mathrm{Na}_{\mathrm{v}} 1.4$ N1609T (DIV)<smiles>CC=CC</smiles>

Pum $\mathrm{Na}_{\mathrm{v}} 1.4$ N1609A (DIV)

C
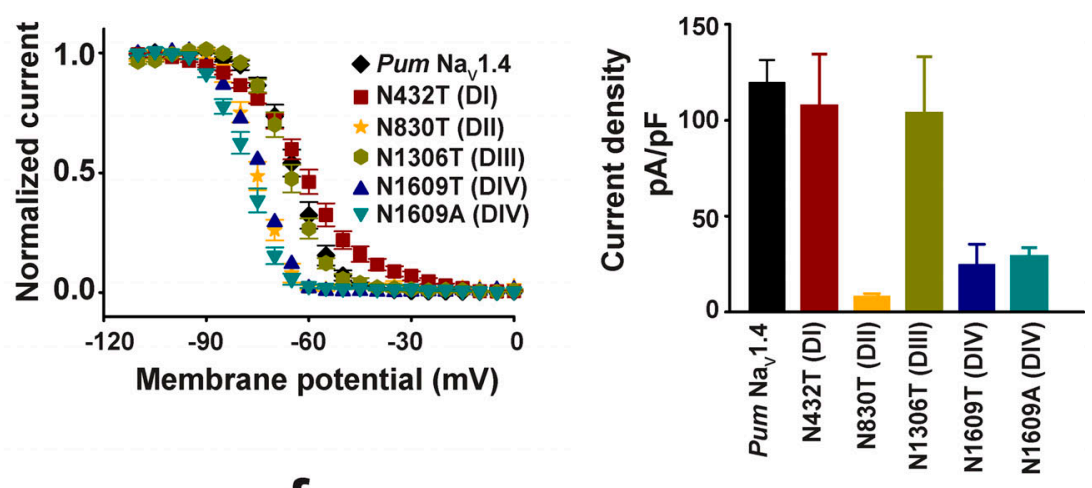

Pum $\mathrm{Na}_{\mathrm{v}} 1.4$ N830T (DII)

(7)<smiles></smiles>

f
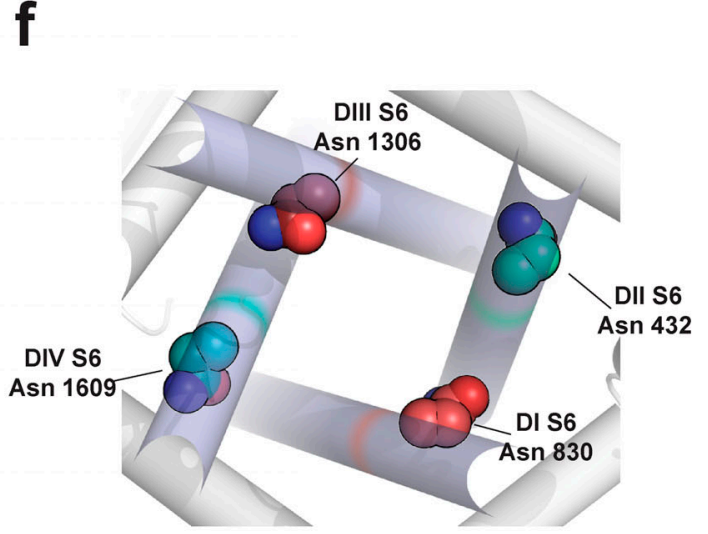

Figure S8. Functional studies of S6 Asn mutants support asymmetric properties of the channel pore. (a-d) Exemplar current recordings (a), G-V relationships (b), steady-state inactivation voltage dependences (c), and current densities (d) for Pum Nav1.4 (black diamonds), Pum Nav1.4 N432T (dark red squares), Pum Nav1.4 N830T (orange stars), Pum Nav1.4 N1306T (green hexagons), Pum Nav1.4 N1609T (dark blue triangles), and Pum Nav1.4 N1609A (cyan downward triangles) expressed in HEK293 cells. Trace at $0 \mathrm{mV}$ is highlighted in each panel. Cartoon shows a diagram of the identities of the S6 Asn for each construct. (e and f) Side (e) and bottom ( $f$ ) views of the locations the S6 conserved asparagines. Residues are mapped on the structure of human Nav1.4 (Protein Data Bank accession no. 6ADF; (Pan et al., 2018) and are labeled using the Pum Nav1.4 numbering. 

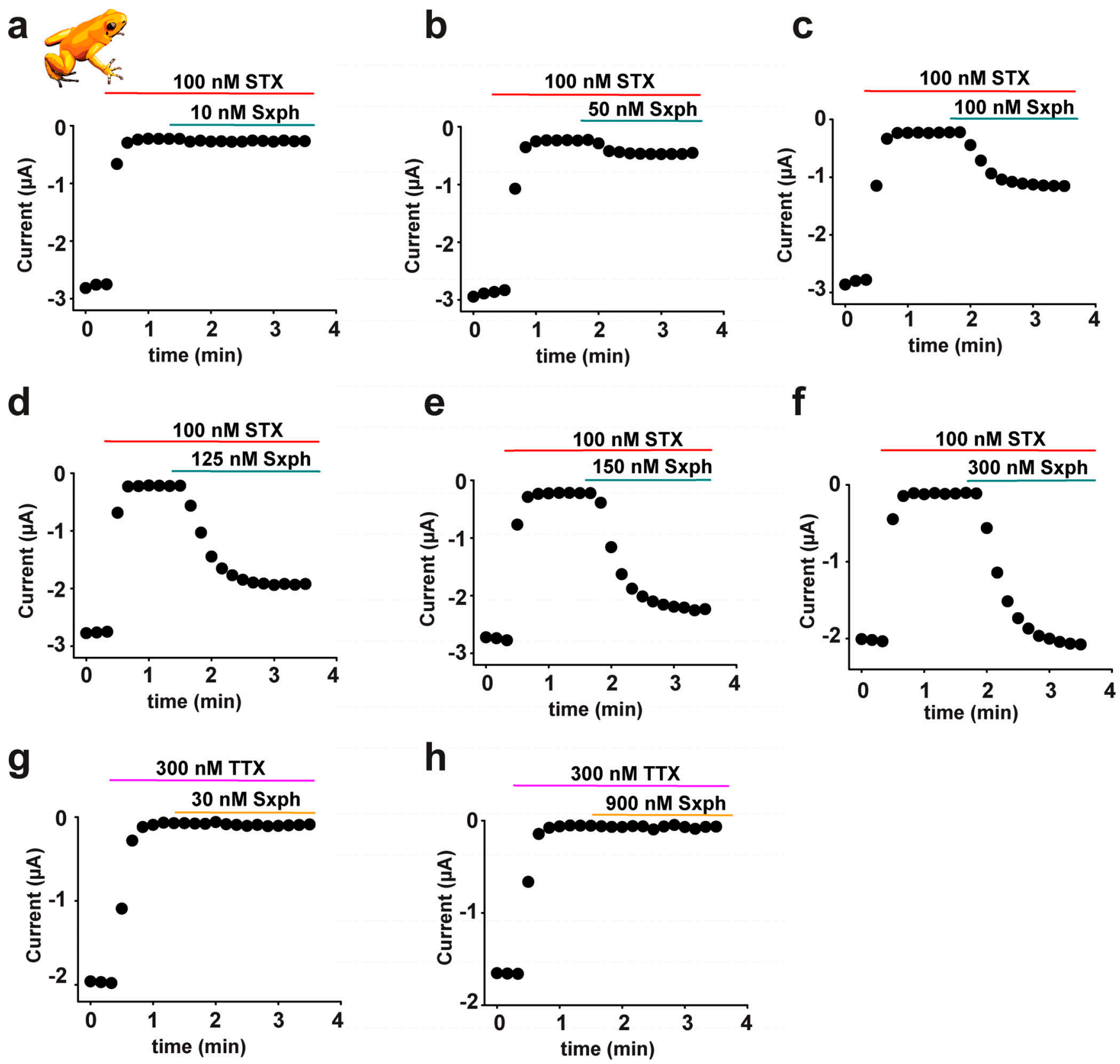

Figure S9. Sxph reverses STX block of Pt $\mathbf{N a}_{\mathbf{v}}$ 1.4. (a-f) Exemplar two-electrode voltage-clamp (TEVC) time courses showing $P t \mathrm{Na}_{\mathbf{v}} 1.4$ peak currents after application of $100 \mathrm{nM} \mathrm{STX} \mathrm{(red} \mathrm{bar)} \mathrm{and} \mathrm{the} \mathrm{indicated} \mathrm{concentrations} \mathrm{of} \mathrm{Sxph} \mathrm{(blue-green} \mathrm{bar).} \mathrm{(} \mathbf{g}$ and $\mathbf{h}$ ) Exemplar TEVC time courses showing Pt Nav1.4 peak currents after application of 300 nM TTX (magenta bar) and the indicated concentrations of Sxph (orange bar).

Three tables and a dataset are provided online. Table S1 lists $\mathrm{Na}_{\mathrm{v}}$ inactivation parameters. Table S2 lists human $\rightarrow$ poison frog Nav1.4 amino acid variants. Table S3 shows the recovery time from anesthesia. Data S1 provides gene assembly scripts. 